Portland State University

PDXScholar

\title{
Teacher Adjustments to Multiple and Continuous Change
}

Cheryll Brounstein

Portland State University

Follow this and additional works at: https://pdxscholar.library.pdx.edu/open_access_etds

\section{Let us know how access to this document benefits you.}

\section{Recommended Citation}

Brounstein, Cheryll, "Teacher Adjustments to Multiple and Continuous Change" (1992). Dissertations and Theses. Paper 1334.

https://doi.org/10.15760/etd.1333

This Dissertation is brought to you for free and open access. It has been accepted for inclusion in Dissertations and Theses by an authorized administrator of PDXScholar. Please contact us if we can make this document more accessible: pdxscholar@pdx.edu. 
TEACHER ADJUSTMENTS TO MULTIPLE AND

CONTINUOUS CHANGE

\author{
by \\ CHERYLL BROUNSTEIN
}

A dissertation submitted in partial fulfillment of the requirements for the degree of

\author{
DOCTOR OF EDUCATION \\ in \\ EDUCATIONAL LEADERSHIP: \\ ADMINISTRATION AND SUPERVISION
}

Portland State University

(- 1992 
TO THE OFFICE OF GRADUATE STUDIES:

The members of the committee approve the dissertation of Cheryll Brounstein presented July 18, 1991.

William D. Greentield, Chair

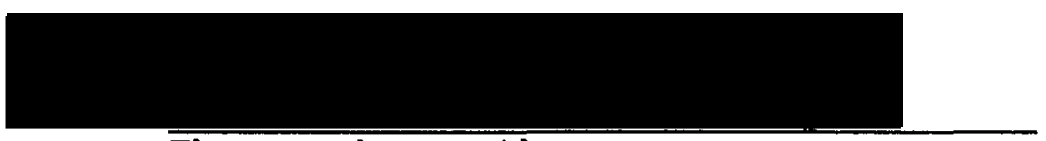

Thomas Chenoweth

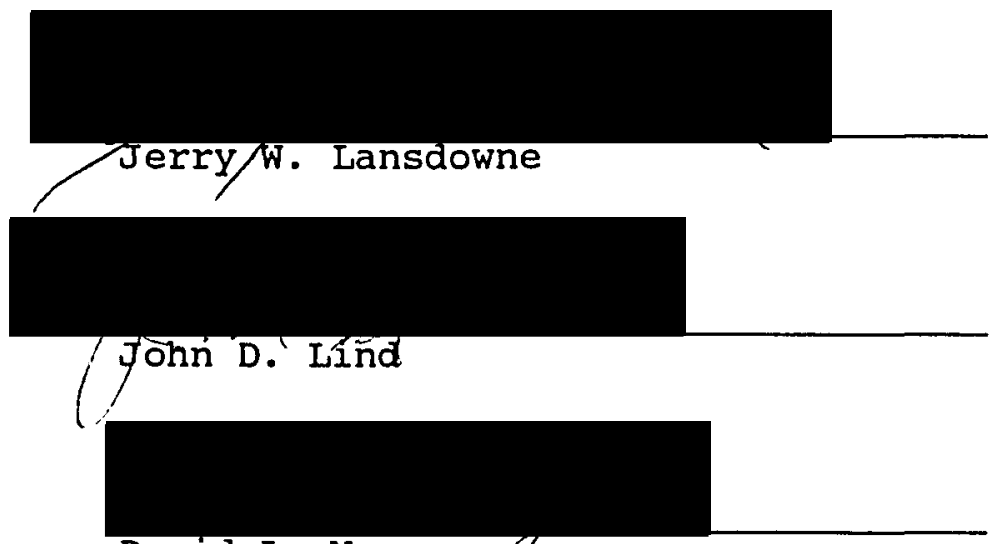

David L. Morgan $\mathcal{O}$

APPROVED :

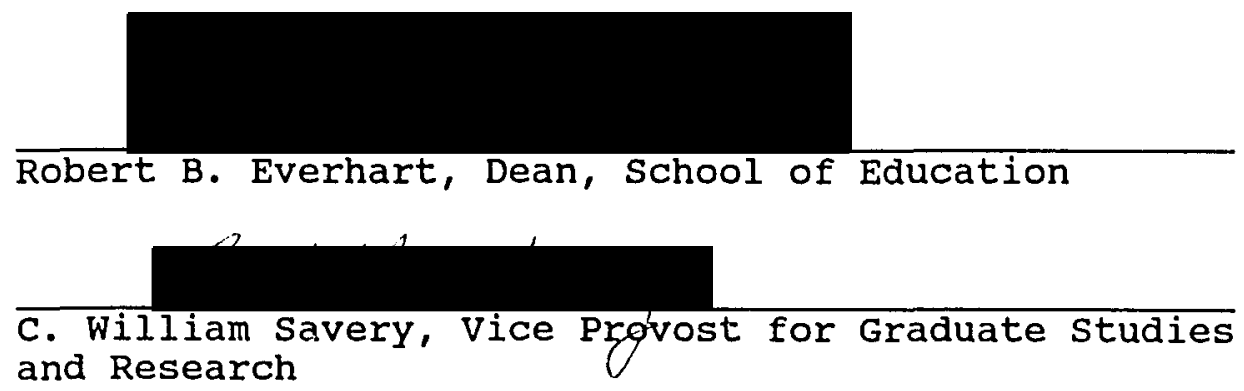


AN ABSTRACT OF THE DISSERTATION OF Cheryll Brounstein for the Doctor of Education in Educational Leadership presented July 18, 1991.

Title: Teacher Adjustments to Multiple and Continuous Change

APPROVED BY THE MEMBERS OF THE DISSERTATION COMMITTEE:

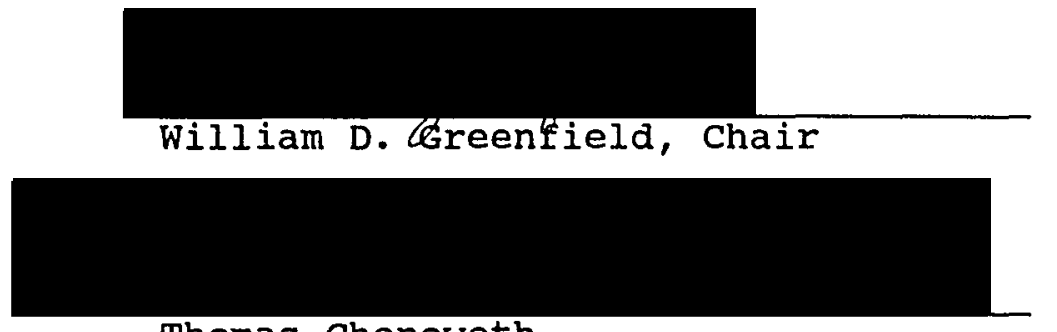

Thomas Chenoweth

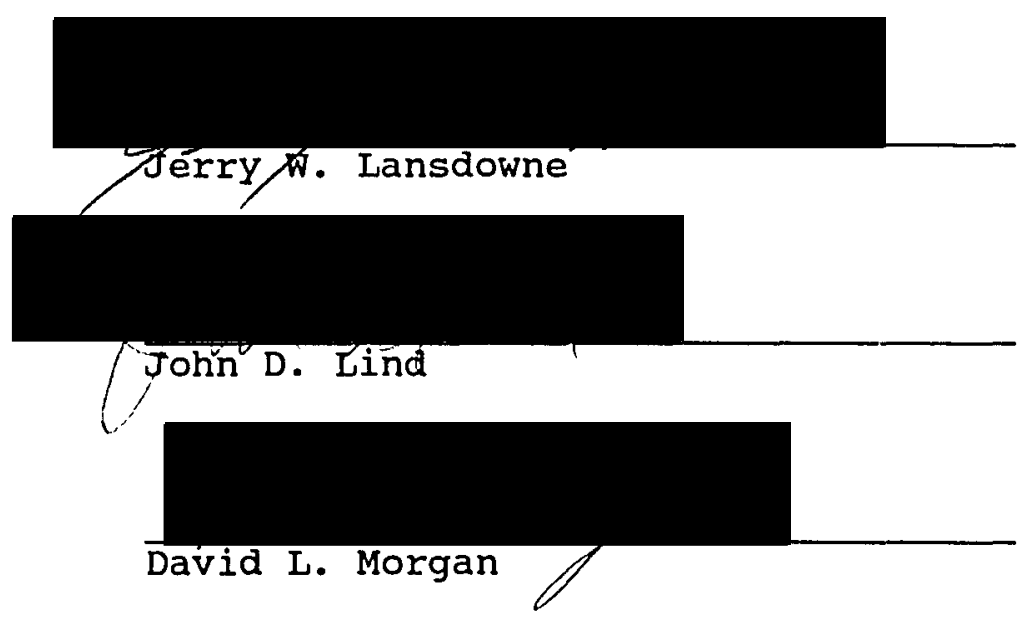

This study examined the phenomenon of multiple and continuous change and the adjustments teachers made in response to the phenomenon. The research questions posed by this study are: 
1. Is there a phenomenon of multiple and continuous change and if so how is it characterized by the participants?

2. Is there an effect of multiple and continuous change on the participants, if so, how do the participants adjust to the phenomenon and how can these adjustments be described?

Methodologically, the strategy for this study was designed to allow for the generation of theory since multiple and continuous change has not been examined as a phenomenon. In-depth interviews were conducted with an "n" of five to allow for in-depth exploratory questioning and comparison and analysis of complex divergent data.

The study utilized teachers' descriptions of their lived experience to provide working definitions of multiple and continuous change. Change is experienced as planned change, and change is experienced as unplanned change. Teachers also described paradoxes that characterize their work milieu. The paradoxes create unanswerable conundrums such as classroom versus school focus, depth versus breadth, commitment versus letting go and fidelity versus rigor.

The phenomenon of multiple and continuous change provokes adjustments that are behavioral and attitudinal. These adjustments impact the instructional domain, professional domain and personal domain. The adjustments 
teachers made did not resemble targeted outcomes. Rather, the adjustments teachers made served as metaprescriptions to assist in the navigation of multiple and continuous change. The composite suggests that multiple and continuous change is complex, interactive and exponential. The behaviors and attitudes that the participants learn mitigate institutionalization of innovations and favor simple adjustments that make teaching more manageable under the circumstances but not necessarily more effective. The significance of this study is that change has been misunderstood because the perspective of the teacher has been overlooked. The misunderstanding of what comprises change disrupts and alters strategic planning. Change in schools is experienced as a phenomenon that is continuous. Administrators, change agents, and policy makers must readjust their thinking about change and develop a paradigm for school improvement that reflects the real world of schools. 


\section{ACKNOWLEDGEMENTS}

I would like to express my gratitude and appreciation to my devoted husband whose advice and support have been invaluable. My children Amy and Adam serve as inspirations for my efforts. Without the love and generous spirit of my family, this effort would not have been finalized. 
TABLE OF CONTENTS

PAGE

ACKNOWLEDGEMENTS. . . . . . . . . . . . . . . . . iii

CHAPTER

I

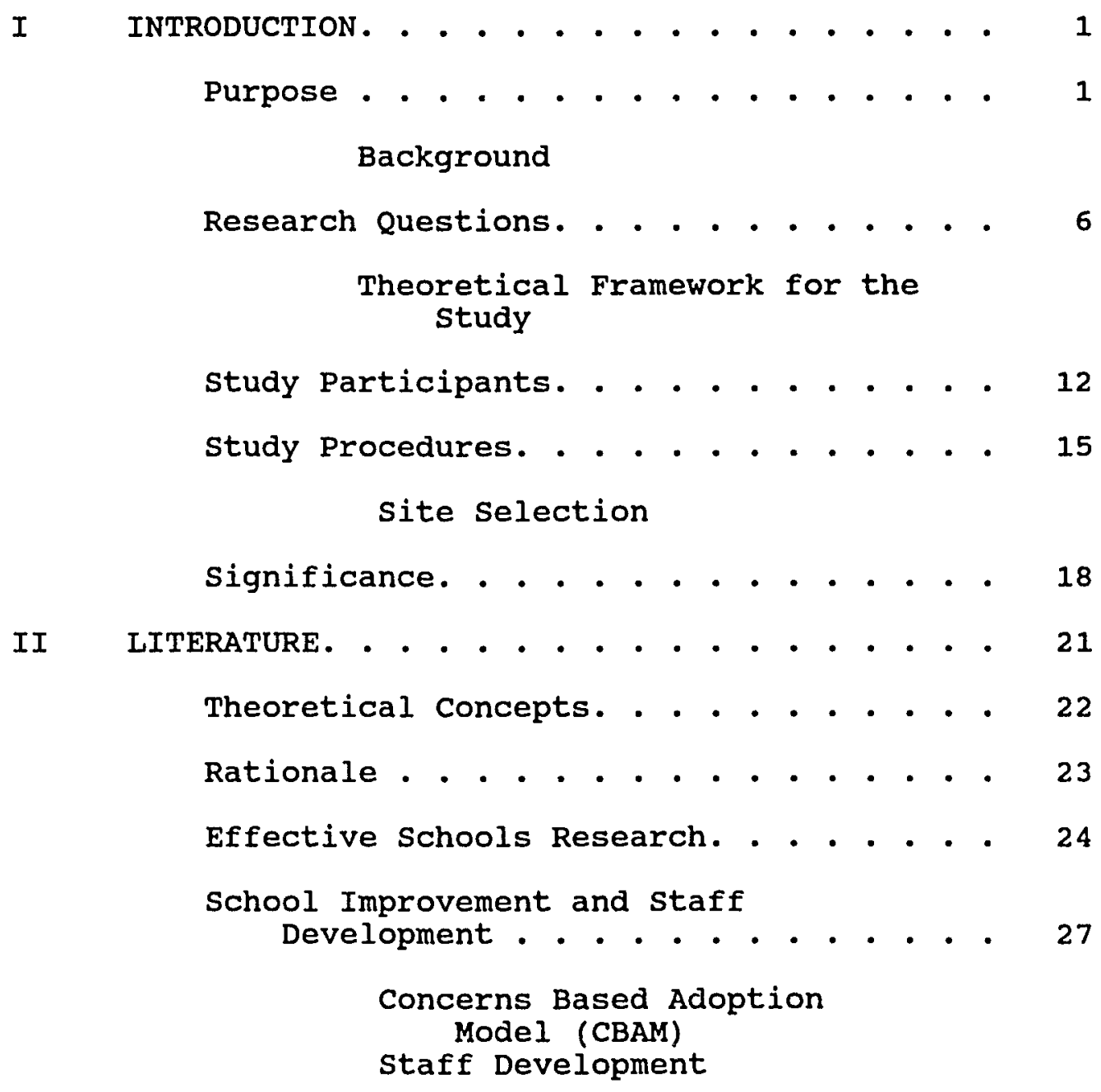


Teacher Behavior. . . . . . . . . .

Teacher Beliefs

Teacher Thought

Teacher Efficacy

Summary

Research Questions. . . . . . . . 4 43

Summary . . . . . . . . . . . . . 43

III

PROCEDURES. . . . . . . . . . . . . . 45

Study Design. . . . . . . . . . . . 45

Methodological Rationale

Data Collection and Analysis

Procedure

Data Collection Procedures

Data Analysis

Interview Format

Interview Criteria. . . . . . . . 59

Reliability and validity. . . . . . . 61

Reliability

Case study standards

Limitations

Summary . . . . . . . . . . . . 65

IV TEACHER EXPERIENCE OF CHANGE: FOUR

VIGNETTES . . . . . . . . . . . . 67

The Innocent. . . . . . . . . . 69

Individual Attributes

Beliefs

Changes and Adjustments

Lessons from Adam

The Survivor. . . . . . . . . 86

Beliefs

Behaviors

Avoiding Textbook Adoptions

Instructional Adjustments

New Innovations

Reframing Change, A Teacher's

Perspective

Lessons from Gene 
The Good Soldier. . . . . . . . . . 97

Changes in the student Population

Too Much Curriculum

Moving Teachers and other Policy Decisions

Personal Demands

Lessons from Dale

The Leader. . . . . . . . . . . 108

School Improvement Versus

Classroom Autonomy

Discrimination Versus

Experimentation

Efficacy Versus Resiliency

Stability Versus Change

Lessons from Amy

Summary . . . . . . . . . . . . 121

$\checkmark$ THE MEANING OF MULTIPLE AND CONTINUOUS

CHANGE. . . . . . . . . . . . . . . . 123

Introduction. . . . . . . . . . . 123

Range of Activities Teachers

Characterize as Change. . . . . . 124

Types of Change . . . . . . . . . 127

Planned Change

Unplanned Change

Teachers' Meaning of Adjustment

Behaviors

"Unchange"

Withdrawing Behaviors

Summary of Behavioral Adjustments

Attitudes Associated with Multiple and

Continuous Change . . . . . . . 140

"Teachers Know Best"

Not Enough Time

What Goes Around Comes Around

"Being Flexible"

Domains of Teacher Adjustment

Summary . . . . . . . . . . . 157 
VI THE PARADOXES OF MULTIPLE AND CONTINUOUS

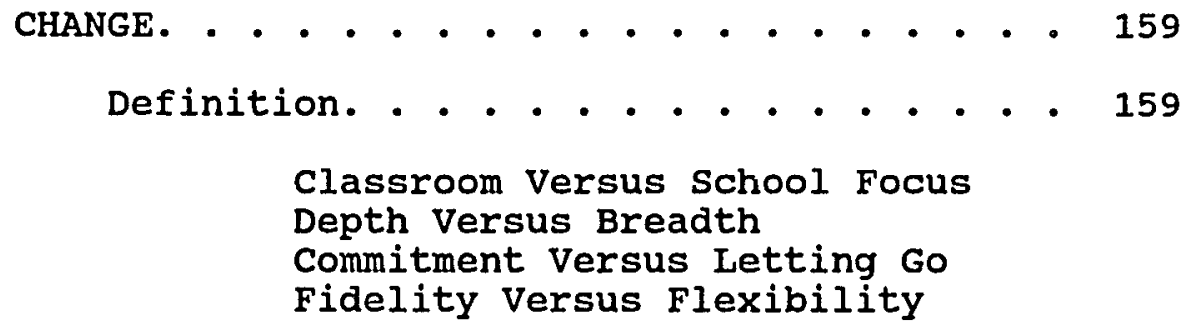

Teacher Adjustments to Multiple and Continuous Change

Paradoxes Produced by Multiple and Continuous Change

Recommendations . . . . . . . . 180

Adjust the Change Paradigm

Provide Teachers with Strategies for Managing Change

Educators, Teachers, Policy

Makers, and Change Agents

Must Become Change

Ecologists

More Research . . . . . . . . . . 184

Summary . . . . . . . . . . . . 185

REFERENCES. . . . . . . . . . . . . . . . 187

APPENDICES

I AM SMART SCHOOL SURVEY. . . . . . . . 194

I AM SMART SCHOOL . . . . . . . . . 196 
CHAPTER I

\section{INTRODUCTION}

PURPOSE

The purpose of this study is to describe and explain the adjustments teachers make in response to multiple and continuous change. While the research on change is extensive, there are limited studies of how the cumulative effect of multiple and continuous change in a given school is actually experienced by teachers.

There is a rich body of literature documenting the complexity of implementing change in schools. Nost of the research on change and theories about change examine only one "change" occurring in the school at any given time. Studies that are grounded on this assumption fail to capture much of the complexity of change and its consequences for teachers' daily lives. It is the researcher's experience that the more common condition in schools is one of multiple an continuous change. That is, teachers' work is characterized by a necessity to adapt and adjust to a seemingly continuous plethora of changes that affect their daily work. The focus of this study is to describe and understand, from the teacher's perspective, what it means to work in a school characterized by multiple and continuous 
change. What is their experience of this circumstance, and what are the adjustments teachers make to that situation?

Schools in general are characterized by changes such as demographics, curriculum, policy, leadership, staffing, and pedagogy, to name a few. These changes beget daily adjustments. The exponential relationship of the multiplicity of variables and their related impact on peoples' lives has heretofore been difficult to measure and assess and thusly has been basically ignored. Yet the lived experience of multiple and continuous change is realistically what comprises the fabric of teachers lives in schools.

The research on school effectiveness is one body of literature that extols the virtues of improvement. A notion sometimes confused as interchangeable with the notion of change. Many schools, in an effort to improve student outcomes, attempt to replicate the attributes of effective schools (Crandall, Bauchner, Loucks, \& Schmidt, 1982). Renewal and improvement of teaching practices are part of the context for change (Joyce, Hersh, \& McKibbin, 1983, p. 11).

Another body of research on change and school improvement acknowledges the critical importance of teachers in the change process (Edmonds, 1979; Fullan, 1982; Hall \& Hord, 1987; Lieberman \& Rosenholtz, 1987). Much of the research on change and improvement focuses on the 
implementation of single goals or innovations (Berman \& McLaughlin, 1981; Hall \& Hord, 1987; Herriot, 1979; Huberman \& Miles, 1984a). However, Joyce, Hersh, and McKibbin (1983) and Patterson, Purkey, and Jackson (1986), among others, observe that successful school change efforts are actually continuous. This study examines the actual consequences of multiple and continuous change for teachers and analyzes the resulting adjustments teachers make in their personal and professional lives. The basic purpose of the study is to describe and understand the personal meaning and the lived experience of being a teacher in a school undergoing multiple and continuous change.

Included in chapter I are the purpose, background, and research questions. Also provided in chapter I is a brief overview of the theoretical framework for the study, study procedures, data sources and site selection. Finally, the significance of this study and its potential contribution to educational policy is described.

\section{Background}

A number of bodies of research provide the backdrop for this study because they provide an understanding of the complexity of planned change and improvement. Most recently "effective schools" received a great deal of attention. Duttwieler and Hord (1987) comment on the enormity of the interest in school improvement: 
By 1983, education had become a focus of concern across the nation and the top priority in most states' legislatures. Since then, more than 300 state commissions and many more local groups have pushed for a new agenda for education. Legislated reforms designed to raise the quality of public school education have included curriculum revision, student basic skills competency testing, increased high school graduation standards and lower student/ teacher ratios. (p. 1)

A by-product of the research has been an effort to generalize those findings and replicate the attributes of effective schools in educational systems across the nation. The results include an abundance of research on school improvement processes. Two related and significant issues emerge from these products: the importance of teacher involvement in the change process and the complexity of implementing and institutionalizing school-wide change.

The initial plan for the proposed investigation was to study teachers' levels of concern in relationship to a school improvement process called onward to Excellence (OTE). Designed by the Northwest Regional Educational Laboratory, OTE is based on a synthesis of research on curriculum alignment, school effectiveness, leadership, change, and school climate. Emphasis is on collection of data, faculty consensus on one school-wide goal, implementation and institutionalization of the goal, and repetition of the process so that school renewal is on-going. A school's initial OTE cycle requires a minimum of two years to complete, and is designed to foster continuous school improvement. 
A survey of teachers' "Stages of Concern" (Hall\& Hord, 1987) was to be the major focus. The faculty in a school who had adopted OTE were presented a pilot survey. Teachers expressed discomfort with the survey, pointing to their inability to distinguish their specific concerns about OTE from concerns related to all of the other changes that were occurring simultaneously in their school. Teachers' inabilities to distinguish among these concerns resulted in efforts to reconceptualize the study and led eventually to the present focus: a study of teachers' perceptions and adjustments to multiple and continuous school-wide change. Fullan (1982) notes that "if educational change is to happen, it will require that teachers understand themselves and be understood by others" (p. 107). Teachers' perceptions of multiple change efforts can be understood more fully by capturing teachers' lived experiences relative to those change efforts. It is anticipated that an empirical description of teachers' adustments to multiple and continuous change will provide the basis for developing school policies that promote more meaningful and realistic support and assistance for teachers involved in school improvement processes than currently is the case in most schools. 


\section{RESEARCH QUESTIONS}

The problem studied has two dimensions and is reflected in these questions:

1. What are the adjustments teachers make in response to their experience of multiple and continuous change efforts?

2. What are the situational variables associated with the adjustments that teachers make in response to multiple and continuous change efforts?

Based on analysis of the interviews, the researcher discovered that the original problem statement was grounded in presumptions that had not been studied or confirmed. It became apparent as the study progressed that the original questions posed were overly ambitious. One issue that surfaced was a lack of clarity in the terminology. The notion of multiple and continuous change while alluded to in the research has not been studied as an independent phenomenon and requires definition. Also neglected and needing more clarification is an understanding of what is meant by "teacher adjustments."

In retrospect the study began with an assumption that the phenomenon of multiple and continuous change is clear and understandable, and most adjustments by the participants would be attributed to responses to staff development and/or school improvement efforts and that the adjustment would align with the targeted outcomes of the 
innovation. It was also assumed that the data provided by the participants would sufficiently identify situational variables associated with multiple and continuous change. The data collected, when analyzed, did not. address the original research questions. Therefore, the research questions were revised to reflect more realistic and requisite goals for this study.

The questions posed by this study are:

1. Is there a phenomenon of multiple and continuous change and if sc how is it characterized by the participants?

2. Is there an effect of multiple and continuous change on the participants, if so, how do the participants adjust to the phenomenon and how can those adjustments be described?

Theoretical Framework for the study

Because this study involves examination of an area previously unexplored, a theoretical framework provides an initial starting point to discover theory. The point of the investigation is not to confirm existing theory but to make sense of a phenomenon which has not yet been described. The study of teacher adjustments to change requires a framework that encourages consideration of a multiplicity of variables in an ever changing context. A phenomenological approach that examines the meaning of teacher adjustments to multiple 
and continuous change from the perspective of the participant is epistemologically consistent with the purpose of the study. The truth that is sought in this study is one that emerges "not as one objective view but rather as the composite picture of how people think" (Bogdan \& Taylor, 1975, p. 11).

Methodologically the strategy for this study is one that purposefully is designed to allow for the "generation of theory." Initial data analysis begins within the context of an over-arching theoretical framework (Glaser \& strauss, 1967). Selection of a theoretical framework is intended to discover "theory that accounts for much relevant behavior" (p. 30). The Brim and wheeler (1966) "Framework for Analysis of Socialization in organizations" combined with Becker's (1964) theory of "situational adjustment," considers organizational and individual variables. These two theoretical frameworks are expected to be useful in this study of teacher adjustments to multiple and continuous change.

The selection of Brim and Wheeler's (1966) framework is based on the premise that efforts to change and improve schools can be conceptualized as socialization processes. Socialization is defined as "the process by which persons acquire the knowledge, skills, and dispositions that make them more or less able members of their society" (p. 3). The nature of improvement activities involves efforts that 
requires teachers to adjust differently to their situations, to learn different roles, and to apply new knowledge, skills, and values. Brim and Wheeler's socialization theory was selected precisely because it integrates individual and organizational situational variables in the analysis of knowledge, attitude, and skill acquisition. The importance of individual and organizational variables in the change process have already been acknowledged in earlier research on organizational change and can be adjusted through this framework (Ashton \& Webb, 1986; Duke \& Corno, 1981; Fullan, 1982; Guskey, 1986; Jackson, 1968; Lortie, 1973).

The schema proposed by Brim and wheeler (1966) includes:

(a) the individual's awareness and knowledge of the norms and role demands being placed upon him,

(b) his ability to deliver the required performance, or

(c) his motivation to do so. (p. 110)

Brim and wheeler (1966) note that:

In order for independent variables to influence an organization and thusly affect socialization outcomes, the independent variable must change (a) the organization's capacity to provide clear and unambiguous norms for performance, (b) its capacity to provide opportunities for learning and practicing the required performance, or (c) its capacity to selectively reward the behavior of its recruits. (p. 110)

The collusion of changing organizational values and individual idiosyncracies is individual and collective. Brim and Wheeler's schema provides an organizational 
framework that takes into account the interplay of individual and organizational variables.

The interplay of multiple and continuous changes presumably influences individual and socialization outcomes, and may well have consequences for the organization. Brim and Wheeler (1966) assume that internal arrangements within organizations differ widely, and those differences influence socialization outcomes. The outcomes may be products or by-products of organizational and individual expectations concerning new practices, opportunities to demonstrate differential performances, variation and numbers of new practices, and opportunities for feedback and reward. "Endless variables" may be linked systematically to variations in organizational outcomes (p. 109). In order to fully address the complex array of adjustments, a second more microscopic but nevertheless theoretically compatible framework is provided by Becker (1964) to assist the researcher in the proposed investigation. Becker's concept of "situational adjustment" directs attention to discrete situations that require people to adjust. Becker describes situational adjustment:

The process of situational adjustment occurs when individuals assume the characteristics required by the situations they participate in. Accommodations to change may be actual changes in behavior that will persist over time or they may be more immediate and superficial. (p. 41)

Becker cautions that changes may seem obvious but are subject to misinterpretation. 
The person, as he moves in and out of a variety of social situations, learns the requirements of continuing in each situation and of success in it. If he has a strong desire to continue, the ability to assess accurately what is required and can deliver the required performance, the individual turns himself into the kind of person the situation demands. (p. 44)

In order to understand teacher adjustments, both the situation and the adjustment require consideration. Situational adjustments are the smaller units of learning that ultimately produce role socialization (Becker, 1964, p. 44). Situations produce adjustments; however, behavioral adjustments may change with each new situation. It is commitment that produces stability: the person subordinates immediate situational interests to goals that lie outside the situation.

The distinction between temporary situations and permanent situations is an important component of situational adjustment that may have implications for understanding teacher adjustments to multiple and continuous change. When situations are viewed as temporary they are more likely to evoke adjustments because the situational adjustments are viewed as temporary. When a situation is viewed as long-term and requiring commitment there is a greater likelihood of resistance, because people are being challenged to change past practices and beliefs. The need for commitment strengthens resistance to change and reduces the propensity to adjust. However, commitment is based on stabilized change. Transient or temporary, the nature of an 
individual's socialization experience influences the adjustment to change (Becker, 1964). Based on Becker's notation of "situational adjustment," a teacher's experience with multiple and continuous change is influenced by the teacher's ability to identify the requirements of the situation, to perform accordingly, and to be motivated to perform according to the nature of the situation (p. 41). Understanding teachers' experiences requires a framework that allows for analyses of discrete as well as broader based adjustments to change. The use of Brim and Wheeler's (1966) "organizational socialization" and Becker's (1964) "situational adjustment" provides the necessary theoretical framework to guide, at least initially, this study of teachers' lived experiences in a school involved in on-going renewal and multiple and continuing change.

\section{STUDY PARTICIPANTS}

A number of criteria were predetermined in order to select a site from which the interviews would be selected, that would provide a context to examine multiple and continuous changes. Criteria were loosely constructed from Effective Schools: A summary of Research (cited in Educational Research Service, Inc. [ERS], 1983) and the work of Huberman and Miles $(1984 \mathrm{a}, 1984 \mathrm{~b})$ on school innovation. Selection was designed to control for variables that might impede the institutionalization of change efforts. Criteria 
considered in the site selection included adequate district fiscal resources, and the presence of leaders at the district and school level who actively supported the change efforts. Also sought was a school with a positive faculty/administrative relationship, and a school with a positive community relationship. The selection criteria were used to select a school that did not possess attributes that would ostensibly create a "barrier to innovation" (Gross, Graquinta, \& Bernstein, 1971). In addition to meeting these basic criteria, the site selected was especially appropriate for this investigation because of the numerous on-going improvement efforts involving a majority of the school staff. Major school improvement activities were begun four years ago and are still in progress. In Fall, 1985, the school began onward to Excellence (OTE). OTE is an on-site improvement effort based on a synthesis of the effective schools research. It is designed to involve the entire school in a process promoting on-going school renewal.

A variety of site-based changes were responses to the fluctuating student population. The changes included teacher reassignments, reduction in teaching staff, new schedules and modified curriculum.

Some of the changes were based on district mandates that included curriculum adoptions, continuation of "Instructional Theory into Practice" (ITIP), and the 
addition of new curriculum (computer technology, AIDS instruction, and drug and alcohol instruction).

The selected site might be considered somewhat unusual for Oregon because of the degree of district stability, both politically and economically; however the selection of a special site is not unique in qualitative research (Wolcott, 1973) .

Support for the study was granted by the school district's Director of Program Evaluation and the school principal. The site was open to visits by the researcher, consent was given to conduct teacher interviews, and the principal agreed to allow access to school documents such as student test scores and records of meetings pertaining to the various school improvement projects. District and school administrators also agreed to be interviewed. The interviewees were guaranteed confidentiality. Invitation to participate in the interviews was to be open. Efforts, however, were made by the researcher to assure that the full range of teacher experience in this school was represented in the data set. Interviewee consent to participate in the interviews was on a voluntary basis.

The issue of interviewee confidentiality poses a difficult conundrum for the researcher. The guarantee of confidentiality affords informants an opportunity for spontaneity and candor, but the promise of confidentiality can impede the researcher's ability to verify informant 
responses. The function of multiple interviews designed to check for consistency between interviews and interviewees allows for verification of responses.

\section{STUDY PROCEDURES}

Data on teachers' perceived lived experiences of continuous and multiple changes was collected for the purpose of identifying their adjustments, professionally and personally, to change efforts. The use of successive, in-depth interviews with teacher participants from a single elementary school undergoing change was the major source of data.

Merton, Fiske, and Kendall's (1956) guidelines for conducting an unstructured interview were adapted for this study. The interview format consists of loosely structured probes designed to encourage the participants to share perceptions of their personal, lived experiences, particularly as they are thought to be influenced by the change strategies. Interviews were taped and transcribed to allow for content analysis and comparison. Informants were selected from the pool of teachers who were involved in the school's changes from 1984-1988. Selection was made on the basis of balancing males and females and length of tenure in the district to heighten the potential for diversity. Documents related to the change efforts in the school were analyzed. The documents included detailed descriptions 
of staff development plans, demographic information and student performance data. Permission to review these records was granted by the school district. Some of these documents are included in the appendix.

The study group size was limited initially to five teachers to allow for in-depth exploratory questioning and comparison of interviews. A limited "N" allowed for examination of a new theory that was dependent on intensive collection and analysis of complex and divergent data. When generating theory rather than verifying theory, Glaser and Strauss (1967) suggest that less attention be given to the representativeness of a population and more attention applied to the examination of a broad number of variables. When attempting to discover theory, consideration of many variables is not realistically manageable with inclusion of a large "N."

Three schools were included in this study. One school was included by virtue of the pilot interview which eventually was included as a vignette. Another school, a junior high school located in the same district as I Am Smart Elementary School, was the site where the CBAM (Concerns Based Adoption Model survey) was distributed and analyzed (Hall \& Hord, 1987). The third school (I Am Smart Elementary School) was the school from whence four informants were selected. 
The phenomenon of multiple and continuous change has not been previously studied; therefore, limitation of variables could impose a researcher bias that could skew the discovery of theory. For reasons of manageability and discovery the "N" was limited to four interviews.

Examples of studies which have utilized a limited "N" are Blumberg and Greenfield (1986), Goodlad (1983), Lightfoot (1983) and wolcott (1973). The inductive nature of the research suggests that the study group size may be adjusted as the data are collected.

\section{Site selection}

A school site involved in the third year of implementing OTE was identified. The OTE goal, selected by faculty consensus, was to increase student engaged learning time. Engaged learning time means to increase student involvement in learning by the reduction of outside interruptions, noise from outside the classroom, and intrusive transactions. Occurring simultaneously with the OTE project were district mandated change efforts. District mandated changes over the last three years included "Instructional Theory into Practice" (ITIP) for all teachers, district adoption of whole language curriculum, AIDs curriculum, computer technology instruction, and drug and alcohol instruction. Also impacting the school were many unplanned changes such as an enrollment shift from a low of 285 in 1980 to a high of 571 in 1987. During this 
time, the number of teaching staff fluctuated from a low of 13 certified teachers and 4 specialists to a high of 26 certified teachers and 11 specialists. During the 1987-1988 year new district boundaries were established and adjustments for reduced enrollment were begun. The plan included reduction of five certified teachers and one administrative position. Other adjustments included physical relocation in the building of teachers' classroom assignments or of schedule changes and revision of teacher grade level assignments.

The site was selected because of the multi-year duration of the school improvement effort (OTE) and because of other variables such as leadership stability, low incidence of at-risk students, community support, and stable district resources. These factors were believed to be supportive influences (in contrast to the not uncommon situation of change efforts being complicated by the absence of these positive influences). The school, at the beginning of this study, was beginning its fourth year of school improvement.

\section{SIGNIFICANCE}

The bulk of research and literature in education reflects the current interest in school improvement. Implicit in the notion of school renewal is multiple and continuous change. Most of the research recognizes the 
teacher as a critical and significant variable in the change process (Brophy \& Good, 1974; Edmonds, 1979; Hall \& Hord, 1987; Jackson, 1968 ; Lortie, 1973).

The reality of schools is that change is on-going and rarely singular in focus. Past and present experiences intermingle to create the whole. The real world of school involves many changes that necessitate a multitude of adjustments. Nevertheless, researchers have found it difficult to adequately describe or measure the intricacies and exponential attributes of multiple and continuous school change on teacher behavior (Duke, 1984; Huberman \& Miles, $1984 \mathrm{~b}$; Jackson, 1968).

The significance of this study is that it attempts to capture the totality of the experience from the teacher's perspective. The vignettes in Chapter IV provide examples of how teachers experience what they are asked to do regarding change. The vignettes also portray the different ways teachers experience and adjust to multiple and continuous change. The paradoxes in chapter VI provide additional data that characterize a world of multiple and continuous change. Understanding what it is we are really asking teachers to do can help in the establishment of realistic expectations and achievable goals. Although recent work has recognized and validated the significance of the teacher in change efforts, scant attention has been given to the impact that on-going change efforts have on 
teachers (Berman \& Mclaughlin, 1974; Brookover et al., 1982; Butler, 1988; Duke, 1984; Fullan, 1982; Jackson, 1968; Lortie, 1973).

Developing realistic expectations and policies that support, encourage, and foster desirable changes in schools are major challenges for educational leaders. The purpose of this study is to generate empirical descriptions and theoretical propositions that can be useful in explaining and perhaps anticipating the consequences for teachers involved in a work milieu characterized by multiple and continuous changes. It is anticipated that these results will inform the theory on organizational change and provide a basis for policy recommendations. 
CHAPTER II

\section{LITERATURE}

What every teacher knows is that the work of school is a social world. Those human beings who live together in the school, though deeply severed in one sense, nevertheless spin a tangled web of interrelationships, that web and the people in it make up the social world of a school . . . I believe that all teachers, great and small, have need of insight into the social realities of school life, that they perish, as teachers for lack of it. (Waller, 1930, p. 4)

Chapter II provides a review of descriptive research that contributes to the pedagogy on teachers' adjustments to multiple and continuous change. The identification of the teacher as a significant variable in school improvement is noted in the research on school effectiveness, staff development, organizational change, and teacher effectiveness. This chapter reviews some of the significant findings that are pertinent to inquiring how teachers adjust to multiple and continuous change. Limitations and strengths of the research are noted.

One of the considerations in thinking about how to proceed with this study was whether or not to focus on particular kinds of changes. For example, changes in structures, tasks, technologies, or changes in the human subsystem represent typical areas within which changes may be initiated in organizations. Given the concern with the 
phenomena of multiple and continuous change, the researcher decided not to attempt to identify or document the adjustments of the teachers to particular targets of change (task, structure, technology, or people). Thus, the focus of the study remains on teachers' responses to working in schools characterized by multiple and continuous efforts to introduce various kinds of change. Criteria for selecting study participants were interviewees must work full-time at the study site, interviewees should include both sexes and interviewees should represent a range of experience.

A traditional review of the literature on change did not adequately capture the extent change influences teachers' lived experiences with multiple and continuous change. For this reason, the review to follow is organized around three literatures: the research on school effectiveness, school improvement and staff development, and teacher behavior.

\section{THEORETICAL CONCEPTS}

Chapter I introduced theoretical concepts based upon Brim and Wheeler's (1966) and Becker's (1964) discussions of adult socialization in organizational settings and personal change in adult life. Both of these theoretical frameworks will serve as initial orienting and sensitizing devices in directing the researcher's attention to two issues. First, that teachers' adjustments are the product, in part at 
least, of an on-going and dynamic relation between person and situation (Brim \& Wheeler, 1966). Second, that the character of teachers' adjustments are the product, in part at least, of their capacity as individuals to assess what is required of them for successful performance in the situation they face, their ability to act on that knowledge of the requirements of the situation, and their motivation to respond to their assessment of the situational requirements (Becker, 1964).

The researcher's purpose is neither to test these frameworks nor to use them as a basis for describing and analyzing teacher behavior. Rather, their usefulness is that they provide the researcher with a conceptual "handle" on the character of the person/context relationship which the study participants themselves represent. The general frameworks posed by Brim and Wheeler (1966), and by Becker (1964), lead the researcher to pose the basic question: What adjustments do teachers make to a school characterized by multiple and continuous change?

\section{RATIONALE}

The review of the literature on change describes what is currently known about institutionalization of innovations and teachers' concerns regarding change. Much of the research is based on the institutionalization of single innovations (Berman \& McLaughlin, 1974; Crandall et al., 
1982; Hord, Rutherford, Huling-Austin, \& Hall, 1987 ;

Huberman \& Miles, 1984a; Loucks-Horsley \& Hergert, 1985).

The research on school effectiveness suggests that certain practices produce better student outcomes (Brookover et al., 1982; Edmonds, 1979).

The research on effective teaching describes the efforts designed to change teacher behavior and includes teacher thought, teacher efficacy, and teacher effectiveness (Clark \& Peterson, 1986; Good \& Brophy, 1982; Jackson, 1968; Little, 1982; Porter \& Brophy, 1988). School effectiveness, change, and teacher behavior are relevant topics for a beginning appreciation of the phenomenon of teacher adjustments to change.

\section{EFFECTIVE SCHOOLS RESEARCH}

The effective schools movement triggered an avalanche of school-wide change efforts currently in operation in many schools. The following overview of the effective schools research describes the objectives and explains in part the underlying thinking that has propelled schools into site-based improvement efforts. The effective schools research has resulted in local, state and national mandates for school improvement, with the most recent emphasis on continuous school renewal (Joyce, 1986, p. 2).

Social institutions tend to deteriorate unless they are continuously rejuvenated, and when patterns of education become routine, life in schools becomes less vital. Schools need constant attention to 
revitalize them and the lives of the children and teachers who live in them. The public faces a continuing dilemma: to preserve familiar, traditional practices, making them as effective as possible, and yet keep up with the times in order to meet the challenges presented by social change. The result is that schooling exists in a social tug of war between proponents of tradition and change, and thus much that is known about what makes schools more effective is not being used. (Joyce et al., 1983, p. 4)

The research on effective schools was begun in the early 1970's in partial response to the Coleman Report, Equality of Educational Opportunity (ERS, 1983, p. 23). Basic tenets of the effective schools movement are:

(1) Schools can be identified that are unusually effective in teaching poor and minority children basic skills as measured by standardized tests. These successful schools exhibit characteristics that are correlated with their success and that lie well within the domain of educators to manipulate. (3) The characteristics of successful schools provide a basis for improving schools not deemed to be successful. (p. 23)

Identification of effective schools was based on correlational research (Roueche \& Baker, 1986). Tangible characteristics of those schools were strong administrative leadership, high expectations for all children, orderly school environments, provision of adequate resources for school improvement efforts, and frequent monitoring of student progress (Edmonds, 1979, p. 22). The effective school movement also was strongly influenced by the beliefs expressed by the late Ron Edmonds (1979):

(a) We can, whenever and wherever we choose, successfully teach all children whose schooling is of interest to us; (b) We already know more than we need to do that; and (c) Whether or not we do it 
must finally depend on how we feel about the fact that we haven't so far. (p. 23)

Buoyed by beliefs that good schools produce improved student outcomes and that good schools have identifiable attributes, many schools have implemented processes designed to produce school-wide change. Many of these processes depend on high levels of teacher involvement. This is in part due to the attention and recognition of the relationship of the teacher to student achievement (Duke, 1984; Edmonds, 1979; Good \& Brophy, 1986).

Although earlier studies, such as the coleman Report, analyzed schoolwide data that neutralized the effect of any one teacher's performance, subsequent research has determined that teachers do make a dramatic difference in student achievement. (Roueche \& Baker, 1986, p. 136)

Many schools have attempted to replicate effective schools attributes with the goal to improve schools (Bloom, 1976). The link between identification of attributes and replication of attributes is not supported. There is a lack of data that links good schools to self-renewing schools.

- . the literature implicitly assumes that self-renewing schools are good schools and that the positive properties of these schools relate to the behavior of the school faculty while the behavior of students is ignored. . . Perhaps self renewing schools are not effective ones, or at least, so the argument goes, the proponents of school renewal have not shown that they are. (Duke, 1984, p. 27)

The imposition on a system to copy measurable outputs of other schools may produce unintended or unwanted outcomes that do not create better environments for student learning (Glickman, 1989). 
A combination of beliefs about schools and teachers fuel many of the multiple and continuous change efforts. The teacher is identified as an important variable in schools becoming more effective and in effective schools (ERS, 1983). Assumptions that schools can become more effective through the replication of effective schools attributes has been the catalyst for many change efforts but has not yet been documented. The ultimate success and the net influence on the entire school system of school improvement efforts over time is difficult to assess.

\section{SCHOOL IMPROVEMENT AND STAFF DEVELOPMENT}

The research on change describes the conditions conducive for institutionalization of innovations, and the research on staff development describes the processes through which teachers learn new behaviors (Hall \& Hord, 1987; Hord et al., 1987; Huberman \& Miles, 1984a; Little, 1981, 1982; Sparks, 1983). The extensive research on change and staff development identifies the extent of requisite teacher involvement in change efforts and adult learning. Important understandings that add to our knowledge concerns the extensiveness of single changes.

The complexities of change are identified by Fullan (1982). Change is described as multidimensional. The process affects people differently and varies from person to person and from group to group. Secondly, change penetrates 
and challenges beliefs, cultural norms, identities, and efficacy. Placed in jeopardy is a person's entire way of being. Thirdly, change consists of a constant interplay of dynamic interrelations. The interplay is influenced by a broad array of variables. Fullan's description of the complexities of change is one of the premises guiding this investigation (p. 33).

A three year project conducted by Huberman and Miles (1984a) produced an analysis of factors leading to higher institutionalization of federally supported innovations in some 145 school districts (p. vii).

It appears that higher institutionalization was likely when there was administrative pressure to implement the program, no serious resistance (seen in low building endorsement or weak user commitment), and a reasonable degree of teacheradministrator harmony. If implementing the program resulted in some degree of organizational transformation, and did not have serious assistance gaps, and ended with use by a fairly large percentage of eligible users, who along with program leaders remained in the situation, then stronger institutionalization was likely. However, if those who owned and managed the innovation decided to disengage, other positive factors (e.g., building endorsement, user master, and stabilization of use) made little difference. (p. 210)

Noted in the research on change are the enormous efforts, resources and support requisite for institutionalization of single innovations. The research is based on institutionalization of single innovations rather than multiple and continuous change efforts. The nature of the efforts, resources, and support that multiple and continuous change requires, imposes, and elicits has not 
been investigated in detail from the perspective of teacher adjustments.

The scope of the research on change is also limited. Change, as it influences other non-targeted educational practices, school climate, community, and teachers has not been studied wholistically (Loucks-Horsley et al., 1987, p. 155) .

Any serious attempt to introduce change needs to be accompanied by an assessment of probable consequences for the teacher, programs or reorientation and preparation and on-going monitoring of actual consequences. (Grace, 1972, p. 107)

The dilemma for educators is in the application of research that is based on a limited set of variables that do not capture the phenomenon of schools. Fullan (1982) notes that:

People do not understand the nature or ramifications of most educational changes. They become involved in change voluntarily or involuntarily and in either case experience ambivalence about its meaning, form or consequences . . . there are a number of things at stake--changes in goals, skills, philosophy or beliefs, behavior, etc. Subjectively these different aspects are experienced in a diffuse, incoherent manner. Change is often not conceived of as being multidimensional. (p. 29)

The key findings on change are based on examination of successful and unsuccessful single innovation efforts. While limited in their scope, the research does note that meaningful change with single efforts is a long-term multi-year process (Hall \& Hord, 1987, p. 23) The reality 
of most schools is that change is multidimensional, planned and unplanned.

\section{Concerns Based Adoption}

Model (CBAM)

CBAM is a look at change from the user's perception. This study is also concerned with change from the user's perspective. The research on CBAM provides some basic understandings regarding single change from the actor's perspective. The users' concerns and experiences regarding single innovation change efforts are explored by Fuller (1969), Hall and Hord (1987), Hord and Hall (1982), Hord et al. (1987). Their work notes the relationship of teacher concerns, motivation, and commitment to change. The nature of teachers' concerns center on issues:

$$
\text { - - about class control, about one's own content }
$$
adequacy, about teaching situations, and about evaluations by supervisors, by pupils, and self assessments. (Fuller, 1969, p. 210)

Additional investigation of teacher concerns suggests these concerns are "quasi-developmental (Hall \& Hord, 1987, p. 59). The earliest stages of implementation are characterized by a self-focused state. Subsequent stages may involve managerial issues such as organizing, scheduling, and implementation. Higher levels of concern focus on students, peers, and universal outcomes (p. 60). The "Concerns-Based Adoption Model" (CBAM) outlines "stages of concerns" that provide guidelines for identifying feelings and perceptions of participants. One of the major 
premises of CBAM is that "principals and other facilitators can be more effective and change can be more successful if the 'concerns' of teachers are considered" (Hall \& Hord, 1987 , p. 53).

Additional work by Hall (1981), Hall and Hord (1987), Hall and Loucks (1978, 1981), Hall and Rutherford (1983), and Hord and Hall (1982) based on stages of user behavior produced a schema on the "Levels of Use" (LOU). Both "Stages of Concern" and "Levels of Use" serve as diagnostic tools designed to collect information that assist identification of appropriate and effective support. CBAM examines concerns and stages of user behavior related to "single" innovations. In order for innovations to be institutionalized, CBAM assumes that change facilitators must actively identify teacher concerns in order to provide effective support and assistance to teachers (Loucks-Horsley \& Hergert, 1985).

Concerns of participants in multiple and continuous change efforts are complicated by the multiplicity of change efforts, and compounded by the cumulative effect of concern and effort. Unanswered by the current body of research, and not addressed by $C B A M$ and other change models, are the following questions: how are teachers' concerns influenced by multiple and continuous change efforts, what are the distinguishing attributes of multiple and continuous change, 
and how can rnultiple and continuous change efforts be realistically supported?

\section{Staff Development}

Staff development and adult learning have been the subject of investigation for many years. Summarized here are a number of findings that contribute to the pedagogy on adult learning. The processes by which adults acquire new skills are relative to our understanding adult learning. What is known is that in order for adults to learn, the content must be relevant, there must be opportunities for practice that are also combined with feedback on the performance and there must be commitment from practitioners (Ashton \& Webb, 1986; Butler, 1988; Crandall et al., 1982; Griffen, 1983; Janis \& Mann, 1987; Lieberman, 1986; Lieberman \& Miller, 1981; Lieberman \& Rosenholtz, 1987; Little, 1981, 1982; Showers, Joyce, \& Bennett, 1987). Underscored in the research is the complexity and time demands requisite for adult learning to occur. What is apparent is the number of variables involved in the equation that produces change.

Recommendations for training adults are based on a synthesis of research on staff development. Suggestions include recommendations that multiple trainings be one or two weeks apart, teachers be involved in the decision making, workshops encourage teachers to visit each others' classrooms, and philosophical acceptance by teachers be 
cultivated by allowing open expression of concerns, doubts or objections. The resistance of teachers to new practices can be reduced through teacher testimony (Showers et al., 1987).

Components of effective staff development projects include presentation of a new skill or theory, demonstration and modeling of the new skill, guided practice within the instructional setting, and opportunity for practice and feedback. Guidance and coaching also should occur within the setting (Showers et al., 1987).

Another component to staff development is follow-up. Crandall et al. (1982) and Guskey (1986) claim that change in teacher attitudes and beliefs occurs after teacher participation, during the follow-up sessions. Follow-up is as critical as the actual training activity.

Interviews conducted with teacher inservice participants suggest that teachers make substantial improvement when they believe in their own ability to make changes and improve their educational environment (Showers et al., 1987).

As Russell Gersten discovered, the organization's efforts at linking teachers with efficacious assistance is a crucial step toward excellence for schools (Gersten et al., 1982). Also such excellence is often connected to the teachers' perception of inservice education as a source of growth, rather than as a waste of time (Armore et al., 1976). (cited in Roueche \& Baker, 1986, p. 32)

Positive school climate is another salient feature of successful staff development efforts (Showers et al., 1987; 
Sparks, 1983). Little (1982) investigated aspects of work places that contribute to "learning on the job." Teachers and administrators were interviewed. Those findings indicate that:

In successful schools more than in unsuccessful ones, teachers valued and participated in norms of collegiality and continuous improvement (experimentation); they pursued a greater range of professional interactions with fellow teachers or administrators, including talk about instruction, structured observation, and shared planning or preparation. They did so with greater frequency, with a greater number and diversity of persons and locations, and with a more concrete and precise shared language. (Little, 1982, p. 325)

The need for teacher commitment and investment of non-instruction time is noteworthy. Also striking is the number of fundamental variables that are requisite for adult learning to occur. Yet unknown are the requirements of multiple and continuous change that are dependent on adults learning new behaviors. Still to be examined is the relationship of unlearning old behaviors to new behaviors. It has been assumed that new behaviors replace old behaviors. There has been little investigation into this phenomenon. Also yet to be analyzed are the influences of multiple and continuous change on school climate and their relationship to adult learning.

\section{TEACHER BEHAVIOR}

Effective teaching provides a description of idealized teacher behaviors. Many of the attempts to improve schools 
are efforts designed to change teachers based on the images of effective teaching.

While no one vision of effective teaching has clearly proven superior, there are known characteristics of effective teachers (Duke, 1987). All of the research on teachers, including teacher effectiveness, teacher beliefs, and teacher thought processes underscore the importance of teachers in the instructional process. "Ultimately, the success of all improvement efforts depends on the quality and determination of the classroom teacher" (Ashton \& Webb, 1986, p. 2). What follows is a discussion of what is known about the practice and art of teaching as it pertains to multiple and continuous change.

The relationship of the teacher to student performance is elaborated in the research on effective teachers (Porter \& Brophy, 1988, p. 75). Good teaching practices include classroom management, pedagogical practices, active teaching, maximization of "academic learning time," and enthusiasm and motivation (Roueche \& Baker, 1986, p. 117). A summary of the behavior of effective teachers is provided. Effective teachers are professionals who:

- are clear about their instructional goals;

- are knowledgeable about their content and the strategies for teaching it;

- communicate to their students what is expected of them--and why; 
- make expert use of existing instructional materials in order to devote more time to practices that enrich and clarify the content;

- are knowledgeable about their students, adapting instruction to their needs and anticipating misconceptions with their existing knowledge;

- teach students metacognitive strategies and give them opportunities to master them;

- address higher- as well as lower-level cognitive objectives;

- monitor students' understanding by offering regular appropriate feedback;

- integrate their instruction with that in other subject areas;

- accept responsibility for student outcomes;

- are thoughtful and reflective about their practice. (Porter \& Brophy, 1988, p. 75)

Efforts that instruct, support, and encourage effective teaching behaviors have flourished. Twenty-five discrete teaching behaviors were enumerated by Bruce Joyce and Marsha Weil (cited in Duke, 1987, p. 57). The nature and the number of behaviors and their various interpretations provide ample content for a melangé of staff development offerings.

The time and effort requisite for teachers to participate in the activities designed to improve their teaching skills frequently poses a complex dilemma.

Teachers often find themselves the focus of political activity. This activity can be crudely divided into two basic types. One type aims to improve schooling by charting, regulating, or circumventing teachers. The other type of activity focuses on helping teachers tackle jobs that seem to grow more complex annually. . . Ironically, 
however, many attempts to help teachers turn out to do more harm than good. Noble ambitions, it would appear, are no guarantee that innovations will leave schools and teachers better off than they were before. (Duke, 1984, p. 93)

A portrait of effective schools and effective teaching emerges that creates a situation fraught with dissonance. Porter and Brophy (1988) note that:

Nevertheless, teachers' classroom practices have been shown to be influenced in important ways by the goals that teachers hold for schooling and the responsibilities that they are willing to accept for themselves. One of the fundamental challenges of teaching is that the number of important goals that could be pursued exceeds the number that can be accomplished within the time and energy available. To cope with this dilemma, teachers simplify their efforts. (p. 77)

There has not been an accounting of the cost exacted from classroom instruction by the continuous pressure imposed on teachers to learn new and more complex behaviors.

The literature on teacher behavior has four dominant strands focusing on beliefs, thinking, effectiveness, and efficacy. Each of these is discussed briefly to illustrate their bearing on the problem being studied.

\section{Teacher Beliefs}

Teacher beliefs have been identified as influential in producing learner outcomes (Good \& Brophy, 1986). High expectations for all students correlate with increased student achievement (Brookover et al., 1982). Research on effective schools suggests that student achievement is more 
dependent on those who provide educational services than prior research indicates (ERS, 1983; Roueche \& Baker, 1986). The input/output research underscores the importance of the quality of student/teacher interactions (ERS, 1983, p. 13). Guthrie notes that "15 of the 19 studies showed some characteristics of teachers to be associated with one or more measures of pupil performance" (cited in ERS, 1983, p. 23). A combination of high expectations and positive attitude towards students seems to positively affect student performance (Good \& Brophy, 1986).

When their attitudes are positive, that is when teachers believe students can learn, classroom strategies are more varied, more homework is assigned and corrected, and students perform better. The students of teachers who approach instruction in a businesslike and talk-oriented way achieve at higher levels. Learning is maximized when teachers view academic instruction as basic to their role as teachers, expect students to master the content of the curriculum, and allocate a maximum amount of time to instruction (Good, Biddle, \& Brophy, 1983). (cited in Lane \& Walberg, 1987, p. 36)

The influence that multiple and continuous change has on teacher beliefs and attitudes has yet to be explored. Teacher beliefs, however, are the tacit targets of many change efforts (Guskey, 1986).

\section{Teacher Thought}

Implicit in the efforts to encourage effective teaching and to improve schools is an assumption that teachers' planning and thinking is an integral part of the educational process. Studies examining "teacher thought" 
elucidate understandings of the complexity of the demands of effective teaching. "The major goals of the research on teacher thought processes is to increase our understanding of how and why the process of teaching looks and works as it does" (Clark \& Peterson, 1986, pp. 256-257). The significance of thinking, planning, and decision making, the hidden side of teaching, is elaborated in the research on teacher thought (Clark \& Peterson, 1986, p. 255; Jackson, 1968) .

Basic to a wholistic inquiry of teacher adjustments to multiple and continuous change is a consideration of the many activities that are part of the teaching act. The potential exists for unanticipated consequences resulting from the net accumulation of adjustments to multiple and continuous change.

\section{Teacher Efficacy}

Efficacy is the conviction that one can be successful in operationalizing behavior. standards for operationalizing behavior are internal but susceptible to influence from external definitions, observations, performance evaluations (self and other), and feedback (Bandura, 1977, p. 191).

Teachers' convictions concerning their capacity to be effective is assumed to influence the degree and nature of a teacher's attempts to master new behavior. 
Efficacy expectations determine how much effort people will expend and how long they will persist in the face of obstacles and aversive experiences. The stronger the perceived self-efficacy the more active the efforts. (Bandura, 1977, p. 194)

Efficacy is a stronger predictor of behaviors in the face of unfamiliar threats than past performance (Bandura, 1977, p. 211).

The research on motivation suggests that the subjective perception of competence is more important for an individual's well-being than is the objective level of competence (Bandura, 1977). (cited in Ashton \& Webb, 1986, p. 176)

Efficacy is not developed through single events; rather, it evolves over time. Explicit goals are useful in creating efficacious situations.

Without standards against which to measure their performances, people have little basis for judging how they are doing or for gauging their capabilities. Subgoal attainments provide indicants or mastery for enhancing self-efficacy. By contrast, distal goals are too far removed in time to provide sufficiently clear markers of progress along the way to ensure a growing sense of self-efficacy. (Bandura, 1981, p. 587)

Bandura (1977) suggests that cognitive processes are significant in the acquisition of new behaviors (p. 192). Behavior is learned through modeling, feedback on performance, and response consequences. Bandura notes that:

Contrary to the current view that behavior is controlled by immediate consequences, behavior is related to its outcomes at the level of aggregate consequences rather than monetary effects (Baum, 1973). People process and synthesize feedback information from a series of events, over long intervals of time, based on situational circumstances, and the patterns of actions that produce given outcomes. (p. 192) 
Withdrawing from situations before mastery decreases efficacy which in turn reduces the likelihood of engaging in future activities.

A person's sense of efficacy may influence their future capacity to make decisions or may influence their perception of events or may impact their selection of options. Decision making is stressful due to the anticipation of new and unfamiliar material as well as the potential for social losses in the areas of reputation and self-esteem.

Three conditions contribute to a person's decision making: awareness of the risks involved, hope of finding better solutions, and the time available to make decisions (Marsh \& Jordan-Marsh, 1985). People typically avoid situations that are fraught with ambivalence and stay in situations that are manageable. The relationship of efficacy and motivation to multiple and continuous change efforts has yet to be determined. The circuitousness of change, efficacy, and loss confounds the phenomenon of change.

Teacher adjustments to multiple and continuous change may better be understood from the actor's perspective. The teacher's perspective provides an understanding of the phenomenon from the lens of key shareholders in the educational process (Duke, 1984). To ignore the perspective of the key shareholders of the lived experience may 
inadvertently jeopardize well-intended efforts to create, encourage, and nourish effective skills.

Summary

The research on teachers identifies attributes and behaviors of good teaching. Yet even when teachers master new skills and possess the knowledge and desire to perform effectively, there are indications that teachers revert to previous practices. The why of that phenomenon has yet to be fully understood (Porter \& Brophy, 1988). Although, Porter and Brophy hypothesize that:

The picture of good teaching that emerges from research features hard work, hard thinking, tough choices, and objective evaluations. The energy required to teach this way is probably underestimated by studies that consider only one segment of a teacher's professional life at a time. Researchers tend to focus their investigations on teaching in small segments, typically concentrating only on particular lessons taught within one subject matter area. . . . Similarly, more needs to be learned about the costs that teachers pay in adopting new approaches to teaching and about how these costs might be ameliorated. (p. 83)

The focus of much of the research on teaching is acknowledged to be of limited scope. The realities of teachers exhibiting effective teacher behaviors on a daily basis, under a variety of circumstances including multiple and continuous change is not addressed. What emerges from the literature is an idealized portrait of effective teaching.

Unaddressed is the dissonance of competing pressures to learn new behaviors, unlearn old behaviors, adjust to 
changes, and maintain effective instructional practices. Examination of the whole is key then to formulating an understanding of what is happening to the teachers in our schools as a result of our efforts to improve and renew curricula and the quality of instruction.

\section{RESEARCH QUESTIONS}

Two questions are being investigated:

1. Is there a phenomenon of multiple and continuous change and if so how is it characterized by the participants?

2. Is there an effect of multiple and continuous change on the participants, if so, how do the participants adjust to the phenomenon and how can those adjustments be described?

\section{SUMMARY}

The real world of schools is one of multiple and continuous change. While there is much description concerning effective schools, change, and teacher behavior, there is little known about teachers' adjustments to multiple and continuous change. There is consistent documentation concerning the complexity of meaningful change. The amount of teacher time requisite for institutionalization of single innovations is noted. Staff development and adult learning are also noted as time 
consuming and complex. Additionally, the literature is replete with data on the importance of teachers being directly involved in the change process and staff development activities. However, there is little information on how teachers are affected by and respond to the multiple and continuous change stimuli characterizing their day-to-day work-world.

Change requires learning new behaviors, expectations, and values. Change is dependent on motivation and skills. Change is also teacher dependent. Based on what is known about change, change can be considered a complex socialization process.

Effective support for school improvement is dependent on understanding teacher adjustments to learning new and multiple behaviors. The practical significance of this study is that the results may provide change agents with direction regarding the policies and practices needed to help teachers sustain and support school improvement initiatives in a matter that is organizationally and individually healthy. 


\section{CHAPTER III}

\section{PROCEDURES}

This chapter provides a description and a rationale for the methodological considerations and decisions of this investigation. Included in this discussion is a rationale for a qualitative study approach, an account of the site and sample selections, an outline of the data collection procedures with particular emphasis on teacher interviews, and a description of the data analysis process. The final section of this chapter consists of responses to the issues of validity, reliability, and case study standards followed by a statement of the study's limitations.

\section{STUDY DESIGN}

The examination of a single phenomenon, teachers' adjustments to multiple changes, examined from the teachers' perspectives, requires an approach that differs significantly from traditional, positivistic, quantitative methodology. This investigation, therefore, is ethnological and utilizes a qualitative approach to examine the phenomenon of teacher adjustments to multiple and continuous change. 
A phenomenological approach, as defined by Bogdan and Taylor (1975), leads to understanding human behavior from the actor's reference: "The phenomenological examines how the world is experienced . . the important reality is what people imagine it to be" (p. 10).

\section{Methodological Rationale}

This study design was influenced by the notions guiding a case study approach. A case study approach examines the phenomenon within its natural context. Yin (1984) defines a case study as an empirical inquiry that: - . investigates a contemporary phenomenon within its real-life context when the boundaries between phenomenon and context are not clearly evident, and in which multiple sources of evidence are used . . . The case study is but one of several ways of doing social science research. (p. 23)

Each strategy has peculiar advantages and disadvantages, depending upon three conditions: (a) the type of research question, (b) the control an investigator has over actual behavioral events, and (c) the focus on contemporary as opposed to historical phenomena. The case study approach may include multiple case studies or may focus on a single site (Yin, 1984). This study utilizes a single case study approach .

Another distinguishing feature of qualitative research is the propensity to detect the unanticipated. Light (1979) suggests that qualitative research can reveal the latent or 
unanticipated consequences of improvement efforts (p. 306). Guba and Lincoln (1983) state that a qualitative researcher:

- . prefers to think of multiple factors and conditions, all of which interact with feedback and feed forward to shape one another. Actions can be understood not as having been caused but as having emerged from the constant interplay of its shapes and which are themselves part of the action indistinguishable from it, shaping and being shaped simultaneously. (p. 321)

Selection of a qualitative research approach presents an opportunity to examine the whole. Yin (1984) states in brief,". . the case study allows an investigation to retain the holistic and meaningful characteristics of real-life events. . ." (p. 14). According to Van Maanen (1979), the significance of qualitative data is that:

- . they are attractive for many reasons: they are rich, full, earthy, holistic, 'real', their face validity seems unimpeachable, they preserve chronological flow where that is important, and suffer minimally from retrospective distortion, and they in principle, offer a form, or precise way to assess causality in organizational affairs... (p. 117)

Qualitative research provides an account of the many variables and the concomitant interplay that creates shared meaning. Bogdan and Taylor (1975) agree: ". . truth then emerges not as one objective view but rather as the composite picture of how people think about the institution and each other" (p. 11).

Guba and Lincoln (1983) identify several axioms that differentiate a qualitative/naturalistic form of inquiry from a quantitative/rationalistic form of inquiry. These 
axioms provide the basic rationale for the approach utilized here.

Axiom 1:

There are multiple, intangible realities which can be studied only holistically: inquiry into these multiple realities will inevitably diverge (each inquiry raises more questions than it answers) so that prediction and control are unlikely outcomes though some level of understanding can be achieved. (Guba \& Lincoln, 1983, p. 321)

Bogdan and Taylor (1975) note:

A situation has meaning only through peoples' interpretations and definitions of it. Their actions in turn stem from this meaning. Thus, this process of interpretation acts as the intermediary between any predisposition to act and the action itself. ( $p$. 10)

An intention of this study was to capture the complex realities of continuous and multiple improvement efforts by seeking to understand the perceived impact of the total experience of continuing change on teachers' personal and professional lives.

Axiom 2:

The inquirer and the object of inquiry interact and influence each other; this mutual interaction is especially present when the object of inquiry is another human being. (Guba \& Lincoln, 1983, p. 322)

Another intent of this study was to gain entry into the participants' world for the explicit purpose of discovering teachers' perceptions of their adjustments to change that occur in the school setting but may influence the teachers' lives beyond the school setting. 
Axiom 3:

The aim of inquiry is to develop an ideographic body of knowledge; this knowledge is best encapsulated in a series of working hypotheses that describe the individual case; differences are as inherently inferring as (and at times more so than) than the similarities. (Guba \& Lincoln, 1983, p. 322)

This inquiry thus was designed to generate new understandings, not to test or refine existing theory. The method of analysis relied upon a process of comparing and contrasting elements of raw data in an effort to discover patterns and regularities, and to account for and explain similarities and differences across data sources.

Axion 4:

An action may be explainable in terms of multiple interacting factors, events, and processes that shape it and are part of it; inquirers can, at best, establish plausible inferences about the patterns and webs of such shaping in any given case. (Guba \& Lincoln, 1983, p. 322)

Patton (1980) notes that inductive analysis is part of qualitative research:

- . that means that the patterns themes, and categories of analysis come from the data; they emerge out of the data rather than being improved on prior to data collection and analyses. (p. 306)

Change is not an event that is context bound and user sensitive. Investigation into the phenomenon of multiple change from a number of perspectives requires sensitivity to the diverse and complex variables that interact to influence peoples' perceptions. 
Data collection and

Analysis Procedure

Research Design. The primary plan guiding this study

was to interview teachers in-depth who have worked in a school setting characterized by multiple and continuous efforts designed to change teacher practices over a period of three to five years.

This is a qualitative ethnographic study that is designed to provide rich description, while exploring causal links, in a real-life context, between extended changes and teachers' adjustments to on-going change.

\section{Data collection Procedures}

Van Maanen (1979) believes that:

A fundamental principle of field work is that the researcher's account of the studied scene should be built on the information provided by the most knowledgeable (and candid) members of that scene. (p. 54)

In addition to the teacher informants, the school principal and director of elementary education were also interviewed for the purpose of confirming data provided by the informant. As noted in chapter $I$, three sites were indirectly involved in the data collections. One site location was used for a pilot interview, one site involved a CBAM survey, and the third provided four informants. Another source of data are school documents that are descriptive of change or improvement efforts. Yin (1984) notes that in case studies, the most important use of 
documents is to corroborate and augment evidence from other sources (p. 80). Yin suggests documents to corroborate data:

- letters, memoranda and other communiques

- agendas, announcements and minutes of meetings, and other written reports of events;

- administrative documents--proposals, progress reports, and other internal documents;

- formal studies or evaluations of the same "site" under study; and

- news clippings and other articles appearing in the mass media. (p. 79)

All documents referred to by the interviewees as sources of information (that fit into the guidelines suggested by Yin) were reviewed.

The process of collecting data from more than one source and by different methods is called triangulation and is a strategy frequently utilized in case studies to guard against threats to validity (Denzin, 1978; Jick, 1979; Patton, 1980). The data collection in this study is based on three kinds of information: participants' identification of their adjustments to multiple and continuous changes, administrative description of the site changes and participant adjustments, and documents reflective of the policies, operations, and procedures bearing upon the school and its teachers' day-to-day work lives. 


\section{Data Analysis}

Yin (1984) suggests that "every investigation should start with a general analytic strategy--yielding priorities for what to analyze and why" (p. 99). The method of analysis utilized in this case study is a modification of the "explanation building" described by yin and the "constant comparative approach" described by Glaser and Strauss (1967).

The process employed in this study involved the analysis of data and the generation of tentative propositions during the analysis of this data. Thus, theory was emergent and reflected the current status of data analysis, which was constantly evolving. Yin (1984) describes this type of analysis as a series of interactions: - . first making an initial theoretical statement or an initial proposition about policy or social behavior; second, comparing the findings of an initial case against such a statement or proposition; third, revising the statement or proposition; comparing other details of the case against the revision; again revising the statement or proposition; comparing the revision to the facts of a second, third, or more cases; and finally repeating this process as many times as is needed. (pp. 108-109)

Until an explanation that includes all of the data evolves, Yin's suggestion for safeguards for explanation-building is the utilization of an over-arching theory that guides the initial analysis and interaction of data (pp. 108-109). 
Glaser and strauss (1967) describe the constant comparative method, an approach akin to explanation building :

In discovering theory, one generates conceptual categories or their properties from evidence; then the evidence from which the category emerges is used to illustrate the concept. (p. 23)

The constant comparative method of analysis utilizes four stages: (a) comparison of incidents applicable to each category, (b) integration of categories and their properties, (c) delimitation of the theory, and (d) writing of the theory (Glaser \& Strauss, 1967, pp. 105-113).

In a theory-generating approach (Glaser \& Strauss, 1967) the researcher begins the analysis by comparing incidents and coding data into emerging categories. Glaser and strauss suggest a basic rule for this first step. "While coding an incident or a category, compare it with the previous incidents in the same and different groups coded in the same category" (p. 106). Glaser and strauss distinguish categories as conceptual elements of a theory that stand by themselves (p. 36). A property is an element of a category. Glaser and Strauss go on to say that categories can be borrowed from existing theories, but the data determines the categories, or the emergence of new conceptualizations (pp. 36-37). Eventually, general theoretical properties of the categories emerge. Generally categories and properties were those theorized, or constructed, by the researcher or those that are created out of the abstraction of the language of 
the situation. Emergent categories or properties are compared against other properties and categories. Interviews are taken apart or "factored," but illustrative examples from the interviews are saved.

The process of integrating categories and their properties progresses from comparisons of incidents with incidents, within properties, and within categories.

Thus the theory develops, as different categories and their properties tend to become integrated through constant comparisons that force the analyst to make some related theoretical sense of each comparison. (Glaser \& Strauss, 1967, p. 109)

The process involves a reduction of terminology. Generalization results from the act of comparing. Through the comparisons, diverse properties are integrated as well. Correspondent with the reduction in terminology is the reduction in the original categorizations. When categories work so that terms and diverse properties can be integrated and no additional categories emerge, the need for new categories is reduced. Reduction of categories also occurs when categories are saturated. Once an incident is generated and there are not new emergent aspects, incidents no longer need to be recorded because nothing new is contributed to the theory. Glaser and strauss refer to this as theoretical saturation.

Delimiting the theory occurs at two levels, theoretical and categorical:

First the theory solidifies, in the sense that major modifications become fewer and fewer as the analyst 
compares the next incidents of a category to its properties. Later modifications are mainly on the order of clarifying the logic, taking out nonrelevant properties, integrating elaborating details of properties into the major outline of interrelated categories and most important reduction. (Glaser \& Strauss, 1967, p. 110)

In the final stage of data analysis the researcher reviews all data, notes and memos and proceeds to identify major themes. The information leads thus to a more abstract or higher level of generalization. "The universe of data that the constant comparative method uses is based on the reduction of the theories and the delineation and saturation of categories" (p. 112).

\section{Interview Format}

The interview is a recognized method of empirical inquiry (Glaser \& Strauss, 1967; Guba \& Lincoln, 1983; Hall

\& Hord, 1987; Lofland, 1971; Merton, Fiske, \& Kendal1, 1956) .

The fundamental principle of qualitative interviewing is to provide a framework within which respondents can express their own understanding in their own terms. (Patton, 1980, p. 205)

Open-ended interviews extend the possibilities for an even broader range of data than other data that is collected from traditional sources.

Interviews differ from other data-collection strategies because of their capacity to elicit a broad range of information while permitting indepth inquiry. Interviews are especially effective in production of data because people are usually more willing to talk than to write . . . an open-form question, in which the subject is encouraged to answer in his/her own words at some length, is 
likely to provide greater depth of response. In fact this penetration exploits the advantage of the interviewer in getting beneath-the-surface

reactions. (Best \& Kahn, 1986, p. 186)

Through the use of open-ended interviews, the interviewer can follow the leads and clues of the subject in a manner that is not possible by means of a structured instrument prepared in advance. Open-ended interviewing allows people to respond to their experience beyond the confines of the workday by not constricting their responses. Interviewing captures what is significant from the actor's perspective. This is especially important, as in this case, when the researcher does not know what the critical variables and relationships are a priori. Interviewees' comments may include observations on both their professional and personal lives. Bogdan and Taylor (1975) state that people interpret things differently and that they focus their attention on different matters (p. 10). The open-ended interview format does not presuppose what is important to participants; rather it allows participants to provide their own meanings and interpretations.

The fundamental principle of qualitative interviewing is to provide a framework within which respondents can express their own understanding in their own terms. (Patton, 1980, p. 205)

In research, there are three primary functions of the interview format: (a) Tire rormat allows for the development of plausible hypothesis because the problem is real and not contrived or controlled through experimental efforts, 
the format moves away from ad hoc speculation by the responses being controlled through a structured format, and (c) the format can examine contradictions or discrepancies in theory and fact (Good, 1966, p. 232). The interview format provides an efficient tool for discovering the personal adjustments teachers make in response to their personal experience in multiple and continuous change efforts. The format also assists in the discovery of situational variables associated with the adjustments teachers make in response to the experience of multiple and continuous change (Merton, Fiske, \& Kendall, 1956, p. 41).

In this investigation, the protocol consisted of a single open-ended question presented to each interviewee at the beginning of each interview. That question was:

"describe the adjustments you have made personally and professionally to the changes that you have been experiencing in your school." The remainder of the interview was built upon the interviewee's response to the question. Through probing, participants were asked to cite examples, provide descriptions, give more elaborations and provide more detailed explanation of their adjustments. Probes are, by design, general:

- . quite simply, a probe is a question used to go deeper into the interviewee's responses. As such, probes should be conversational, offered in a natural style of voice, and used to follow up critical responses. (Patton, 1982, p. 173) 
The intent of open-ended interviews is to avoid leading the interviewee. The goal as Merton, Fiske, and Kendall (1956) so aptly describe, is for the interviewer to "seek to obtain a maximum of self revelatory reports of how the situation under review was experienced" (p. 95). The guidelines for conducting interviews, suggested by Good (1966), were adapted for this study:

1. An interviewer generally should open an interview by asking factual non-threatening questions.

2. The interviewer should locate the major data by unstructured "lead" questions.

3. The interviewer should make an effort to pick up leads.

4. The interviewer should cut through generalities with well-formulated probes.

5. The interviewer should stick with the fruitful areas once they open up.

6. The interviewer should reflect on the meaning of emerging data and ask questions that clarify or amplify the meaning for the research problem.

7. The interviewer should be especially alert to follow up only areas where the respondent shows emotional involvement.

8. The interviewer should try to redirect the interview to more fruitful topic when useful data are not emerging. (p. 235)

Good's guidelines correspond with the suggestions of Merton, Fiske, and Kendall and Patton (1982). The probes to be used were neutral in affect and were only attempting to elicit a fuller, more complete response from the interviewee.

Examples of probes used were: 


\author{
"Give me an example." \\ "Describe in more detail what you mean by that." \\ "Explain in more detail, if you can." \\ "Tell me more about that."
}

INTERVIEW CRITERIA

A critical aspect of the data collection process involves on-going review and evaluation of the interview process. Four criteria for assessing an effective interview are identified by Merton, Fiske, and Kendall (1956).

1. Range. The interview should enable interviewees to maximize the reported range of evocative elements and patterns in the stimulus situation as well as the range of responses.

2. Specificity. The interview should elicit highly specific reports of the aspects of the stimulus situation to which interviewees have responded.

3. Depth. The interview should assist interviewees to describe the affective, cognitive and evaluative meanings of the situation and the degree of their involvement in it.

4. Personal context. The interview should bring out the attributes and prior experience of interviewees which endow the situation with these distinctive meanings. (p. 12)

Attention to the criteria and recognition of their interrelatedness was on-going through the data collection process.

The single question interview protocol is designed to encourage the informants' retrospection of their adjustments to school-based changes. For this study, there were a series of two practice interviews with a teacher not 
involved in this case study. The intent of the practice sessions was to refine the interview process by providing a rehearsal opportunity to evaluate and adjust the process in order to reduce the possibility of unintended researcher bias. Revision of the protocol occurred as necessary throughout the study.

Multiple interviews were scheduled with each informant. The actual number of interview sessions was determined by the content and emergence of theory.

As noted in Chapter I interview sessions were in-depth with probes. When no additional information was provided by the informants, additional interviews were not undertaken. It was anticipated that a minimum of three interviews was required with data analysis occurring between interviews. This was true in all except one case when two interviews were sufficient.

Interviews were taped and transcribed following each session. Participants were asked similar questions although relevant issues raised by the informants were pursued. The number of interviews depends on the emergence of theory. Glaser and Strauss (1967) comments/observations were instructive:

- . the sociologist still cannot state how long all of his interviews will take because a new category might emerge at any time; this emergence will call for lengthy open-ended conversations . . . (p. 76) 
Theoretical sampling aims at following an incident or an observation over a period of time and requires sequential interviews, with no clear notion of when the sequence was terminated.

\section{RELIABILITY AND VALIDITY}

In qualitative research "correspondence of fit of the data to the phenomenon being studied is the test of validity" (Bogdan \& Taylor, undated; Guba \& Lincoln, 1983). Patton (1980) notes that the validity can be assured if one can trust the data (p. 332). Data are trustworthy when the data are checked for internal homogeneity and recurring regularities and when external heterogeneity and differences are bold and clear. Patton recommends:

1. There exists internal and external plausibility. Internally the findings are consistent. Externally the data depicts the whole picture.

2. All of the data and information are accounted for in the findings.

3. The findings are reviewed with the informants. Credibility is checked. (p. 331)

Validity can be assessed by the number of times a finding appears, the number of times the finding appears across cases, the number of times it appears across interviews and the number of times it occurs across other data sources (Yin, 1984; Zetterberg, 1965). Becker (1964) states that it is important to understand "semantic transformation and context" (p. 6). The cross checking of 
multiple viewpoints is identified by Patton (1980) as an effective method of triangulating data (p. 331).

Glaser and Strauss (1967) address the concern for validity through comparing and contrasting divergent and common themes. Theory sampling occurs through maximizing the sampling of data.

Maximizing brings out the widest possible coverage on ranges, continual degrees, types, uniformities, variations, causes, conditions, consequences, probabilities of relationships, strategies, process, structural mechanisms, and so forth, all necessary for elaboration of the theory. (p. 57)

Reliability

Frequently researchers feel the need to apologize for the limited generalizability of their studies, especially when working with a limited $N$. The difficulty for the qualitative researcher may be with the definition of reliability. Patton (1980) suggests that qualitative research is reliable when it consists of rich description, when a competent person can make sense of the categories, and when competent persons find similar interpretations of the data (p. 311). Bogdan and Taylor (1975) define reliability as stability. Stability refers to the degree that findings are consistent when changes in situation, context, and research are held constant.

Qualitative researchers tend to view reliability as the fit between what they record as data and what actually occurs in the setting under study, rather than the literal consistency of different observations. (Bogdan \& Taylor, undated, p. 3) 
Jick (1979) states that qualitative data are apt to be superior to quantitative data in density of information, vividness and clarity of meaning, characteristics more important in wholistic work than precision and reproducibility (p. 609). "It is the strength of a small $\mathrm{N}$ that allows the researcher to explore phenomenon in depth" (Guba \& Lincoln, 1983, p. 324). Mintzberg (1979) inquires:

What for example, is wrong with samples of one? Why should researchers have to apologize for them? should Piaget apologize for studying his own children, a physicist for splitting only one atom? Is it better to have less valid data that were statistically significant. (p. 582)

Yin (1984) purports that "yes," single case studies are of value (p. 25). They have a distinctive place in evaluation research (Guba \& Lincoln, 1983; Patton, 1980).

Reliability does not necessarily imply exact replication. The uniqueness of individuals prevents that from occurring. Rather, Guba and Lincoln (1983) state that "first designs are emergent so that changes are built in with conscious intent, and second emergent designs prevent an exact replication of a study in any event" (p. 326) . However, "The essence of the scientific method for producing generalizations is comparison" (p. 340). Reliability begins with a single instance.

This is a case study that examines teachers' perceptions of their adjustments to multiple and continuous changes. Reliability occurs through the use of rich comparisons from the actors' perspectives. 


\section{Case study standards}

Yin (1984) identifies several attributes of an exemplary case study. These attributes were utilized as a final critique of this case study. There are five general characteristics of a study to be critiqued.

1. The case study should cover a topic of "unusual and of general public interest." The issues should be of some importance and contribute to one's discovery or a theoretical breakthrough as in a case study replication.

2. The case study needs to be complete. This includes a distinction between context and phenomenon. The evidence should be relevant. There needs to be an absence of artifactual conditions.

3. The case study needs to address alternative perspectives. This occurs through in-depth interviews of informants who have expressed alternative perspectives.

4. The case study needs to be an end product of adequate and sufficient evidence. This means that evidence is neutrally examined and selected and that all critical pieces are included in the study.

5. "The case study needs to be composed in an engaging manner" (p. 144). These attributes were reviewed and revised in conjunction with the findings. 


\section{Limitations}

This study focuses on a single elementary school. The "N" was limited. Data collection procedures allowed for consideration of many variables, related and unrelated. Exact replication is impossible. In conclusion, this is a study that examines the perceptions of teachers in a limited organizational context.

\section{SUMMARY}

The purpose of this study was to describe the adjustments that teachers make to multiple and continuous changes. The case study method was utilized to guide data collection because it allowed the researcher to examine the phenomenon of change from the actors' perspective. Unstructured interviews were selected because they allowed for maximization of self revelatory reports while providing opportunity for discovery of new information. The collection and analysis of data from documents used a modified version of Glaser and Strauss's (1967) constant comparative method and Yin's (1984) "explanation building."

Validity was addressed by reviewing the correspondence of data between interviews (Bogdan \& Taylor, 1975). Reliability was addressed mainly through density of information collected from a small "n." The gathering of data involved collecting multiple perspectives, comparing and contrasting, maximizing diversity, examining external 
consistencies, checking findings with informants, transcribing all interviews, and collecting rich descriptive data. Finally, attributes of an exemplary case study were used as a final review for critiquing the research. 
CHAPTER IV

TEACHER EXPERIENCE OF CHANGE: FOUR VIGNETTES

This chapter describes the results of the analysis of data collected through a series of open-ended interviews. As noted in chapters $I$ and II, there is a dearth of research on the lived experience of teachers involved in multiple and continuous change. Historically, educational change research has tended to focus on the achievement of intended goals or success or failure of innovations in schools. Notably absent is an understanding of the cumulative impact of multiple and continuous change and what comprises multiple and continuous change from teachers' perspectives. The first category of results are the "lived experiences" of the participants involved in multiple and continuous change. Four vignettes are provided that illustrate teachers' experiences and adjustments to the phenomenon (the names of individuals and schools are not their actual names). Greenfield (1983) notes that "each human being perceives the world in an individual way, i.e. from his own limited perspective and that no two such perspectives are necessarily identical" (p. 2). These four vignettes portray the unique complexity of teacher's "lived" 
experience and serve to illuminate both the collective and singular nature of multiple and continuous change.

I Am Smart Elementary School is located in a wealthy expanding suburban district. The district has long relished community support both economically and politically and the end result is leadership that has been stable and unchallenged.

The student population is represented by middle class caucasian students.

The large district is noteworthy for its close ties with the local university and its generous and cutting edge staff development within the district.

I Am Smart Elementary is perceived as an exemplary school. The faculty pride themselves on being involved in leading the district in test scores and cutting edge practices such as technology. Their leadership too has been stable and unchallenged. Much of the strain and stress experienced by the staff is a product of growth and boundary changes combined with a plethora of demands levied from the state and district mandates.

Each of the vignettes presents an individual's characterization of the lived experience. "The Innocent" is a young man in the first three years of teaching. His story depicts the socialization process that incorporates multiple and continuous change. "The Survivor" is still an enigma. He guarded and protected himself from unwanted intrusions 
including the researcher. He is a seasoned veteran who controlled his own change process. While he is a mystery, I have known "survivors." They do and will continue to challenge and baffle zealous change agents. The "Good Soldier" is a change agent's dream teacher. She embraced the new trends, tried to do it all, and struggled internally with the meaning of change. She too is a familiar face in the landscape of school improvement. Finally, the leader, a teacher from the pilot site, illuminated the tensions between school improvement and teacher effectiveness--an issue that is increasingly becoming prevalent in our schools with the support of site-based improvement and school restructuring. Each of these teachers is unique and familiar, and for that reason they are included in this study.

\section{THE INNOCENT}

This is a story of a good teacher and the many unintended lessons learned from his experience of multiple and continuous change. It is not a tale of a school doing bad things to good teachers. Rather, it is a portrait of a teacher involved in a setting that is similar to many middle class suburban elementary schools. This is the story of the numerous elements thrust on teachers that must be negotiated in order to teach. It is one description of the cost that "school improvement" exacts from the participants. 
There are those qualities that are unique to new teachers, fresh from college, exuding excitement, untainted by disappointment or failure, potent in the belief that young minds can be educated, and unguardedly candid in their efforts to accomplish the task at hand that are reminiscent of kindergartners going off to school, faces bright and alert minds and bodies eager for each new school day. In time, the optimism diminishes, the anticipation depletes, and the excitement vanishes. This is the story of the transformation of an eager enthusiastic teacher into a seasoned veteran. The story is one of lost innocence, naivety forever banished.

His smile was ready even though he was unsure that he could be helpful in the interviews. His experience was not vast. He had only been a teacher for three years, albeit in the same school. I shared his doubt and believed that his view might be limited, but I was interested in his perspective. The risk was rewarded by his wisdom and insightfulness and an openness untainted by ambition or fear. Adam still retained the unguarded candor of youth. His willingness to talk honestly about his experiences provided a lens into school improvement that is hauntingly poignant in its portrayal of the lived experience.

\section{Individual Attributes}

The true significance of Adam's story would be lost without an understanding of Adam. Adam is the faculty 
member typically most sought after by principals because he is affable, bright, savvy and non-disruptive. Adam wants to please his colleagues, principal, parents and students, and Adam is a teacher who works at improving his instructional skills. Adam puts it this way:

I grew up in a household of educators and I can't remember my dad ever getting home before six o'clock. That's just something that I've come to grips with even though for some people "it's four o'clock--I'm out of here." It's very seldom that I get out of here then, so I don't worry about that.

Adam chose to be a teacher for reasons depicted by his. statement towards the close the last of three interviews:

I like my job, I like the kids. If the kids weren't around it wouldn't be as fun. That's what I like. That's what my friends who are not teachers don't understand. Have you ever spent two hours with a bunch of fourth graders that really like you? They have never done that . . . or a bunch of fifth graders who think they can get away with something and I have to contain myself to keep from laughing at them. They are just so full of the devil. But you see, people just don't understand that.

Adam does understand what being a professional teacher requires. He epitomizes the positive traits of educators and his experiences characterize one teacher's efforts at reform and improvement.

\section{Beliefs}

We began our precarious journey with both of us unsure about where it would take us. The story began somewhat predictably. Initially, Adam believed that the greatest liability to his students' achievements were his own limitations as a teacher. Adam attempted to make up for his 
limitations by hard work. His dedication is evidenced by this statement:

I am a hard worker. I don't think I have ever left school early in all my days of working here. I felt bad when I had to have a day off for my sister-inlaw's wedding. I worried about my kids the whole day I was gone. It's because I like my job so much and the kids so much I don't want to screw up that relationship I have with my work.

Adam believed that if he worked at improving and expanding his instructional strategies, if he familiarized himself with the curriculum, and if he developed professionally, he would eventually become a master teacher and his work would become easier. But recently Adam was beginning to question these beliefs. He found that instead of improving it was more painful and nearly impossible to maintain the level of instructional excellence he had at one time envisioned. Adam said:

It's hard to let go of anything, because I'm a stubborn person. I love language arts. We do language arts everyday and many things with spelling. I see many other applications of other things. I'd like to do Social studies a lot more than I do but I can't, because of time. still, I try not to let go of anything.

Time was one of Adam's greatest enemies. Even in the best of circumstances he did battle with this vexation.

Adam believed it was necessary to plan lessons. Otherwise, things snowballed, and the end of the year could arrive without students having received instructions on essential skills. When teachers' routines are upset and when too many lessons are consequently set aside, 
"snowballing" occurs. Adam described what happened when he lost his valuable planning time.

Well, in my planning time I have things I need to do during that time and some of those plans that $I$ do during that time are for the next period kids show up. So last Wednesday we ended up doing some painting and some things on our social studies projects. Since I didn't have that planning time until the last of the day we did not get to do that and we still haven't gotten to do it. It's Wednesday of this week and we'll be lucky to get it in before Friday.

It also was important to Adam to continue to contribute to the already earned reputation for excellence that his school had achieved. Adam was proud of the school's reputation and believed it was due in part to the principal's leadership in requiring that teachers be accountable for teaching the district level curriculum. Sometimes, Adam felt that the expectations of his principal were stressful and overly demanding, but usually Adam felt that the school was better because of the high level of expectations. Fundamentally, what was most important to Adam was the desire to provide his students with an excellent education.

\section{Changes and Adjustments}

The most significant changes noted by Adam during his brief career were the increases and reductions in his school's student population. Those changes necessitated numerous adjustments in staffing and scheduling. Adam talks about the consequences of those "nasty rapid changes":

A lot less teaching goes on and a lot more "busy work" goes on. Communication, with me, I don't want 
to talk to anyone, I don't want to help with anything. I just want to do my own stuff. Leave me alone today. I hate to be that way.

The frustration for Adam was that he wanted his students to learn. When things were constantly disrupted by odd days, short days, and rescheduling, lesson plans were set aside and student routines disrupted. Adam felt bad and cranky because he felt powerless and impotent to provide his students with good instruction. By his own description he was less "approachable"; this made him feel worse and continued the cycle of being "unapproachable." When school life became more frustrating, Adam responded by withdrawing from his colleagues.

There were other reasons, in addition to the schoolwide adjustments to the changing demographics, that pulled Adam from his teaching. Normal routine communication amongst teachers did not occur. Perhaps Adam felt it was because his colleagues were also withdrawing and not communicating. A result was that coordination that normally was well-managed did not happen. Adam's instruction was affected. Playground rules and routines were not observed. There were increasingly more classroom interruptions. Lessons scheduled by specialists were abandoned with increased frequency. Adam's emphasis out of necessity changed from teaching to maintaining his students behaviorally. Normal planning was constantly disrupted and, out of necessity, cast aside. 
Adam describes the difficulty he experienced:

Discipline-wise, school-wide, it made it very difficult, because you'd want to communicate to your children some sort of behavior that we wanted them to do and they'd say "it's not the same as so and so" and you'd have to go down to search out this other team. As you know, it doesn't work that way. It's just too much leg work and pretty soon you're just fighting your battles on your own and it's just that you lose your effectiveness with the kids and I feel that the behavior and the things that go on on the playground and the extra curricular activities always kind of seem to blend themselves into the classroom as well and so that was a big thing there.

The emphasis in the classroom shifted. Adam was learning a set of behaviors that potentially could and did generalize to other changes. They were not a set of behaviors that brought Adam closer to his original goal of becoming a master teacher. They were, however, a set of behaviors that became essential for his classroom's survival. In a classroom, "survival" translates into keeping students occupied and maintained. Adam candidly describes his performance that sustained his class despite all of the changes:

Well, it made me have to become a really busy, busy teacher. Like with my kids last year, I had to have busy work and I had to keep having them doing that. Independent work just went out the window. It seemed like what was important was getting them settled down to work. I couldn't have the kids come right in and go to work on something independently. It was just like the first hour of school every time they had a break. As I look back on it, it was a really well behaved group of kids and they seemed to turn into little animals when they went out on the playground and then, because we didn't have any set of rules or discipline, it wasn't very well coordinated. . . It seemed to be very stressful--a long year, and I look back on it and I think I don't 
know if I really got to teach my kids as much as I really wanted to.

Adam found instead of moving closer to his dream of providing the optimum educational experience for students he was failing to just teach and maintain his classroom.

Adam wanted to do something to make the school function effectively and to reduce disruptions and alterations in classroom routines. Even though he was frustrated, he did not give up; he still wanted to see things fixed. He talked with his teammates and no one seemed to know how to make it better. Things were so complex, and nobody seemed to have any time to plan. Adam noted: "We would try to do certain things we felt would help but in the end it just never was resolved."

Despite the frustrations Adam kept up his level of involvement in his school's activities. He went along with the site Improvement Team's (SIT) goal to increase engaged student learning time; a goal that according to Adam teachers were already doing. Adam was required to spend time filling out a "bunch" of surveys. Adam describes the SIT improvement goal's impact on his instruction this way:

The SIT improvement goal, that has not been a major thing for me. It's no big deal. Great, that's a goal. It's always been a goal for me. It was like, big deal. If you're going to pick something, pick something that everybody isn't working on. Gosh, I want my kids to work all the time anyway. That's how they learn, right? And that did not change my on-time behavior one bit, I don't think. I mean, you guys get paid for this? How do I get on this committee? That was my first response. 
In contrast, the sex education curriculum adoption claimed an enormous toll personally and professionally. When he was first told about the adoption, Adam naively had no idea what the next series of events would require of him. Adam asserts those were "the most stressful professional activities I have ever done." Adam was expected to meet with groups of parents to tell them how he was planning to instruct his students on "AIDS and sex." Many of the parents were conservative and vocal opponents of the curriculum. They had been given permission by the district to come in and observe the teachers while the curriculum was being taught. objecting parents were told that their children could be excused from class. Adam felt scrutinized and fearful professionally. He felt equally concerned and compelled to plan for the excused students. He was sensitive to the feelings of these students and worried about the stigma the students might feel from being excluded. The strain was excessive and an experience that Adam had not been prepared for emotionally or professionally.

There was not much training, only a half day's inservice. Adam was not confident in his preparation. This is how Adam describes the experience:

We had in fourth grade, twelve children pulled out of our classrooms. The fifth grade had two and the sixth grade had one. There were only three in my classroom. But then there were people wanting to come in and watch me do this; and it's a pilot program. Here we are with a pilot program, and it's 
like inventing the wheel; you don't know how it's going to work. I don't really know what I'm going to say, even though I can plan to death. But until I get up in front of those kids and start talking, you know, it just doesn't work. I scripted it out and everything, but there's always going to be one question or something that will throw you off. It can all go down hill from there. Unfortunately, it was down hill in that case; I felt frightened for my job even though I know I couldn't get fired for that. I felt like if I said something wrong or said something I shouldn't, I would really have a lot of heat on me. It wasn't just teaching sex education that exacted a price from teaching, it was the hours of planning time just to get ready with my colleagues. It was the meetings and calls to the staff development folks to see if it was being taught correctly, and personally it was the loss of sleep.

Adam says:

When parents ask me how do I feel about it I want them to know I promise I am not going to effect their child's mind or whatever. I don't want to come off as non-caring or something. I want to prove that I care about their kids and I want people to know that this is a big thing and I tried to get involved with that. I dreamed I was going with the principal and I had a dream that I was teaching sex ed and I looked up and I had three kids and 45 parents in the back of the room.

Adam did teach the sex education curriculum and he said he did drive his health facilitator crazy because he was so panicked and worried. There were powerful lessons for Adam that were outgrowths of these experiences. Adam learned that no one could provide him with satisfactory answers to the dilemmas he faced in the classroom because there was an absence of awareness and appreciation for the complexity and ramifications of a seemingly single change (a sex education adoption). Adam learned that what may appear to be a single change requires time and that time is 
subtracted from other educational necessities. Those necessities led to decisions that required juggling a plethora of competing demands. Adam's number one commitment was to teach, a priority that at times seemed to be shared and valued only by other teachers and a priority that often seemed more of a dream than a reality.

Adam describes what really happened (not what he told the district) when he taught sex education:

Well, we just, we did it, we weren't supposed to but we did it a little bit differently than the district told us to. We just didn't follow the plan, I guess. We got away with it, I think.

Adam believed that "getting away with it" was really in his students' best interest and in his. Adam was in the process of being socialized; learning to adjust to change as a result of his experience with change.

Sex education wasn't the only curriculum adoption that he needed to adjust to; there were others. There was the work that was being done on computer instruction. Adam felt that he really had some strengths in this area and that there was a lot he could offer the school. Computer education was valued as an important academic skill that Adam believed was essential for his students. Adam notes:

$I^{\prime} m$ a strong believer in computer education yet $I^{\prime} m$ never asked about it. I'm just asked since I'm the writer in the building. It seems like anymore I'm asked, "Well, can you write this up for me please?" Well, yeah, sure but are we going to get anything out of it? So I get very frustrated about that, and again I think that my computer instruction and things like that have just totally dropped off. Because what we have now is not being used by me 
because I feel really frustrated that we don't have enough stuff. I don't have enough computers for my students.

There were other adoptions and other complications when new English textbooks were adopted in his classroom and an insufficient number was supplied. One set was shared by three teachers. This necessitated a lot of coordination with colleagues, which created yet another drain of time, an already limited and dwindling resource. Adam coped by staying with what he was already doing. Maybe he was rationalizing when he said it really was not that different. But Adam had to make choices. He simply could not do it al1. Adam was quite candid when he noted, "I just don't do it. And even though they tell you that you sometimes should. Or, I just do it in a different way. A way that they don't suggest." Adam was learning to make decisions about what was best for him and for his classroom because no one else really understood the cumulative effect on him and thusly, how all of it could realistically be implemented. There was one adoption, a writing curriculum, that did seem just fantastic to Adam. It reassured Adam of the reasons why he continued in the profession, something which Adam was increasingly questioning. The new writing adoption provided general goals that stimulated his creativity. Materials were provided, and instructional strategies were simple and varied. Adam described why he liked the new adoption: 
There's a lot of support there and they don't tell us how to do it. They just tell us an outline of how to do it. Here are several ideas. If something strikes your fancy go for it. But other than that, they just give us a few cards, a poster here and there, and this and that, and today we spent forty minutes in the classroom writing and we talked about all kinds of things and the kids are all excited about it. And I'm excited about it, and I've really gone for it. And that's a big thing and because I like it. . . and because I think it's neat, I spend more time at it.

This curriculum adoption was a rare exception in Adam's experience because it did not hinder creative and enthusiastic teaching. Instead, in his view, learning was enhanced.

In addition to the various curriculum adoptions he was asked to incorporate, there were a number of district staff development projects such as Instructional Theory Into Practice (ITIP). Every teacher in the district was required to participate in the training for such projects. Adam experienced the demands as minimal after the initial training. During the year staff development folks would come and observe to make sure teachers were using ITIP in the classroom. Adam says,

I took ITIP and I took it with kind of a grain of salt. And I learned the language and the vocabulary and I teach the same way that I used to teach, but I just learned to apply new names to the stuff. And if that's cheating on ITIP then I'm doing it. of course, maybe it is, I don't know. They tell me that it is and some tell me it isn't. One instructor told me that ITIP is learning to apply names to the things you do now, and another told me this should alter your teaching behavior somehow. It may have in ways that I don't realize. We had the ITIP swat team come to our building. These little staff services people come and bring all 
their subs and they observe the lesson and we present our lesson and it's such an artificial environment it seems like to me. If anyone is watching me give a lesson I may do it a little more flashy than if I'm alone. I play to the odds...

Adam was learning to survive in an environment where teaching for him became increasingly more convoluted. He discovered ways to become more efficient, and methods to salvage time. He adjusted his expectations and he became increasingly more flexible. Things that upset him at first, because they disrupted the class, he eventually learned to accept. He became a little deceitful. He pretended that all of the things he was asked to do were happening so that he could use time and energy on important and necessary activities. Adam discovered that by appearing to support district values he could make choices that were in the best interest of his students.

Despite the set backs and disappointments Adam still wanted to be an effective teacher. He believed that he had learned some strategies and techniques that would contribute to improving his instruction, and he did believe there was one area where he was really improving. Adam felt he was becoming proficient in his pedagogy. For an elementary teacher, the number of subjects and the amount of preparation necessary to teach all subject areas in a grade level is overwhelming. The opportunity to really improve lessons occurs with practice and reflection. Each time Adam taught a lesson he looked for ways to embellish and improve 
it. Adam realized that it would take some time to add to his resources before he would ever feel really satisfied, but Adam believed he was becoming expert at his craft.

Because of this Adam was really looking forward to his third year of teaching. He had plenty of materials, the population of the school had stabilized, he had weathered the sex education adoption. He felt that this year he could finally adequately attend to students and lessons. But one day the inconceivable happened to Adam without any warning. Adam was told, casually and without fanfare, that he was going to be teaching at a different grade level. Lesson plans, enrichment, bulletin boards, all of his thinking, collecting and observing were wasted, useless from Adam's perspective. The real meaning of the grade level change for Adam is described in his words:

One day while walking down the hallway, I was told that $I$ was going to be a fourth grade teacher next year. It was just kind of like in passing. So I figured that's okay, fourth grade's all right and I kind of took it on the chin a little bit and groused around a little bit and kind of resigned myself to the fact. And then there turned out to be three fifth grade teachers this year! And so I kind of felt like they didn't have to change me. I wasn't quite sure if he felt like I wasn't quite doing a good job or if he was kind of doing a favor for another teacher or what. And I still feel a little mad about that. I still don't know why I moved. I never will and I will never get the guts up enough to ask. That decision. . . I don't know, I just, it makes me angry. The stressor is in not knowing why. Not knowing if $I$ was doing a good job in fifth grade. I mean, our team situation was what he thought was the best. I thought that we did a wonderful job. I thought that we were working together really well and we were really coordinating and we were starting to plan together for the next 
year . . starting in April. We were already bouncing around ideas about what we were going to do in language arts and writing. Next thing you know, phtt, you're gone. All that planning and all that work I put in for the fall. . basically I can't use it.

When Adam was asked how that change affected him, he replied:

Well, I won't commit again. When I see changes coming up--no way, no way, I'm not even going to tough it out. I'll just say, "we'll wait and see" - . because no way, I hurt once. I have other choices I can do.

Adam has made other choices and is still involved and committed to his profession. Adam recently wrote a proposal that describes an outstanding lesson plan. Adam was also hand-picked to move to a new elementary school in the fall. But Adam still retains the memory of old lessons. "I have begun to form the opinion that if you hang on to a strategy long enough it will become popular, kind of like bellbottoms and short skirts."

The teacher Adam is today is in part a product of the lessons learned from being a participant in multiple and continuous change. Adam's lessons are too familiar and his last words too disquieting. We shook hands. Adam slowly raised his eyes and said goodbye, blinked, and quickly said: "If teaching was just the kids it would be a great job."

\section{Lessons from Adam}

There are many forces that pull and tug at teachers and that take them away from their primary task--teaching. 
Improvements tend to be planned in isolation, and may (or may not) contain a real potential to enhance teaching and learning. It is the cumulative effect of planned and unplanned changes that teachers live and experience. It is the exponential reality of these changes that disrupt and undermine daily instruction so that any net improvement often seems incalculable and obscured, and is perhaps even lost.

In order to survive the chaos of daily disruptions teachers learn survival behaviors that allow them to cope with the stresses of performing seemingly impossible tasks that keep them from teaching effectively. Ironically, the very behaviors that serve to help them survive also mitigate implementation and institutionalization of new innovation or change.

Adam's experience suggests that multiple and continuous changes occurring in a school potentially elicit a number of unanticipated and dysfunctional consequences for teachers and, ultimately, for children:

- The over-use of busy work.

- The expenditure of valuable and meaningful planning time for non-instructional activities.

- The undermining of teacher commitment towards new strategies.

- The loss of instructional time to classroom management issues. 
- Disruptions to curriculum.

- A reduced sense of efficacy among teachers.

\section{THE SURVIVOR}

Gene was quite different in his orientation from that which I expected to find among teachers who expressed a willingness to be interviewed. He had been referred to as "one of the best," "a top notch teacher," "a man who cares deeply for his students." This contrasted sharply with the man I encountered; one who was cautiously defensive, autonomous, and change resistive. It was the seemingly unorthodox combination of success with students and avoidance of change that elevated him to an almost heroic status in his school. At first I was unable to make sense of the two antithetical impressions. The answer I found was grounded in Gene's "lived solution" to surviving the experience of multiple and continuous change. It presented an unanticipated challenge to what I knew about how good teachers improve. This is Gene's story of his adjustments to multiple and continuous change.

\section{Beliefs}

In order to navigate multiple and continuous change Gene depends on his appraisal of change as it relates to his teaching. Gene's self knowledge concerning what is important to him in order to improve his classroom is in part responsible for his success and reputation. School 
change, as Gene experiences it, is a natural condition of schools, yet it is a condition from which he intentionally distances himself. Gene describes it this way:

Well, I think that we're all in a constant change. Myself, as a teacher, I think it's good. I think change is good. I enjoy it. I have taught fifth grade now for most of my years of teaching, and it's 1988 now and I started teaching in 69, and although I've taught fifth grade for most of that time I do enjoy change. Except that I like the constant of fifth grade because I've experienced other grade levels. I have three years of substitute teaching experience . . . that is, changing constantly, and I found that my reach was the fifth grade. That's my preference, but I do like a change.

Gene's comments reflect what he believes comprises change. Gene uses the switching of grade levels as a reference for change. Absent in Gene's comments are references to improvement efforts. Perhaps for Gene improvement efforts can be avoided while the changes provoked by a switch in a grade level teaching assignment are inescapable. Regardless, Gene believes that change is inevitable, and something that he must manage based on what he knows is best.

In schools, change and improvement often are viewed as interchangeable and synonymous. We often assume that improvement does not occur without change and that change is a prerequisite for improvement. As you will see in this brief encounter, Gene's experience of multiple change suggests that change and improvement are not necessarily positive correlates. Gene developed a talent for resisting involvement in many of his schools' improvement efforts in 
order to protect the resources necessary to insure meaningful educational improvement in his classroom. What Gene experiences as change was not stimulated by school-wide improvement.

In order to cope with the barrage of change in his school, Gene learned to practice selective consumerism. That means that Gene determines what is fundamentally important for improving his classroom instruction. Gene's learning that allows him to manage teaching and improvement further underscores the need for a reexamination of the meaning of change and continuous improvement.

\section{Behaviors}

Gene's behaviors are consistent with his beliefs. Gene adjusts to multiple and continuous change by avoiding active involvement in his school's improvement efforts. To Gene that means balancing the intended or potential effects of his school's efforts at improvement against his estimate of their impact on his classroom instruction, and then determining his level of involvement based on the answer he derives from that calculation.

Some improvement efforts require minimal activity from Gene. One example is the goal established as the school improvement goal, a goal to decrease classroom interruptions:

Well, the only time it's had a major effect on me is when I've had to fill out a questionnaire on my reaction to activities that have required my 
inputting my information into what the goals should be or should not have been.

Gene also practices behaviors to protect his classroom from unnecessary change, and to protect himself from unnecessary involvement. Gene describes his behaviors related to school improvement:

Well, it gave me something else to do after school besides what I do normally. . . . It's just another meeting to go to. And another change to go through.

Gene practices behaviors that allow him to manage his classroom. Gene avoids potential aggravation by behaving passively and by not being involved. He does not elicit undue attention to his resistance, and he is able to slip unnoticed through the myriad of changes that are part of the landscape of his school.

Gene further elucidates how he "goes through" change:

You participate in meetings . . and sometimes you don't participate, you just experience meetings like that, and sometimes you don't interact with them at al1. You just accept them and you know it's part of the training of the team, or part of the experience of life, or the . . . I guess it's just one of those things of participating in a public school system.

For Gene, efforts to change what he sees as the natural conditions of schools and public education are much like the potholes of an old county road. . one learns to accept the potholes as a natural condition and one expects to adjust one's driving.

I don't think that. . . there isn't a public school system or a public work system that does not have improvement schemes that either will work or don't work or are just exercises in futility. 
Teachers are often pressured professionally and

administratively to support innovations without question. Open resistance to change, even well-intended resistance, can be viewed as tantamount to insurrection and potentially might subject teachers to scrutiny and harassment by supervisors or proponents of change. Gene's strategy is to resist quietly but deliberately.

Gene's cautiousness is learned regarding change and improvement. His experience suggests that requisite work does not always equate with improved instruction.

Those committees, the school improvement committees, basically make up, generate, a lot of paper, long meetings, and come up with lists of things for teachers to do. And sometimes, a lot of that energy is just kind of spinning along. And you don't work with kids, you come up with a list of rules and procedures some teachers are going to follow and some aren't, and sometimes, even if all the teachers follow those rules, there is no change.

Gene developed and depended on his own set of rules and behaviors for adjusting to changes.

\section{Avoiding Textbook Adoptions}

Gene ignores textbook adoptions. He is clear about his attitude toward textbooks. As he states it:

Textbook adoptions. Now we've had a lot of textbooks and they're continually being adopted at a rate of, probably, I think the cycle is one every seven years. A math adoption every seven years, and an English adoption every seven years, and a reading adoption every seven years, and the cycles are within cycles so that is a constant state of change. And I think it is a great thing for all the textbook lovers out there. I try and use a textbook as little as possible. 
The pedagogy is more important to Gene than the adoption process or the particular book. Gene's vision for his students is expansive and less encumbered by cycles and processes.

Fundamentally, what Gene cares about is having a really good year with his students. He describes it this way:

Having a real good year with the students means making a personal difference in their lives. Teaching them to the best of both the teacher's ability to teach and the learner's ability to learn. Making a difference in their lives. Being someone that they can trust and confide in.

\section{Instructional Adjustments}

Gene is always watching his peers just in case they might really discover something that truly is effective. Gene practices a "wait and see" behavior based on his experiences that teachers are the best judges of improvement. Many of the changes Gene practices are instructional adjustments that are borrowed from other teachers, and are based on Gene's assessments of what his students need.

Gene identifies ways his teaching has been influenced by his colleagues. Gene says:

The things that have really impacted my teaching are a result of observing others work within to learn as much about teaching as possible. I try too become a little bit better teacher each year. Usually how I do that is by observing other teachers and what works for them and what doesn't work for them and translating that. I adopt what works for them into 
my repertoire of teaching. I am very much a team player.

Gene believes he knows best how he can become a better teacher in a meaningful way for his students. He uses the concept of teaming and informal peer observations to adapt and create practices that will improve learning for students. He chooses what will work based on its track record of success in other teachers' classrooms.

\section{New Innovations}

Sometimes Gene stimulates significant changes that do not have a proven track record. Described below is how one of the major initiatives in Gene's school, computer literacy, evolved. Gene originally came to the school because he was intrigued by the instructional technology that was part of the new building's design. But the equipment wasn't used, even though the teachers had received an afternoon's inservice; the computer was tucked away. One day Gene just decided to make it happen. He would do it. He wheeled the computer out of the audio visual room, where it had been safely hidden because no one yet felt comfortable using it for instruction, and brought it into his classroom. Gene believed that teachers should learn with their students and that he should model this practice. Gene learned as his students learned, and he shared along with his students in the excitement and enthusiasm that 
accompanied their collective involvement in learning and achieving mastery.

Soon other teachers were observing Gene's successes

with his students. They discerned the eagerness of students. They heard about the enthusiasm of the students' parents who delighted in their child's new proficiencies. The teachers asked Gene for assistance.

When the teachers observed Gene's successes, their motivation was piqued. They were interested in replicating the situation in their classrooms. This promulgated a need for an additional lab so teachers could make computer instruction available to their students. Curriculum goals, objectives and assessments were also developed by the teachers to accompany the booming interest in integrating the use of the computer with other aspects of the school curriculum.

Now every student in Gene's school receives instruction in using computer technology. Many teachers routinely are using computers as an instructional tool. All of this happened because Gene made some major alterations and changes in his instruction which reverberated in the school, changing the lives of students and teachers. Gene describes the situation this way:

When I first decided to move to this school, it was one of the things that was spoken at the very first faculty and staff meeting. The dream was to get a computer for the school. So we'd get this computer, and of course nobody knew what to do with a computer; so a year after the school opened, we 
attained the goal of getting the computer for the school and then everybody had to take a course in how to operate the computer; so they would know what to do with the computer here at the building. It was an Apple II Plus, 32K in memory. It was on a cart and kept in the teacher's room. The teachers would come in there and play games on it and practiced and mastered their skills and tried to learn the programs on it. It was kept there for about one and one-half weeks until everybody got sort of bored with it, and I didn't see it anymore. since it was on a cart that had wheels on it, I decided to take it to the classroom, and since there were no rules about not taking it to the classroom, I showed the kids how to use it. They taught me, I taught them. I reckon that is what teaching is about. All teachers ought to learn from kids and kids ought to learn from teachers, and if you aren't learning from the kids and the kids aren't learning from you, you better take a look at the situation and try and change it. once we got the computer down to the room and the kids all used it, all of the kids wanted a computer and teachers wanted more computers.

Most recently Gene was selected to be a faculty member at a brand new elementary school. His expertise in computers was a significant factor in his selection.

Because Gene believes that most change is inevitable and juxtapositly that most improvement efforts are insignificant, he is a "closet renegade." He countermands change by maintaining his own stability and by pretending to go along with change in order to foster meaningful classroom instructional improvement. Gene practices change discrimination so that externally mandated change will not dictate his instruction. Past experiences have taught Gene that the panaceas of the past frequently have had deleterious effects on the future of his students, and that the prophets of the future frequently forget the relevance 
of the realities of the present. Gene has learned to trust teachers and himself above the external interest and pressures brought to bear on schools.

Reframing Change, A Teacher's Perspective

Gene has evolved a paradigm that generates meaning out of chaos. The daily intrusions, upsets, disrupted planning and havoc for students and teachers that is so common is transformed by Gene into a personal understanding of schools and change. Gene describes it this way:

The goal is just to cooperate with each and every one of the staff members of the school to achieve their goal at being the best at whatever they do, even when it can be a pain in the neck to help out. You have to realize that when you can't teach your lesson in reading today because you have five of your children going to the talented and gifted program, and you have sent four kids out of the room to assist in the cafeteria, and that leaves so many kids in your reading class. You have to adjust your lessons. Well, I just made up something different because that's exactly what happens. I couldn't bemoan the fact. I couldn't say "Oh, woe is me. My entire year is shot because I can't teach proofs today in reading because four of my children are gone to the cafeteria and four are gone to the talented and gifted program." I just realize that I'm not the only teacher in the world, and I'm not the best teacher in the world, and that maybe the bus driver is also important. I realize that I just am in a constant state of flux, and you just have to constantly adjust your lessons and sort of do it. But you see, I'm coming from the point of the real world of teaching. And whether teachers like it or not I believe it is a constant state of change. That's growth, and to me that's a realistic perspective.

Gene does not let the latest curriculum adoptions dictate what should be taught. Gene's focus is not on using 
the most current instructional strategies. Instead Gene is interested in discovering how to meet the daily instructional needs of his students. Gene did not switch grades. Rather, he concentrated on improving his own mastery.

Gene's response to externally mandated change seemed normal. At the close of our series of interviews Gene was less of a mystery to me. At the outset of our conversations he exemplified the antithesis of how I believed effective teachers should behave. He clearly resisted change, and he was iconoclastic in his brazen disregard for textbook adoptions and site-based school improvement. He clearly marched to his own drummer, yet by the accounts of his colleagues he was a great teacher. When Gene talked about his students, the caring and concern that punctuated his sentences was penetratingly authentic.

He made a difference in his school by accepting the inevitability of change, while creating his own stability. That particular talent allowed Gene to make significant developmental advancements in his own skills that translated to instructional improvement for the young people he served. He was a master at managing multiple and continuous change, and he was a survivor in the best sense of the word. 


\section{Lessons from Gene}

There are several lessons from Gene:

- Change and school improvement mandates do not always equate with improved classroom instruction.

- Good teachers are change discriminators.

- Effective teachers learn behaviors that protect them from unnecessary and counterproductive improvement initiatives.

- Teachers need a level of stability to maintain and perfect requisite skills.

- Teachers may often gain useful insights on lessons and teaching strategies by observing their colleagues in action.

Gene reminds us that good teachers ultimately will determine what improves learning for their students.

\section{THE GOOD SOLDIER}

Dale's story is the portrait of a second grade teacher whose experience with multiple and continuous change underscores the multiplicity of variables accompanying a changing and diverse population of students, a controversial and swollen curriculum, and new, unfamiliar professional and personal demands that deplete one's capacity to be a "really good teacher." Although Dale might not describe herself as a master teacher, she is unquestionably an experienced and dedicated professional. Dale's love of teaching and 
students manifests itself throughout the accounts of her adjustments to change. In part because of her commitment to teaching, and despite the demands of her two young children, husband, and home, much of Dale's private time is spent thinking about her classroom and wondering how well her students are doing. Dale's story is instructive because it illustrates the magnitude of the constantly altering conditions that can require of teachers a substantial personal sacrifice in order to do "a really good job." Dale's story is illustrative of the landscape of change in one school.

\section{Changes in the student}

Population

Dale teaches because she loves children. This is exemplified in her concern that all of her students experience academic success. One of the major changes in Dale's school is the infusion of a culturally and educationally diversified student population. That translates to the classrooms as an inclusion of all students; students with learning disabilities, students with emotional problems, students with physical handicaps, and students for whom English is a second language. While Dale believes in the mission to prepare all children, she feels ill-prepared to contend with the practical realities of that task. Her ensuing commitment to do a "really good job" extracts massive energy and time. 
Dale describes the adaptations necessary to instruct children from different cultures and with different abilities. She says:

This year I have a little English as a second Language (ESL) student, a little Afghan refugee, while she is delightful, she's never been to school before. She's been in several other countries in Europe and in Turkey before she came here. And so it's like starting at square one. When these children are put in our classroom, just a regular classroom, our teaching becomes really different. We try to deal with all the different abilities that we have, not only the ESL but the children who are handicapped with learning disabilities. Many years ago when I first started teaching there was not much mention of learning disorders. So if a child wasn't working up to grade level, the only solution maybe was to retain them . . . where you were thinking they weren't bright enough. Now we're learning that there are some very bright children that have learning disabilities, so we're serving those children and reaching them in any way we can.

Dale's school district provides support and generous resources to teachers in the form of staff development and materials. Despite the appreciation Dale feels towards her district for their offers of support, she notes:

our district is really good and we have lots of resources where I can call and say "Well, I've got this child who does this and does that and send me some materials," and the next day we're got a wealth of things. But the frustrating part of that is that you don't have the time to preview all of that to see if it's what you want, and that you're organizing the curriculum so you're spending a lot of weekends individualizing and making up a list of studies for one or two children in the classroom. So there's a lot of extra time and energy if you want to really feel like you're doing a good job.

One dilemma for Dale was balancing the needs of her

"special" students with the needs of the average and gifted students. It is, in fact, one of her biggest frustrations. 
She stated, "I spend a lot of time at night lying awake saying I don't feel good because I can't reach all of these children."

There are other changes in the student population that "spill over" into the classroom. Because many parents now juggle careers and parenthood, children are sometimes neglected and arrive at school hungry, are frequently sick, or are emotionally needy. From Dale's perspective, for teachers, this is one more change, although not officially designated as such by the district. Dale does not feel critical of working parents, since she herself is one, but as a teacher it requires that Dale provide additional caregiving. She believes the nurturing she provides is a prerequisite for learning; because of this, she incorporates nurturing and care-giving into her teaching.

Dale described the reasons for her adjustments this way:

The kids are important. I'm really an emotional person and I guess that's why I'm here. It's not because someone tells me I have to work with these kids. It's just that I can't stand to see them sit by and not get what they're needing. Also, being a parent myself really helps. It really helps me because I know what I expect because I have to send my little boys off to school each day and hope that somebody will do for them the very best thing. So, I come here and pour out my blood and hope that somebody else is doing that for me, because I can't be there for them. It's kind of similar to when you go to another professional in another occupation that provides a service. You really expect them to do . . . you trust them and expect them to do the very best job they can do, and that's the commitment that I feel that I have to give these kids. I'm not saying that I do my very best when I'm all stressed 
out, and I spend a lot of time knowing that I'm not always doing the right thing. But I try my best.

Dale routinely adjusts personally, professionally, and instructionally to the new requirements generated by a classroom population heretofore unfamiliar to her. But, although she believes in the importance of acquiring new skills, Dale is unconvinced that she still is doing "a really good job."

\section{Too Much Curriculum}

In addition to teaching all types of children and providing for their emotional requirements, it is necessary to cover the new curricula adopted by the district. Dale's school district, similar to other districts, revises curricula every seven years. There are also new curricula adoptions. For Dale, that has meant learning a new set of skills in computer technology, environmental education, AIDS education, critical thinking, occupational information, and re-learning skills to contend with major revisions in the language arts and math curricula. Dale says:

I think we are dealing with an overload. I see every year more and more things added to our curriculum and nothing much dropped or taken out. But in a scheduled day, there is just so much content that needs to be taught in so many different areas that teachers are having to integrate more and teach across the curriculum, in order to get the basics across, and because of the fact that there are so many areas that they are shoving at us, and that these are part of your curriculum priorities: environmental education, human sexuality education-just a whole round of things, so many things--it is no longer that a teacher is just teaching reading and writing, you know. It is all these areas: 
computers, I could just could go on and on and on - . all the different things they are placing emphasis on.

The changes as Dale experiences them, and as noted by the other interviewees, are a product of the adjustments and additions to the ever-growing compilation of mandates and expectations that bear down upon teachers. However, it is Dale's sincere effort to respond to each of the expectations that makes her story unique and informative. Dale tries to do it all and believes she is doing nothing well. Dale experiences tremendous ambivalence toward any improvement because any time spent in adjusting to the new demands must be subtracted from classroom planning and other classroom demands. New lessons or adaptations demand expanded planning time, and usually are accompanied opportunities for training, practice, and feedback.

Moving Teachers and other Policy Decisions

In Dale's school, teachers frequently are transferred to different grade levels in an attempt to encourage teachers to expand the range of their skills or to force individual change. Minimal time is provided to learn all of the curricula associated with a new grade level. This practice is in part a product of a perception of elementary school teachers as generalists. However, Dale feels that she needs three years in a given grade level before she can be comfortable and competent in the pedagogy associated with 
that particular curricula. She describes her feelings about grade level transfers this way:

We have less and less control of the grades we are going to teach, the buildings we are going to teach in, and just less and less control that way and it is very, very difficult when you are constantly teaching a different grade or in a different community or different socio-economic group. That is really a difficult change for a teacher and it takes five to six years to really feel like you have got it made. This is my third year at this grade level, and I finally feel like I know what I am supposed to do in second grade.

There are other deleterious effects to changing teachers' instructional assignments. Dale notes one such consequence:

There isn't a satisfaction of mastering. You are just on a treadmill. Probably the more creative a person you are, the more you are called upon to keep it up, keep designing, do more, and it becomes really frustrating.

It is perhaps the sense of mastery that enables some teachers to become change discriminators (like Gene). Possibly Dale's lack of confidence in her ability, fostered by an overabundance of expectations, stimulates the treadmill of too many changes and too many adjustments on her part.

Also contributing to Dale's sense of inadequacy were the immeasurable losses she experienced when she was transferred. Dale, like many of her peers, such as Adam, had lessons she had pridefully developed and embellished; lessons that were exemplars of her craft and expertise; lessons that hinged on an understanding of the subtleties of 
the concepts; lessons that demonstrated a depth of substantive understanding of relationships and that promoted higher levels of thinking. When Dale could no longer teach those lessons, she lost a lifeline to validation, to pride and to efficacy. She lost a part of her professional identity and her belief that she was doing a really good job, and perhaps Dale also sensed a loss of opportunity for her students to experience quality learning.

Another impact of a grade level change is the problem of time that can never be recovered but must be replaced. It takes time to develop good lesson plans. It takes commitment and dedication to create lessons that are meaningful to students. Dale characteristically enjoyed going into her son's school and noting other teachers' ideas that could enrich her lessons. When Dale was forced to switch grade levels, her work, preparation, and identity as a fourth grade teacher were obliterated in a way that could never be recovered.

Dale recounts her experience this way:

Another thing that is difficult is, like when I came over from where I was before, I had my files built up with some of the really great things I had done in intermediate. Well, you can't use them in primary cause that's infringing on intermediates. or you might see a really neat art project that you thought that you'd come up with or that you'd stole off somebody's wall or, you know what I mean, how you go into buildings and look at the wall and go "Wow." Look at that. I'll copy that. You see it being used and you think, "well I can't use that this year because they're using it in third grade or fourth grade or fifth grade so I can't even adapt it down and use it in second grade." It bothers you 
when you see some excellent project that you did in fourth grade and some fourth grade teacher is using a project that you did. But not doing as good a job at it. Well, you want to say, "the way I did that project was much better but we can't do that." It was hard the first year I had to say I teach second grade. I kept slipping and saying that I taught fourth grade and I would have to apologize and contain myself. The oregon state history was one of the things I really enjoyed. It was kind of my forte. And I'd see things being done and I'd kind of, it would be to hard to keep your mouth shut, and keep from saying "Did you ever think of . . ." It is really hard to give it up.

\section{Personal Demands}

Always omnipresent are the interminable demands that intrude and compete for Dale's time beyond the designated school day. The competition is not limited to Dale's professional life and the toll overflows to her personal time. The demands are such that Dale spends precious family time thinking or dealing with her teaching duties. Ultimately, she is left with little time to care for her needs. Despite her own personal concerns, Dale can't seem to escape her sense of responsibility for her students. The job never gets easier but her desire to do a "really good job" never seems to falter.

Dale describes how she reacts to all the stress:

Ask my husband. I've been sick for about two years now with colds and things. You know, you're staying up late at night and you're not sleeping and you're trying to put together curriculum and you're never done. I get sick. I just really get run down. Last year I was in the hospital for walking pneumonia and that kind of thing because $I$ don't deal with the stress very well. I feel that one thing that could be done for teachers is promoting wellness. But, I mean, I have no time during the 
day to myself. No time to exercise. So maybe one day you squeeze those types of things into your schedule. When do you do this? you start your exercise program on Saturday and it ends on Saturday. And then you start it up again over Christmas.

Dale's tasks may seem impossible to most of us. Dale must constantly reevaluate and adapt a multitude of priorities that compete daily for her time. It becomes difficult to understand why Dale believes doing a good job is feasible. This is what Dale believes that allows her to make sense so she can adjust to multiple and continuous change:

You have to be in this job to survive and not just be holding weekly hours. I mean you have to be a really flexible person. That's one thing that I'm getting better and better at and $I$ used to not be as good at. I thought things should go in a more organized way. This is a job that you never ever finish with. You take it with you all the time. You go home at night and you still have stacks of things in your basket and all these other things, and you are never ever finished with it. You are never at a point where you can say I'm done. Whereas you sometimes just yearn for a job where you can say I got that done. I did my job. Today, I made fifty carts. That's not how our job is so you have to be used to the fact that our job is never ever over. And that you're never ever doing all that you can possibly do. There's always something more that you could do. There's something to clean up a little bit better--a lesson, or a child that needs help with struggling or something that you could just tie in better. The room or the planning or next month, or this unit is over and we're into this one but I really need to go back and re-teach this area and check for understanding and review this and go on and teach this and it's never really over. And just when it is over finally and you're in the summer it's like boxing or football. There's always more that you can put in your time limit and then it's just "ding" it's over. Well, then you have that little breather. Then you're right back into it again. I think that certain personalities 
like myself; we just sort of thrive on that. That's okay. You can be really locked in and really organized. I know a lot of teachers who are really like that. But you can't let just the fact that there's always loose ends and always the fact that you could be doing more upset you. You just would go crazy.

All of the teachers in the study noted the importance of becoming flexible or not being ruffled or upset by change. Dale is a product of an educational system that does not practice nor encourage good consumerism. For Dale, letting go was not moderated by discrimination. Dale tended to be more of a responder than a discriminator of change. She tried to do everything.

\section{Lessons from Dale}

Dale's story reminds us again that good teachers are called upon to master impossible tasks. The satisfaction of doing a good job, of being excellent, is complicated by constantly changing planned and unplanned events and activities that are exacerbated by fluctuating priorities and oscillating policy decisions that create new and additional demands.

Dale's story portrays the valiant effort of one teacher to respond to an overabundance of mandates and policies. Dale's experience is punctuated by a sense of powerlessness and hopelessness in achieving the unattainable. She is the good soldier who genuinely tries to respond to all of the commands of her leaders. She has 
been encouraged to execute the orders of her district. She is the "good soldier."

Dale's story forces us to consider:

- The effects of an overabundance of curricula, diverse student population, and multiple and changing improvement goals on effective teaching.

- The cost that involvement in many changes exacts personally and professionally from participants who attempt to satisfy all of the expectations levied on teachers.

- The relationships between teacher efficacy, effective mastery of critical curricula areas, and selective consumerism.

- The attitudes of administrators towards teachers wherein specialization in a grade level is not valued nor recognized as potentially significant.

Dale attempted to adjust to the never ending demands imposed on her. Is Dale a better teacher for her efforts, and could most teachers improve given experiences like hers?

THE LEADER

As a member of her school's Improvement Committee, Amy's story illustrates the relationship of improvement, change, and tradeoffs generated by teachers' adjustments to responsibility assumed beyond their classrooms. It is the story of one individual's discovery of the meaning of commitment to multiple and continuous improvement based on 
teacher leadership. It is also a story that resonates with the memories of the cost that improvement exacts from the classroom teacher.

Amy identified as a major change her decision to participate on the school leadership team. For Amy, her decision meant greater empowerment to influence the school and less autonomy to influence her classroom; more time spent with peers on school issues supporting and encouraging practices, but less time spent on instructional preparation or implementation of new innovations; increased teacher discrimination but reduced interest in teacher experimentation. Amy's efforts on leading her school translated into greater professional efficacy but less resilience to deal with daily classroom problems. The nature of the tradeoffs stimulated by Amy's involvement in school improvement and the subsequent changes and consequences for her are the substance of Amy's story.

\section{School Improvement Versus}

\section{Classroom Autonomy}

For Amy the costs produced by her involvement in school-wide change are balanced by a positive work environment. However, the enhancement of her work environment, although desirable, also extracted a toll that included loss of instructional autonomy.

It was Amy's recollection of her school before opportunities for teacher involvement and her beliefs about 
that situation that motivated and sustained her desire to make the changes. Some of her beliefs preceded the changes, some of her beliefs precipitated the changes, and some of her beliefs were products of the changes. It is the whole experience as it unfolded for Amy that illuminates another example of the meaning of teacher adjustment to multiple and continuous change.

Amy's description of the school before all of the changes is helpful:

In my very first week in school, it was very much told to us that it was not olkay for teachers to hit children and I heard, I mean my door's open, and I heard and my children heard, and they were all aghast. A teacher in the hallway was spanking a child. And there were loud noises and the kid was screaming and I had worked a whole week on helping kids feel comfortable in the classroom and I worked to build a lot of trust. It really affected my classroom. And I never said anything to anyone that day. I just, I just quietly shut my door and I tried to reassure my kids that it wasn't something that happened in our class and that I was sorry that it was going on. But it really affected me. I went home and I was in tears and I didn't know what to say. I guess that I have feelings that somebody has to stand up for what they feel is right in school, and that people had to be honest with each other as to what effects them, and that somebody's personal decision might effect another person. Therefore it is not okay. So from that point, that very low point, I mean at that point I felt really bad and I started kind of closing in my classroom a little bit more and little bit more.

For Amy the nature of the climate in her school before the school improvement effort required significant adjustments from her on an on-going basis. For Amy the changing climate of her school was singularly important. 
Amy continued to close her doors. There were benefits that were by-products of isolation. According to Amy:

Well, it made me really dedicated just to my class. And I started, and I really closed my door a lot and got more into my classroom and just didn't involve myself in the school a lot because there was a part of me that said there's no hope. There's too many negative people. There's too much. Personally at home, it was really stressful. It was really hard. But it was really neat in one way because I was just totally focused on my classroom and that was a very positive place.

When Amy experienced stress she pulled back from her peers, which exacerbated her sense of isolation. Amy noted, as did Adam, that when there was too much stress from too many changes, adjustments assumed the form of withdrawal from one's peers.

Even though Amy managed to keep her classroom positive, the disruptiveness of the school environment permeated Amy's professional life. Amy was willing to relinquish some of her professional autonomy to eliminate a negative school culture. Amy believed her influence would positively change the direction of school improvement in her school. Amy was willing to make a tradeoff. Amy traded autonomy for empowerment.

Amy believes that the school is improved because of her efforts and the efforts of other site Improvement Committee members. This is why, according to Amy:

One of the goals that we worked on was a behavior goal about the hallways and just the atmosphere of the building. My room is situated across from the bathrooms plus this is the main hallway where people come in and go out and first, second and third graders pass by and kids going to the library go by, 
so I'm really effected by anything that goes on in the hall and to be quite honest our halls were just a mess. Kids were really disrespectful of people in the hallway. And my blood pressure would go up, you know, and you return to your classroom just a little ticked even though you're trying not to be, but you're a little ticked. I can't tell you the last time I disciplined somebody in the bathroom, including my own kids. I mean, you just don't have to deal with it any more. And people are taking ownership in not only their own kids but in other kids.

When teachers believe the changes are improving their classrooms, they are willing to make the necessary adjustments and are more open to working with their colleagues.

Even though Amy believes the school is better, there are immeasurable costs and incalculable tradeoffs. One cost is time. Amy's time is consumed with activities that seemingly have little direct influence on improved instruction. Direct involvement in school improvement can drain valuable teacher time for activities unrelated to instructional improvement. Amy describes what happened to her.

It's really, ah it's like apples and oranges because there's so many tradeoffs. I guess when you're a school of committees you involve yourself on different levels that, you've never been involved before, and then you're open to hearing things that you've never heard before, which takes time, takes energy, and I'm not sure that it's real important. So I feel like it's a waste of my energy. I'll be focusing on something and just go why, why am I thinking about this. Who cares? It's just going to be. So sometimes I think I don't get paid enough to think about it even. 
Emphasis on non-instructional issues can distract professionals from their mission of teaching children. Unlike some of her colleagues, Amy continued her involvement in leading her school because she believed her life was appreciably better.

Amy also was convinced that the school was a kinder and nicer place for children and teachers. In Amy's opinion, the environment was less stressful, there was more consistency among classrooms, and Amy's colleagues seemed more positive. Still, for Amy, it meant relinquishment of some of her decision making, it required abiding by group decisions, and it demanded time for a plethora of seemingly meaningless activities. Amy gained more influence over school policies and relinquished some of her autonomy in the classroom. The change required tradeoffs.

Discrimination Versus Experimentation

There are other costs associated with participation on the leadership team. One of those directly impacted her classroom. Amy says:

I'm not as willing to try as many new programs because I don't have the time to just sit down and mull over "Well, how could I design this or how could I do that?," and I tend to use things that I've seen before or done before because they've worked and they don't take the time and energy to develop something new. And that doesn't mean I don't get excited about new things. I have tried new things too, but I tend to rely on the older things because I'm too busy to design something totally new. 
The constant arain of time away from the classroom eventually reverberates in the classroom. The cost, for Amy, for her involvement in school-based change, is a reduction in time, interest, and motivation available for experimenting with innovations.

Paradoxically, the empowerment Amy experiences as part of the leadership team generalizes to her practices in the classroom. Amy believes she is empowered to select programs or adoptions for implementation in her class. Amy practices discrimination. She notes:

I used to be more fearful of consequences if you didn't go with the flow. And it's not that I'm rebellious, but I just feel like there's probably more for an ear on individuality within the classroom so that I don't feel judged. And I also feel like if somebody said something to me about it that it would be okay for me to argue my position and that it wouldn't be like boy are you in trouble.

Amy's work on school improvement increased her interactions with her peers, and exposed her to new ideas and practices that were effective with students. The support of her colleagues and the application of their ideas meant Amy did not have to do it all. It meant potentially greater efficiency, but it also meant a significant proportion of Amy's time outside of the classroom was absorbed in planning and sharing.

As a result of her interactions with her peers Amy is more discriminating. Instead of major changes, Amy is more likely to make meaningful but smaller adjustments based on the successful practices of her colleagues. In the past Amy 
believed she was always changing. Now Amy feels the changes are more in context:

I just don't feel that need for a change within a grade level or a curriculum. I can't think of a day that we don't share an idea at our grade level. That somebody doesn't come in and say may I try this and I really liked it. or gosh did that ever bomb. You know, we shared something just really informaliy. So we make contact very informally. We also make sure that we have regular grade level meetings and do a lot of curriculum planning together and it's not really serious time. We also have a lot of fun with each other so that makes a big difference to me.

Empowerment for Amy translated into greater authority to make significant classroom decisions. It also meant freedom to not change. It also exposed Amy to ideas and practices of her peers that were viable strategies for improving instruction.

It is noteworthy that Amy and Dale are teachers who are approximately the same age and possess the same amount of experience. Amy, however, has learned to make tradeoffs.

\section{Efficacy Versus Resiliency}

Amy experienced the cost of her participation in her school as a new level of exhaustion that transferred to her personal life and occasionally "spilled over" to the classroom. Amy says:

I guess an overall general feeling in the last three or four years is that on Fridays I am far more exhausted than $I$ have ever been than in any other time in my teaching career. I think there's just a whole lot more put into it physically. I've also had to do stress management kind of things. I went through a period of insomnia and I learned yoga and started practicing yoga which really helped kind of 
getting me centered. And then I started doing dance to let go and release. So those have been changes in my personal life as a result of school being more stressful and having more energy to put out in one area.

Much of the extra time Amy spends on improvement and change is skimmed from her personal life. As Amy reflects she describes the situation this way:

It's really, ah it's like apples and oranges because there's so many tradeoffs. I feel like a lot has been sacrificed on my own personal part. I don't think that the classroom suffers but I think my personal life suffers more than the classroom. But then again, if I think about it, I am a happier person because the school is a better place. And I don't carry that stress, that negative stress that the school was something that I was involved in that I didn't care for. So, It's almost like I've traded, even though it's more of my own personal time, it's less of my personal stress.

Amy's tender is her personal time, energy, and physical well-being. All of the teachers, with the exception of Gene, noted the cost of change on their personal lives. Amy provided an example of how her resiliency has been effected by her involvement. She describes a change in her attitude towards sick days. Amy now comes to school even when she is sick because she is convinced that her presence is vital to her classroom and the school. Presently, when Amy's health merits rest and attention, she comes to school. There is another reason Amy is reluctant to miss days from teaching. Amy has been absent from her classroom because of meetings and training necessitated by her involvement in her school's improvement efforts. This 
creates discomfort when illness demands more time away from her classroom. She says:

I suppose a big change that has happened for me personally is that $I$ used to feel like if $I$ were kind of sick I would stay home from work because I felt like I needed to take care of myself. Whereas, now I feel like if I'm kind of sick I need to come to school because I've missed. I have subs in my room because I'm on so many committees or I've missed so much already that I can't miss any more. So that's a change. So I make all my kids sick in my classroom, too. So there's one change, that I don't honor myself and take my time that I used to take to go get well.

Amy continues to contribute time to improvement committees, and to come to school sick, which reduces her resilience and expendable energy. Amy's new sense of professionalism, however, enhances her feelings about her work even though the quality of her work in her classroom cannot be measured nor calculated.

The meaning of her involvement, the willingness to sacrifice, and her commitment to school improvement are explained this way by Amy:

To be quite honest, it's more work to be in charge of your own school and I think I put in far more time. I think the whole staff puts in far more time working on the mechanics of the school and how it runs because we were more into the running of it, but there is also a lot of power involved there and that felt good and it was also very exciting to see a transformation of individuals and of the school that has some power and had some things going for it and that kind of thing.

Amy's sense of power and energy is derived from a belief that she influences her environment and is not helplessly relegated to a position of simple reactivity. Her 
involvement exacts many tradeoffs that produce changes in the school and in the classroom. The totality of the change is difficult to measure and, consequently, to evaluate.

\section{Stability Versus Change}

In Amy's accounting, she describes the condition of increased stability as a critical condition to managing a change. With increased teacher participation in improvement, there is a need both for predictability and stability. In order to survive the chaos, maintenance of routines, for Amy, assume a greater level of importance. Amy's belief that the experience of people involved in change is similar to stepping onto a boat is an excellent analogy. She suggests that one needs to have one appendage with firm footing on stable ground before moving on to a shifting craft. Amy attempted to moderate the number of changes occurring in her classroom in order to cultivate a condition that would allow her to sustain her participation and involvement in school improvement.

A second concept related to stability and change is that change is cumulative. When energy is drained to manage the school, little upsets create insurmountable overloads because there is no reservoir of emotional latitude. Amy describes one particularly upsetting morning that depicts what happens when emotional resources are depleted. She notes: 
I remember one time. I was overwhelmed with everything that was being asked of me. It was report card time, we were doing a lot of OTE work, pulling things together, I think I had a lot probably going on in my personal life, it might have been even like Thanksgiving time. For some reason, we had a substitute janitor and he had skipped cleaning my room. And I walked in that morning and the room was just as we had left it, which was a pit. And I can remember bursting into tears. And it was like even though I knew it was silly, it was like why me? Why do I even have to ring the buzzer to go out and call the office to tell the other janitor to come in and clean my room. There must have been something that I did that made this happen in my life. And it was just overwhelming at that time. And I felt silly crying but then there was another part of me that went well, you're not really crying about the fact that your room's not clean, you're crying because there's too much right now.

Amy struggled valiantly to manage the overall complexities of multiple and continuous change and in order to do so she learned to make tradeoffs.

\section{Lessons from Amy}

Most recently there has been an emphasis on increased teacher involvement in school improvement efforts (Showers, Joyce, \& Bennett, 1987, p. 80). Schools have responded by encouraging greater faculty responsibility for improvement through the formation of site committees and leadership teams. Committee membership exacts dues that are tendered in the limited resource of teacher time. Teachers are left to adjust to the changes by negotiating the tradeoffs personally, professionally and instructionally. Amy's experience with the on-going process of change in her school is not unique. Nationally, schools are involved in similar 
processes that ignore the cumulative meaning for teachers. Amy's story highlights the adjustments made by a school leader in response to increased involvement in a long-term school focused improvement effort.

School improvement exacted a high interest rate that Amy was willing to pay. Amy remembered the consequences of a negative school environment and the intrusions into her class despite her efforts to withdraw. A negative school climate adversely effected Amy's stress level, robbed her of energy, and assumedly damaged her students. Amy experiences her school as a better place to work now because of her efforts. She felt supported emotionally and professionally by her colleagues, which fostered on-going instructional adjustments, which for Amy were a by-product of collegial sharing. In part because of Amy's new found sense of strength in her own ability as an instructional leader, she became increasingly more confident in her ability to function discriminatingly towards change and innovation. There are pitfalls associated with adjustments teachers make to multiple and continuous change. There is a susceptibility to participation in activities that pull teacher attention away from instructional improvement. There is a constant drain of energy that is subtracted from the classroom. There is less resilience to minor irritations. The measurable or observable changes in practice and teaching are oblique and greater autonomy may 
undermine future innovations. Not until all of the tradeoffs are accounted for and factored into the improvement can we know if our schools are improving. Amy's experience instructs us:

- To calculate the costs school improvement has on classroom instruction.

- To examine the relationship between stability and change.

- To recognize that tradeoffs are a component of change.

- To recognize that teachers are a limited ecological resource.

- To acknowledge the connection between teacher empowerment and teacher willingness to change. Amy's story captures the subtle and concrete, cumulative and immediate, attitudinal and rational adjustments teachers make to change directed at school- wide improvement. Ultimately change has the potential to improve, disrupt, stimulate, and empower.

\section{SUMMARY}

The purpose of this chapter was to present findings that are illustrative of how the participants characterize and experience change. Four vignettes were presented that describe four different perspectives and responses to multiple and continuous change and provide lessons 
concerning the effect of the lived meaning of multiple and continuous change. One of the participants opted to lead the school in its, efforts to manage change. Another teacher successfully avoided change while implementing new technology into his classroom. Still another teacher tried to respond to all of the changes and struggled painfully to improve her instruction. One teacher newly socialized in the profession, worked valiantly to "just teach children" despite the many changes that inhibited the realization of his goal.

The composite suggests that multiple and continuous change in schools is complex, disruptive, individual, personal and produces dilemmas to which there are no easy solutions. The behaviors that the participants learn mitigate the disruptive influence of change, and perhaps the institutionalization of change, while operating in favor of simple workable adjustments that make teaching survivable. Finally, the composite suggests that teachers' lived experience of what comprises change is very different than the picture depicted by the research and theoretical literature on change. The absence of information about what teachers actually experience confuses and misleads well-meaning policy makers and school leaders in calculating realistic improvement goals and strategies. 


\section{CHAPTER V \\ THE MEANING OF MULTIPLE AND CONTINUOUS CHANGE}

\section{INTRODUCTION}

A major purpose of this study is to describe and understand a phenomenon referred to as "multiple and continuous change." The existence of such a phenomenon, while alluded to in the literature, has not been investigated as a distinct phenomenon. This study also provides a beginning analysis of the meaning of change as it is derived from the teachers' lived experience in schools.

The findings presented in this chapter suggest that teachers adjust to change as a multiple and continuous experience. Delineated are examples of the range of activities teachers characterize as change: descriptions of the types of change included in their characterization, descriptions of teachers' adjustments associated with the phenomenon of multiple and continuous change, and a description of the domains influenced by teacher adjustments to multiple and continuous change. 


\section{RANGE OF ACTIVITIES TEACHERS CHARACTERIZE AS CHANGE}

The experience of multiple and continuous change was filtered through the participants' unique perception of their lived experiences. Illustrative of the subjective nature of each study participant's characterization of change was the variation of each of the participants' responses at the outset of the interviews.

In the pilot study, Amy began her interview by talking about her school's culture:

When I first entered our school it had a pretty good reputation, or bad, however you want to put it, for being a tough school. The teachers had a very punitive air about them. Our principal had only worked here over a year and she was trying to create some changes. She was in the middle of what I would have called a war zone. There were factions. People would call you up. I mean they would even say "which side are you on?" "Are you on this side or are you on that side?"

Amy's reference point for change was the school's environment. Her characterization of what she perceived to be change was influenced by her perception or her filter of that experience.

Gene's characterization of change contrasted with Amy's. His initial response included a description of how he managed to not change grade levels. He noted:

I have taught fifth grade now for most of my years as a teacher. It's 1988 now and I started teaching in 1969.

Gene began describing his recollections of change with examples that referenced his efforts to maintain stability. 
Gene expressed a belief that grade level switches could cause significant changes in his life.

The response Adam provided began with descriptions of changes he had made in respionse to the fluctuation of student numbers. He said:

I think the biggest change that we've had this year is a reduction in population. That has been a change for me, not because I have less students but because of the difference I see in the way the staff deals with problems. Iast year we would deal with problems by trying to kind of push them to the side. Well, next year it will be better because there won't be as many students. We'd blame a lot of our problems on what are we going to do with all these kids, there's too many $\mid$ kids $\mid, 654 \mathrm{kids}$. There is no kindergarten and all these types of things. That was not very satisfactory to me. Whereas this year, if we have a problem, we solve it immediately, or we see ways of trying to solve it.

The alteration in student numbers, for Adam, stimulated daily adjustments including student management practices, alterations in instructional strategies, and an increase in his daily work load. Adam's descriptions of his experience began by focusing on the fluctuation of student numbers. Adam described this experience as posing significant changes for him and his colleagues.

Dale mentioned "What really comes to mind is that it seems in the last couple of year's there has been a real thrust and almost an over-emphasis on mainstreaming." Dale found herself contending with students that could not speak English, students that were unable to follow classroom routines, and students that required instructional 
adaptations. Dale's initial descriptions of change differed from the descriptions by her peers.

Carol's characterization of change was derived from the adjustments she managed in learning to work in an open school setting.

A major adjustment and change that I've had to deal with is working in an open class setting. In some ways it has taken away from a part of my teaching that I really enjoyed, just being spontaneous. I have had to alter my style of teaching.

What emerged as significant from the interviews was the range of descriptions the interviewees provided as examples of their lived experience. A characteristic of the phenomenon of change is that individuals experience different activities as change.

Supporting this finding were the variations of responses provided by teachers who had completed the faculty survey, question two, "Identify an improvement effort in your school that significantly influenced your teaching and describe how you are different" (see Appendix A) . Identification of a variety of changes included: six respondents identifying nothing, four identifying fewer classroom interruptions [the onward Toward Excellence (OTE) goal], two identifying Richard strong strategies, one identifying Instructional Theory Into Practice (ITIP), one identifying the School Improvement Team, and two identifying team teaching. The variety of responses provided by a single faculty serves to illustrate that change includes a 
range of experiences that are colored by the individual's perception.

These initial responses to the questions posed at the beginning of the interview, and the faculty responses to question two on the open ended survey, depict variations in individual conceptualizations of change

- There is some variation in the range of activities that teachers perceive as comprising change.

- The category or definition of what comprises change is not static. It is influenced by the individual's lived experience.

TYPES OF CHANGE

Prior to data collection, the researcher conceptualized change as synonymous with the notion of innovation implementation, an assumption grounded in the research on educational change (Fullan, 1982; Hall, 1981; Huberman \& Miles, 1984a; McLaughlin \& Berman, 1979). Change as depicted in the literature typically includes organizational efforts, school-wide improvement goals, policy or innovation implementation, and staff development. However, the data from this study indicate that there are two distinct kinds of change that differ somewhat from the change research. One category is planned change and is derived from innovations such as the types described in the research literature. A second category is unplanned change, 
which while not conceived as change in a formal planned sense, nevertheless has the very real effect of altering teachers' work lives in concrete ways. Unplanned changes are experienced as "change."

\section{Planned Change}

Planned change is a product of innovational efforts. Based on the interviewees' descriptions, planned change has the potential to provoke many distinct, interactive, and comprehensive changes, some of which may be unplanned. Becker's (1964) theory of "situational adjustment" sensitized the researcher to this category. The numerous changes that are by-products of by single innovations might be thought of as a series of "micro" changes associated with the implementation of a "macro" change (Fullan, 1990). An example of how a single innovation was experienced as causing multiple changes was provided when two of the interviewees described the multiple changes necessary to implement a new AIDS curriculum. Carol referenced the complexity of issues associated with the AIDS adoption. Carol said:

I think that's why when we had to do this sex education thing, it was so hard. We were being asked to teach something with which we had little familiarity, and we had very little input. We were just being asked to teach all of this information. Yet our parents were traumatized. They wondered what we were teaching their kids and $I$ was wondering too. I mean you know there are certain things you are not supposed to teach them, but it's like okay, how am I going to teach this. We were told we were going to do it. We would have to do it at a certain 
time because that was when the material was arriving. And, we had to somehow fit it into our schedule and make it work, and that really was hard.

Carol described the adjustments she made:

We had to cut down, shorten our reading classes. We had to move things around. We had to adjust time slots. We had to cancel reading for a couple of days a week. Yeah, we had to do some major adjusting.

Adam also referenced the implementation of the AIDS curriculum. He enumerated the changes in his routine:

We had to sit down and we had to talk about it. It took us about three hours on our planning day, plus one day solid. All we talked about was sex education. It took so much time. So much personal time such as loss of sleep. We ended up having to come back for another evening to present it to the parents. Then two other teachers and I had to come back for a local school committee meeting voluntarily and I really felt like a shithead because $I$ don't know, I felt like it was taking me a little bit on the personal side. I guess to a point which I shouldn't have had to give so much of my personal time.

Carol and Adam's statements are illustrative of the number of changes required by teachers to implement a single innovation. Both noted that the addition of the AIDS curriculum required adaptation of other subjects in order to create time to teach the new curriculum. Planning time normally used for daily lessons was expended on learning, implementing and assessing the new curriculum. Carol and Adam were also required to participate in team planning, staff development, adjustment of student schedules, and increased parent contact. These two teachers, out of necessity, adjusted many aspects of their normal routines. 
Evidenced in all of the interviews was the exponential, interactive and cumulative nature of change that accompanied planned innovations. single improvement efforts were described as setting off chain reactions of adjustments that stimulated changes beyond the goals of the innovation. A single innovation can require numerous "micro" changes. The "micro" changes stimulate other peripheral changes creating a ripple effect that is interactive and exponential.

- Planned change can require numerous "micro" changes.

- Planned change can often provoke multiple, interactive, adjustments in non-target areas such as scheduling, behavioral management systems, etc.

- Single macro innovations, as experienced by the interviewees in this study, require many more discrete changes than portrayed or recognized by the literature on change.

\section{Unplanned Change}

Many changes that are part of the landscape of schools, but are not characterized as planned changes, require major adjustments by teachers. These changes are unplanned by-products of changing demographics, shifts in policies or procedures, changes in leadership, and changes in staffing. Non-innovational changes are frequently miscalculated and overlooked because they are not formalized. They can result in many discrete adjustments by 
teachers on a daily basis. Therefore, they are experienced by teachers as change; they, too, are "macro" or "micro" changes, but they are the result of a different stimulus. One situation exemplary of this type of change that was identified as significant by all of the interviewees was the alteration of teaching assignments (being transferred to a different school or changing grade levels). Based on the teachers' comments, this was deemed a significant change due to the sheer magnitude of adjustments required by the subjects.

Dale described her feelings about switching to a different grade level. She said: "I was scared to death."

Adam talked about his anxiety about changing teaching assignments. He said:

Last year we knew we were going to lose six teachers and $I$ knew that I was not going to be one of them, because $I$ was a new teacher in the building and they weren't allowed to do that. However, some of my teammates and colleagues were a little on the stressed side.

Adam went on to describe his feelings when he learned that although he had not been transferred he was being switched to a different grade level.

Next thing you know phttt, you're gone. All that planning and all that work I put in for the Fall basically I can't use it. Well, I won't do it again.

Carol described what changing grade levels stimulated in her:

oh boy, you find out how helpless you are. Well, you go to the curriculum guide. The district 
curriculum guide becomes really important. You no longer know by heart all the different ways. It takes more time. First of all you have to move. You know, you're going to be moving physically from one classroom to another. You have to get to know new teammates. It's kind of sad you know when you lose a working situation that was very positive and comfortable. It's hard to walk away from that and just kind of be dropped into another spot.

Gene described the impact of moving his classroom to another part of the building:

It was the first time that I'd changed a room in seven years. I got to pack up all my things and move to another end of the building and also have the thrill of a change in my life, which I'm still recovering from because I get to move again at the end of the year back to another room at the end of the building. It affects me. I lose a lot more things. So that's frustrating. So I end up wasting more time than if I knew where things were.

Another example of a non-innovational type of change that disrupted teaching and learning and required teachers to make adjustments in their teaching plans and daily routines were changes in specialists' schedules. Because specialists serve different teachers and different schools, changes in their schedules can also disrupt and stimulate unplanned changes. Adam talked about the "snowballing effect" of such unplanned changes.

Adam commented:

I think on a daily basis, I really get frustrated and I try to accommodate this by being an extra big planner. It seems like our specialists take advantage of classroom teachers too much. A good example of this was last week we had a short week because of Thanksgiving. Well, as a result we have a special PE schedule on Fridays when I take my kids to $\mathrm{PE}$ at a different time. Well, they didn't tell me about that and so I take my kids down at their normal time on Wednesday and there is no teacher. I 
have planning time that's been changed, I have an appointment, so I didn't have anything planned for that time. Luckily for me I had this stack of stuff back at my desk where I could just go and grab it and go with it. Well, I haven't had to do that before this year. I don't complain about it because I want to stay on the good side of the music and PE teachers. But everything gets slowed up. We're going to be behind on a particular unit and it really snowballs. It starts out small, but pretty soon it gets bigger and bigger and it goes downhill.

Multiple and continuous change as depicted in teachers' statements was problematic because of the degree of disruptions in daily routines and the need for adjustments by teachers. These types of events were not officially identified as "changes" because they were unplanned, they were not labelled as planned school improvement efforts, and they frequently were not recognized as "significant disruptions" by school administrators.

- Many events experienced as change by teachers were not officially identified or recognized as change.

- Unplanned changes were experienced as problematic because of the degree of disruptions and adjustments required by teachers.

- The miscalculation of what comprises teachers' experience of change means that necessary planning and support may not occur.

- Planned change and unplanned change and are interactive and can trigger unintended changes. 
Teachers' Meaning of

Adjustment

The meaning of adjustment in this study includes responses by teachers to stimuli in the school work setting experienced by teachers as a change. Although there is a range of activities experienced as change, the adjustment described by the teachers in this study include two broad categories, behaviors and attitudes.

\section{Behaviors}

Behavioral adjustments to multiple and continuous change, as described by the participants, included two subcategories. These categories emerged as the interviews were analyzed. They are distinguished for the purposes of this discussion. In reality they merge and blend together as part of a whole experience of multiple and continuous change. All of the interviewees described behaviors that could be categorized as "unchange" behaviors. Also emerging from the interviews were behaviors categorized as "withdrawing." The behavioral adjustments described by the interviewees were derived from both planned and unplanned changes occurring in school.

\section{"Unchange"}

"Unchange" behaviors, as practiced by the participants disguise, obscure, mislead, and deceive others (usually administrators or their representatives) into believing that changes have transpired. Becker (1964) noted that: 
Many of the changes alleged to take place in adults do not take place at all. Or, rather, a change occurs but an optical illusion causes the outside observer to see it as a change quite different in kind and magnitude from what it really is. (p. 41)

During the interviews each of the teachers provided recollections of their adjustments to multiple and continuous change that involved behaviors which concealed or disguised the authentic events occurring in the classroom. The identification of "unchange" behaviors by the interviewees suggests that the appearance of change may be misleading. Furthermore, the adjustments that did frequently occur were not the intended responses of change agents. In fact, teachers' descriptions of their adjustments suggest a conspiracy (consciously or unconsciously) designed to mislead change agents into believing that innovations were being implemented when in fact the institutionalization of the change effort was being undermined.

Gene described the "unchange" as: "Yeah, I just don't do it. And even though they tell you that sometimes you should, I just do it in a different way, a way that they don't suggest." Adam described his responses to a survey on the school-wide improvement goal. "They try hard to make it work. When the survey came around, I just answered what they wanted me to answer."

"Unchange" misleads change agents to assume that there exists a line of teacher ownership. Undetected "unchange" 
confuses change agents and disrupts improvement. It is a behavior that is provoked and sustained by multiple and continuous change.

"Unchange" behaviors may also include intentional lying on questionnaires or learning the jargon but not applying the skills or process. An example of this was provided by Adam who stated:

I took ITIP and I took it with kind of a grain of salt. I learned the language and the vocabulary and I teach the same way that I used to teach. I just learned to apply new names to the stuff and, if that's cheating on ITIP, then I'm doing it.

Carol, another interviewee, noted:

ITIP was something I think was already in place in my classroom. Well, I felt as though I had a pretty good handle on most of those features, I just didn't have names for them all, and I felt it was really a good thing. I didn't really change that much.

"Unchange" is a learned behavior that allows teachers to create the impression that a "change" had been incorporated into their routine, but in effect this response enables teachers to maintain and preserve the status quo. It is also a behavior that may serve to allow teachers to continue their current practices and to maintain stability.

- Teachers learn behaviors that suggest change is implemented when it has not been implemented.

- "Unchange" allows for the maintenance of the status quo.

- The appearance of "unchange" can mislead change agents into assuming that the change has been implemented. 
- "Unchange" is a behavior that allows teachers to cope with multiple and continuous change.

\section{Withdrawing Behaviors}

"Withdrawing" was mentioned in conjunction with multiple and continuous change by all of the teachers that were interviewed in this study. Withdrawal was depicted as a behavioral adjustment to the cumulative effect of multiple and continuous change and refers to teachers' avoidance of stimulation and interpersonal interaction. The teachers in this study had little control over many of the planned and unplanned changes that impacted the instructional process. withdrawing reduced inputs and stimuli from other sources. It also served to reduce the excessive stimulation of multiple and continuous change. Withdrawing seems to help teachers feel as though they could control the background noise that constantly disrupted their focus and attention. As teachers characterized their adjustments to multiple and continuous change, they described their "withdrawing" from social interactions with their colleagues, administrators, and family and friends. The excerpts below are illustrative of this type of adjustment. Carol described feeling emotionally drained and unable to provide support to the individuals who, because of boundary changes in the district, were being transferred out of her building. "I tried to avoid the persons once I knew 
who they were. I just felt so badly for them and the changes they were in for."

Amy talked about the changes that led her to eventually withdraw from her peers. She described keeping her classroom door closed so she would not have to manage additional stimuli. Amy said:

There were many, many changes . . it was very, very stressful the first couple of years. There were maybe three or four of us who felt very isolated. We tried really hard not to just close our doors but to keep on sharing with people. We wanted to continue to try and be positive even though there was a huge air of negativity about who we were.

Eventually Amy hit a low point. She said:

So from that point, that very low point, I mean at that point I felt really bad and I started kind of closing in my classroom a little bit more and a little bit more.

"Withdrawing" behavior was not limited to co-workers;

it also impacted teachers' personal lives. Adam recalled "withdrawing" from family and friends.

Well, I'll bet I wasn't the best person to live with for a while, that is for sure. When I'm frustrated I just withdraw myself because I figure I don't want to hurt anybody else. I tend to hurt my spouse or someone else close to me more. That is probably the biggest stressor of my life, so far as teaching goes.

Withdrawing for Carol meant separating school and home. She attempted to eliminate the intrusion of work into her homelife.

That was another thing I had to let go of. I would just become so upset about a situation in the child's home that I couldn't focus on anything else. It was like that was all that was on my mind. It's 
not that I don't care about the kids anymore. It's just that I don't let those things consume me.

Multiple and continuous change provoked a behavioral adjustment described by teachers as withdrawing. This behavior provided teachers with a means of reducing some of the stimuli in their lives.

- "Withdrawing" is a behavior by which teachers attempt to reduce stimuli.

- Teachers isolate themselves from input, particularly "people input."

- Withdrawing is a learned adjustment to multiple and continuous change.

- Withdrawing behavior is not limited to the school setting. It can influence a teacher's personal and professional life.

Summary of Behavioral

Adjustments

- Teachers learn behavioral adjustments that assist them in coping with the constant change they experience in their work environment.

- The adjustments help them to cope and manage areas of their work lives over which they may or may not have control.

- The behaviors can occur in the instructional, professional, and personal domains.

- Two behaviors were referenced by all of the interviewees; "unchange" and "withdrawal." These adjustment 
strategies were used by teachers to navigate multiple and continuous change.

- The behavioral adjustments have the potential to generalize to new change efforts since change in schools is experienced as a phenomenon that is multiple and continuous.

\section{ATTITUDES ASSOCIATED WITH MULTIPLE AND CONTINUOUS CHANGE}

There were a number of attitudes evident in the interviews that were associated with multiple and continuous change. The four attitudes that emerged were "teachers know best," "not enough time," "what goes around comes around," and "being flexible." These attitudes influenced teachers' predilection to future change efforts and evolved from their lived experience with multiple and continuous change. The attitudes seem to help teachers navigate the constant intrusions that disrupt their world of work.

\section{"Teachers know Best"}

Teachers' statements revealed a prevalent attitude associated with multiple and continuous change that is best depicted as teachers, not change agents, know best. Amy expressed this as:

I feel like they don't know exactly what the make up of my classroom is, and they don't know who my students are. Every year I have different students, and they need something different than the previous year. I feel like I need to watch out for my students. 
Adam described his reaction to the district staff development trainers this way:

I still don't understand it. We're all in the staff room and it's "Oh, not these people again. What a pain in the neck. We have to dress up our lesson." That is what they are saying more or less even though they don't say it. Some people really respond positively to it and then there are people who are like me, and who are kind of on the fence. I think, I don't know, it seems like kind of a waste of money to me.

Dale expressed her attitude about teachers knowing best a bit differently. She stated that: "I think we are being asked by the district to teach things we do not know how to teach with little understanding of what it takes to teach those areas."

The attitude "teachers know best" seemed to influence teachers' predilection to learning from their peers. When changes were made, they frequently were the result of teachers' interactions with peers. Gene noted:

The first couple of years of being able to learn math I discovered that I could learn a lot from other teachers just by listening in on their presentations and being snoopy and nosey, and trying to get the whole of their lessons, so I could see what works for teachers and what doesn't work for teachers.

Although the teachers in this study expressed the attitude that "teachers know best" in a variety of ways, their attitude was derived from their lived experience.

- Teachers know their own classrooms best. 
- Outsiders, because they lack understanding of the classroom, ask teachers to do things that would not be in the best interest of children.

- Teachers change when they observe their peers successful practices (an opportunity that is closed when teachers withdraw from each other).

\section{Not Enough Time}

Constant change (planned and unplanned) reinforced an attitude that there was "not enough time" for any extra work beyond the necessary activities to manage their classroom. Amy's statement captures this attitude. She said:

Well, basic to a teacher is planning, having enough planning time and having enough correcting time. That means as soon as you infringe on teachers' planning and correcting time, it becomes too much work. You know, then they have to find another time to fill those in. I think my school was pretty much dedicated to a belief that you don't correct during class time. You know, that it's a teaching time and a time to interact with kids. So our time before school and after school, and our prep time during the day is pretty sacred time. When you start taking more than two or three of those times away for committee meetings or for grade level meetings or for team meetings of some kind, that's when people start to get pretty negative. You had better make sure the meeting is something worthwhile or I'm not going to be feeling good about being here.

Contributing to this attitude were the panoply of activities essential to instructional delivery such as parent contacts, paper work and preparation for teaching. These activities rapidly exhausted teacher planning time. In combination, non-innovational changes drained additional teacher time and also contributed to a tension between improvement and high 
quality instructional delivery. The experience with multiple and continuous change further reinforced the belief held by the teachers in this study that there simply was "not enough time" to change.

Although many teachers acknowledged the value of change, many did not involve themselves in efforts deemed valuable because of the attitude that there was not enough time. Lack of time reduced the likelihood that teachers would willingly commit their time to new changes. Amy described a situation that reflected this attitude. She said: "There was a lot of time involved and I didn't even have a prayer to present it to the kids." Carol's sentiments about not taking her students to the computer laboratory reflected her attitude that there was not enough time:

You know, when you have a whole class that has to go to computers or you have to pick up your kids and go into the computer classroom or you have to wait for a time when you can go in and it doesn't match up with times that you have in your schedule. It's just another one of those things.

Lack of time in each of the domains, instructional, personal, and professional was described by all of the interviewees. Dale believed that:

It seems like we used to spend a lot of time on our rooms and decorations and things more than we do now too. So now we're spending a lot more time actually teaching. Except for the fact that we have to spend a lot more time mothering and with the health care and all that we're spending a lot more time. 
Amy described the time required by her commitment to

new change.

Based on my involvement with the OTE project over the last three years, I would suggest in the coming years, that anybody who's on OTE, not be on any other committees, because it is so much extra time and work, that it's like three or four committees. I don't think people realize how much work and how much energy and how much time it is. So, because we haven't honored that and we have the lottery system and you have to sign up for so many committees which on one side I think is good and on the other side is negative. You know, I will on the average have three of four committee meetings a week that I have to attend before or after school. And usually they occur during the time when it would be my prep time to get ready for the classroom. So then that prep time has to be extended into some other time of mine which normally means that I have to stay later or I need to take stuff home and plan at home.

Carol stated:

When we were working on our school improvement team, some of us got a little nervous because it took a lot of time, even though we were compensated for our time, it took a lot of time that we were not compensated for like extra reading, and just trying different things in our classroom that we hadn't really thought about. There were extra things to plan for and take into consideration and questionnaires that needed to be filled out as well as surveys.

Even when the district attempted to address the issue of lack of time, the intervention did not effectively alleviate the concern. Substitutes were one way the district attempted to assist teachers. Substitutes, according to Gene, just did not provide an equal exchange for teacher time. Gene said:

My district likes to free teachers with substitute coverage. I didn't like it when I was taking training because I was removed from the classroom. And rather than go to my school as if I had a 
choice, I had to take my precious time and make plans for another teacher to come in and try and operate my classroom. Standard operating procedure is that there is only one teacher that can be teaching my classroom and that is me. So that when I am gone, I am God. I'm the only one that can run this class without copious notes and plans for another person to come in and fill my shoes.

The attitude regarding time seemed to flow and be fed from the stream of activities described as multiple and continuous change and the lack of effective ways to compensate teachers for their time.

Planned changes require multiple adjustments or micro changes. These micro changes were frequently misunderstood or underestimated by the change agents. The misunderstanding of the amount of time actually required for implementation of a new practice invariably contributed to a teacher perception that there was "not enough time." For the teachers in this study their barter was time. Time for teachers was one of their most valuable commodities and as such it became the pecuniary exchange unique to teaching and learning. Participation in change activities was translated by the teachers in this study into the coinage of time.

- Teachers believed that there is insufficient time for all of the activities associated with teaching and learning.

- The attitude that there was "not enough time" was associated with multiple and continuous change.

- Teachers frequently did not engage in change because of an attitude that there was not enough time. 
What Goes Around Comes Around

An attitude held by teachers in this study was that most innovations eventually will be discarded only to be resurrected and discarded ad infinitum. The interviewees felt that many innovations were re-inventions of past, failed efforts. This skepticism, in part, was perpetuated by multiple and continuous change. This attitude interacted with the attitude already described as "teachers know best." Gene's experience with onward Toward Excellence (OTE) promulgated his notion that "what goes around comes around." He said:

Things like OTE require a lot of energy of certain people when you are put on certain committees or something like that. A couple of years ago when we were going through school improvement plans and we had several meetings, and it was out in the forefront, it was a major issue to us, and now it has sort of slumped back into nothing. It is sort of like I don't know anybody who mentions it anymore.

Amy described her attitude toward a new innovation.

She said:

People started using success in Reading and Writing. They became like disciples. You know, it was like they oh, it's the newest, it's the best. And almost because of that, I rebelled against it because there had been so many things that had come through that I had just had enough of it. I think I've seen it all and I don't think I can handle another thing that's "the best."

Amy eventually implemented Success in Reading and Writing after she observed the success that her peers had with their students ("teachers know best"). 
Adam echoed Amy's sentiment when he talked about educational practices. "They're like long hair and bell bottoms. They go away and then they come back again." Carol commented: "Hey, I've come full cycle. I remember what we went through 20 years ago." Carol noted:

I am a little bit concerned about whole language. It is coming up again. I started teaching when we were doing whole language and I don't think it's all that good. So I'm not going to throw out the baby with the bath water.

Based on their lived experience of change as a multiple and continuous phenomenon, teachers believe that if a change is going to go away again (like it has before) they might as well continue what they are currently practicing, especially when there is "not enough time," and "teachers know best."

- Most changes will be discarded.

- Once discarded many changes become popular again.

- Teachers distrust new educational practices.

- Multiple and continuous change fosters this

attitude.

\section{"Being Flexible"}

The teachers in this study adjusted to multiple and continuous change by "being flexible." Flexibility was an attitude that helped teachers manage the ever-changing goals, expectations, routines, and daily upsets posed by daily uncontrollable alterations. "Being flexible," as practiced by teachers, involved anticipating the need to adjust plans and change expectations and thereby responding 
by making necessary adjustments. "Being flexible" reflects teacher acceptance of the inevitable reality of multiple and continuous change.

Adam described "being flexible" this way:

You come to work with the attitude, well, we'll just see how things go, instead of having to be so regimented to your plans. It (change) makes you more flexible. You are not so blocked. Your planning changes a lot because you don't feel like you have to have everything just that way. So now lesson plans are just kind of a broad thing. If something comes up, you don't hear as much anymore, "oh you can't do that because we are going to do math."

Amy described the importance to her of the attitude of "being flexible."

Nothing is predictable when you're in a change. You never can count on anything. You can't control other people's reactions. Sometimes you can't control your own reactions because you don't know how you're going to be effected by what's going on.

This attitudinal adjustment to multiple and continuous change served to reduce feelings of frustration and powerlessness teachers experienced when their hard work and lesson plans were disrupted.

Adam described a situation that occurred with little warning when the lesson plans he developed were set aside because of a series of changes in the school schedule. The unplanned changes resulted in his using already scarce planning time to make adjustments. Adam managed the situation by being flexible. Adam said:

Well, in my planning for my day, I had things I needed to do during my planning time. Some of those plans include designing activities for the next time 
the kids show up. So last Wednesday we ended up doing some painting and some things on our social studies projects. Since I didn't have my planning time until the end of the day, we didn't get to do our lesson. We still haven't gotten to do it and it's Wednesday of this week. We'll be lucky to get it in before Friday.

Gene offered an example associated with a book fair, a school function that occurs annually and requires "being flexible." Gene commented:

Well, it effected us with the parents. Parents came back to the school to run the book fair [in the school library]. I think the book fair ran for three days and two evenings. Two evenings the school was open from 3:00 until 9:00 in the evening so parents could come back with their children or without their children if they wanted to do sneaky Christmas shopping or whatever. There were parents here in the building operating the book fair past the obvious school day at 4:00. Of course it disrupted the school day. There were teachers who normally would have had sent their children to the library for a lesson. Those three days their schedules were interrupted because there was no place to send their children. They had to make their own personal changes in their schedules. I would reckon that there were teachers that were flexible enough to do that and that there were those who were not so keen or as able to bend in their life. I guess that happens.

Multiple and continuous change created conditions that necessitated "being flexible." It is not surprising that "being flexible" was mentioned by every teacher interviewed as an attitudinal response to multiple and continuous change. This attitude appears to reduce the cumulative frustrations of plans and lessons gone awry and allows teachers to cope with daily upsets that persist as a result of multiple and continuous change. 
- Being flexible helps teachers manage the ever present upsets that are products of multiple and continuous change.

- "Being flexible" means that standards for rigor are reduced.

Based on the interviews, teachers expressed many other attitudes that were directly or indirectly related to their experience with multiple and continuous change. The attitudes teachers expressed concerning change influenced their current and future reactions to school improvement, daily adjustments, and curriculum innovations.

- Teachers learned to not trust outsiders to determine what is best for their classroom.

- Teachers learned to protect their instructional time.

- Teachers held an attitude that changes consume and use up time and may not improve teaching and learning.

- Multiple and continuous change provokes an attitude that "what goes around comes around."

- Teachers adjust to multiple and continuous change by developing an attitude of "being flexible."

- All of these attitudes interact with other attitudes and behaviors already delineated. 
Domains of Teacher

Adjustment

During the interviews, teachers described adjustments to multiple and continuous change that occurred in the classroom, with their peers, and in their home. Multiple and continuous change influenced areas beyond the targeted scope of change stimulating adjustments in the instructional, professional and personal domains of teachers' lives.

Typically, planned change in schools has been associated with adjustments in the instructional domain. Hall and Hord (1987) state that teachers generally respond to new innovations by thinking about "how will this effect my classroom" (p. 57). Hall and Hord go on to say:

Ultimately, teachers are predominately concerned about how their teaching is affecting students and about how they can improve themselves as leaders. These concerns focus on the effects of their teaching and on ways they can be more effective. (p. 57)

Many of the adjustments teachers described in the interviews occurred in the instructional domain. Examples of those references include Gene's description of the adjustments he made in teaching math. Gene said:

So, I like to team teach because there is a rapport between the teachers in handling a larger group of kids. When we do a team-teach, a situation like I'm doing right now, the other teacher will present an assignment and I will roam the room and make sure the kids are following along. I have things I am helping them do and I get to observe the students while the other teacher is instructing. In a large group, I am trouble shooting with each of the individual kids, and if $I$ see a lot happening, I can 
give her feedback on it, better than the kids can. Then she can react to the feedback. After she presents, I will teach a math lesson and she works the field the same way $I$ do. So, although we aren't working with smaller groups of kids, I think we are doing a good job. It is a nice rapport between teacher to teacher because the teacher learns from the teacher and the kids also learn, the different styles too. So that is one way I have changed my teaching.

The team teaching situation allowed Gene to observe another teacher and to monitor and adjust. Gene changed his teaching in the instructional domain by altering lesson plans, instructional strategies, and student interactions. As referenced earlier in this chapter, Adam adjusted planned and unplanned changes by altering lessons plans, student management procedures, and teaching strategies. Some of Adam's adjustments in the instructional domain were stimulated by changes in specialists' schedules. Adam said:

But thank goodness I had my stuff ready to go because if I had not I don't know what I would have done with the kids. I guess I would have them read silently at their desks or something that would keep them occupied. I hate to say that but that's what I end up doing because I'm not prepared.

Gene adjusted his instruction by becoming expert in technology. The adjustments made by Gene occurred in the instructional domain. He noted:

When I first decided to move to this school, it was one of the things that was spoken at the very first staff meeting. The dream was to get a computer for the school. So, we'd get this computer, and of course nobody knew what to do with a computer, so a year after the school opened, we attained the goal of getting the computer for the school and then everybody had to take a course in how to operate the computer, so they would know what to do with the computer here at the building. 
It was an Apple II Plus, $32 \mathrm{k}$ in memory and it was on a cart and kept in the teacher's room. The teachers would come in there and play games on it. They practiced and mastered their skills and tried to learn the programs on it. It was kept there for about one and one-half weeks until everybody got sort of bored with it and didn't use it anymore. since it was on a cart that had wheels on it, I decided to take it to the classroom, and since there were no rules about not taking it to the classroom, I showed the kids how to use it.

I brought it down to the room and I figured since we had a computer in the building, and the teachers quit using it, that we might as well give it to the kids.

Many of the adjustments described by teachers occurred in the instructional domain; an area that is a frequent target of planned change.

A second area in which teachers made adjustments was the professional domain. The professional domain includes interactions between peers, administrators, parents and the community. Many of the adjustments teachers referenced occurred outside the classroom. The adjustments which occurred were frequently responses to changes targeting the instructional domain.

Adam described the unplanned adjustments that occurred in the professional domain that influenced his relationships with his peers. He tells it this way:

I was here back in 186-87 and even though we were large we had this great support system. Being new to the building, I knew if I talked to my team leader the principal would hear about it.

My colleagues and I knew what was expected. We had a great communication between the specialist and grade level teams. Everything was really good here. We dealt with those nasty rapid changes that we had 
always dealt with very well compared to 187-88 when there wasn't any communication going on.

During 1987 and 1988 the student population had increased significantly. Adjustments occurred in the professional domain.

In 87-88 there weren't team leader meetings. There weren't communications between specialists. It was just little memos in your box everyday. People didn't respond to them very well. You felt very isolated. It was very frustrating.

I don't know which structural changes took place first. It just happened. It was like the first week of school we decided we were going to have these meetings every week and then there just wasn't any follow up. Then we didn't have them anymore. I don't know if everyone down in the office was too busy then or if they had too many irons in the fire or what.

We didn't know what to expect and we were trying to deal with all of these problems just on our own. There wasn't any direction. We can do that, but it's not a coordinated effort. That was always the first thing I was impressed with regarding this school. You know, we'd show up and we'd try to do everything together here and we would try to work together. When we don't have that between the grade levels and the specialists, it just kind of all caves in.

Dale commented that the constant change altered her relationships with her peers, so that she experienced greater dependency on her peers. She said:

I think that my peers are really important, at least they are to me. Even more now because I actually feel that with all of the changes, other people can't possibly understand my job. You know, it's like nobody really knows what I'm doing.

Again evidenced by Dale's statement is the interactive aspect of multiple and continuous change. Dale's attitude 
that "teachers know best" stimulated adjustments in the professional domain.

Carol described what effects switching grade levels had on her relationships with her peers. Switching grade levels is one of the multiple discrete changes already discussed in this chapter. She said:

One of the things that happened when I first came to this school is that I indicated $I$ would like to be either in second grade or fourth grade and being in second grade represented a change. The principal needed me in the second grade, and that was my first choice, but that is where he wanted me to be, and apparently he felt that personality wise it would be a good match for me and the other person he had chosen. Well, he happened to choose a person with a very strong, dominant sort of personality, which was okay for a while because $I$ was feeling new in second grade, I thought well I have a lot to learn from this person. Anyway it got to a point where I felt as though this person was so well organized and had everything just so that it was really hard to disagree with her plans and I needed more time to think through what I really wanted to do. I didn't feel entirely comfortable with everything that was already planned out, yet on the other hand I felt like saying I didn't want to do it, I would rather do it this way. It was a little bit hard to deal with that. I guess what I finally ended up doing was just letting her go ahead and produce the material and $I$ just used what $I$ felt comfortable using and basically just branched off a bit on my own. That is how I coped with that. I found myself kind of being pulled along in situations that $I$ didn't feel totally comfortable with.

Teachers made adjustments in their professional work world even when the implemented change did not target a particular domain.

The third area in which teachers adjusted to multiple and continuous change was the personal domain. Included in the personal domain are all of the areas of teachers' lives 
beyond the scope of the instructional and professional domains. Topics most frequently mentioned were personal time and interactions with family/friends. A lack of empirical data on how change influences the personal lives of teachers currently exists. However, the teachers in this study described adjustments they made in response to multiple and continuous change that occurred in the personal domain.

Amy talked about the adjustments she made in her personal life. Amy said:

I had to put, and I have to still to this day, put more of my own personal time into school. I have to take things home more often than I used to. I am more apt to talk about school though.

Dale said that she had to adjust her personal life because of all of the changes in her school.

I just feel that teaching is really, you spend so much time working at your job. It would seem that things should get easier with our profession, but our job never does. We are just always spending more and more time and energy in our jobs. Because of that I never have time for myself.

Adam noted that his work caused him to withdraw from his family and friends. Teachers in this study described adjustments in their personal lives that were a result of changes occurring in their work environment. Multiple and continuous change seems to provoke those unintended adjustments that influences their personal lives. 
- Multiple and continuous change has the capacity to stimulate adjustments in all of the domains of a teacher's life: instructional, professional, and personal.

- The phenomenon of multiple and continuous change necessitates adjustments in a variety of unintended ways.

- Adjustments in one domain can set off a "chain reaction" of adjustments in the other domains.

- Behavioral and attitudinal adjustments interact with discrete planned change and unplanned change.

\section{SUMMARY}

The findings suggest that teachers experience a range of activities that they characterize as change. These experiences differ from the activities explicated in the change literature. Depicted as change are discrete adjustments to planned change and adjustments to unplanned change. This dimension of change is likely to be overlooked by change agents because it has been ignored in the literature. The failure by change agents to recognize the panorama of activities that cuimprise ceachers' livea experience of change erodes the management and support of meaningful school improvement.

Another finding of this study is that teachers make behavioral and attitudinal adjustments to the phenomenon of multiple and continuous change. In this study it was found that participants behave by pretending to implement intended 
outcomes ("unchange"), and by "withdrawing" from friends and colleagues. Three attitudes associated with multiple and continuous change were described by the participants. One attitude is that "teachers know best." Teachers believe that "what goes around comes around." Finally teachers develop an attitude of "being flexible." The adjustments teachers made served as metaprescriptions to assist in the navigation of multiple and continuous change (Brim \& Wheeler, 1966).

The composite of stimuli and adjustments reported by teachers suggests that multiple and continuous change in schools is complex, interactive, and exponential. The behaviors and attitudes that the participants learn mitigate institutionalization of innovations and favor simple adjustments intended to make teaching more manageable under the circumstances, but not necessarily more effective.

Historically, there has been a miscalculation by researchers of what comprises teachers' experience of change in part because of the focus by researchers and change agents on single innovational implementation. However, the real world of teachers suggests that multiple and continuous change characterizes the lived experience. Multiple and continuous change is a phenomenon that is part of the landscape of schools. As such, teachers make adjustments in response to the phenomenon of multiple and continuous change. Those adjustments influence the success of future improvement efforts. 
THE PARADOXES OF MULTIPLE AND CONTINUOUS CHANGE

This chapter presents an unanticipated finding that emerged from a subsequent analysis of the data. The phenomenon of multiple and continuous change produces a number of paradoxes that further serve to confound the landscape of schools. The paradoxes are yet one more dimension of teachers' lived experience of multiple and continuous change. By paradoxes, the researcher means those situations that are contradictory or produce contradictory adjustments.

\section{DEFINITION}

Paradoxes of change are the products of conundrums that produce unresolvable dilemmas and counterproductive solutions. It is hoped that by delineating the paradoxes created by multiple and continuous change, more viable methods of promoting improvement and eliminating barriers can be devised. The paradoxes characterizing the phenomenon of multiple and continuous change are the result of seemingly unresolvable, complex problems that are perpetuated by the adjustments teachers make to school improvement. 
Four paradoxes emerged from the teachers' characterizations of change: classroom versus school focus, depth versus breadth, commitment versus letting go, and fidelity versus rigor. The "vignettes" (Chapter IV) and the meaning of change (Chapter V) provide reference points for understanding the paradoxes discussed here.

Deciphering the paradoxes was assisted by utilizing Brim and Wheeler's (1966) theory of socialization. Brim and Wheeler suggest that desired socialization outcomes are more likely to be achieved when organizational expectations are clear, when there are appropriate opportunities to learn and to practice the knowledge, skills, and attitudes needed to meet the expectations, and when appropriate rewards are provided to those who meet organizational expectations. In addition, there are several individually specific variables associated with accomplishing desired socialization outcomes. They include the ability of organizational members to understand what is expected, the motivation of members to learn and perform appropriately, and the skill and ability of members to achieve the organizational expectations.

In schools that are typified by multiple and continuous change, the climate is fertile for the development of confusing, contradictory, and changing expectations, opportunities, and insufficient rewards. Opportunity and time to master necessary skills for carrying 
out organizational expectations is impacted. Motivation of organizational members is diminished by a history of failures to implement innovations combined with a discarding of past innovations.

Each of the teachers interviewed described paradoxes that created professional, instructional and personal dissonance. Four tensions emerged that dominated teachers' experiences with multiple and continuous change.

\section{Classroom Versus School Focus}

One such tension, characterized by teachers, is the reconciliation between time spent in the classroom and time spent out of the classroom; instructional improvement versus school improvement. The dilemma is exacerbated by multiple and continuous change because planned and unplanned change exhaust the limited resource of teacher time. The tension is further stoked by numerous and varied maintenance activities that require teacher time for essential routines and service delivery. As demands increase for teacher participation in activities for school governance, staff development, curriculum alignment, and teacher leadership, teachers are forced to make choices regarding expenditures of their time, between instructional service delivery and teacher participation in school governance.

Kate describes the dilemma for teachers this way:

Well, a basic issue for teachers is planning, having enough planning time and having enough correcting time, or improvement becomes too much 
work. I think our school's pretty much dedicated to a belief that you don't correct during class time. You know, that it's a teaching time and a time to interact with kids. So our time before school, after school, and our prep time during the day is pretty sacred time. When you start talking more than two or three of those being used for committee meetings or for grade level meetings or for team meetings of some kind, that's when people start to get pretty negative. Teachers think you had better make sure this is something worthwhile or I'm not going to feel good about being here.

Teachers adjusted to the paradox of school versus classroom improvement in a variety of ways. Amy consciously decided to focus more of her attention on school improvement and leadership activities than on her classroom. Because of her involvement on the leadership team, she had less time for her classroom, was unable to attend to her health, and had less resiliency in managing unplanned changes. In order to participate in leading her school, Amy spent less time on classroom preparation. Although Any felt rewarded for her efforts and believed that her school was improving, Amy struggled with the difficulty of balancing pressures for classroom and school improvement. She noted:

So there's a trade off there. Ah, I suppose that I also feel, a little bit, that my programs are probably not as current. I'm not as willing to try as many new programs because I don't have the time to jut sit down and mull over well, how could I design this or how could I do that. I tend now to rely on things that I've seen before or done before because they've worked. I don't take the time and energy to develop something new. Now that doesn't mean I don't get excited about new things. I have tried new things too, but I tend to rely on the older things because I'm too busy to design something totally new. 
Gene resolved this dilemma by choosing to not be involved in his school's improvement effort. He passively resisted efforts that pulled attention away from his teaching. Gene's protection of his instructional time allowed him to feel good about his teaching but resulted in negligible involvement in collaborative school-wide improvement of district curriculum. It was Gene's protection of his time that allowed him time to focus on computers. Ironically, his efforts ultimately influenced school-wide institutionalization of computer instruction. Adam had not yet decided nor learned what was most manageable for him. He remained ambivalent, and attempted to balance the two. As Adam stated earlier, when activities outside of the classroom took the focus away from instructional preparation, Adam adjusted by adapting strategies that were not effective instructionally, such as giving students busy work. The balance of school improvement and classroom instruction translated for Adam into inadequate time for both foci. As a result Adam frequently experienced frustration and guilt in his efforts to be an excellent educator.

Dale bravely attempted to meet all of the expectations of the district. In the vignette Dale's frustrations with instructional improvement were complicated by the multiple and continuous changes that directly impacted her teaching. Dale struggled to find opportunities to realistically meet 
the district requirements which were undermined by an increase in the number of limited English speaking students, mainstreaming of handicapped students, and changes in her teaching position. Dale's expectations were further frustrated when the district changed its definitions of improvement and curriculum. The net outcomes for Dale were unattainable goals and rewards.

Finally, Carol reduced her own expectations for herself as a classroom teacher. She did not grade all papers. She learned shortcuts that allowed her to be involved in more school-wide activities. Carol resolved the dissonance between effective schools and effective teaching by accepting the paradox as a reality of schools and determining that district expectations were not achievable.

All of the teachers struggled with school improvement versus classroom improvement. For these teachers the conflict was not resolved and perhaps not resolvable. Yet, the research on effective schools suggests that both effective teaching and school improvement are necessary to create excellent schools. The paradox between effective schools and effective teaching produces competing demands, unclear expectations, lack of viable opportunities to achieve multiple expectations, lack of time to develop the needed skills, and lack of knowledge as to how to accomplish everything. 
Depth Versus Breadth

Multiple and continuous change presents another paradox--depth versus breadth. This paradox is evidenced by the inadequate opportunities available to teachers to receive thorough training or preparation to teach mandated curricula. An example of "depth versus breadth" paradox is the tension between striving to accomplish required common curriculum goals and the inadequate time allotted for staff development needed by teachers to master the application of those goals. "Depth versus breadth" is further exacerbated by the emotional and personal needs of increasing numbers of "at risk" students. All of these issues are complicated by multiple and continuous change. Frequently teachers begin to experience a level of competence only to have that competency replaced with the need to learn yet a different skill. This paradox stimulates a too familiar situation for teachers by creating unclear expectations, inadequate opportunities, and mixed rewards.

The teachers in this study were called upon to teach traditional curricula while additional curricula such as sex education, computer technology and drug and alcohol education were being added. Teachers were switched to different grade levels, expected to learn new curricula for new subjects, and expected to understand and use instructional strategies for a different developmental level 
when minimal time was provided for teachers to learn the new requisite skills.

Adam and Carol experienced the paradox of "depth versus breadth" as they struggled with implementing the AIDS curriculum. They were concerned about the many issues that might emerge for students when sex education was presented to students. The curriculum was scripted for teacher presentation with minimal allowance of time and latitude for teacher response to student questions. The timeline to implement the new curriculum allotted inadequate time for teacher training. curriculum expected to be taught was not reduced which left inadequate instructional time to teach the new curriculum.

Carol experienced the dilemma this way:

There isn't a satisfaction of mastering. You are just on a treadmill. Probably the more creative a person you are, the more you are called upon to keep it up, keep designing, do more, and it becomes really frustrating in that way.

Dale talked about the pressures to teach all of the curricula objectives so that students could meet district expectations and master essential learning skills for grade level matriculation. She said:

Well, one thing is that you can't do everything. That is what is so frustrating. It seems like now there are tons of strategies. When we first started teaching, it was just like get in there and just teach reading and math. You worry a lot now, because now you say, oh I'm not meeting kids' learning styles. I'm not doing this, and I'm not doing that. You are worried more about if you are doing it properly and, there is just so much to give. I felt I would become a better teacher, but I 
still feel like I'm spinning my wheels and probably spin my wheels more because the kids and their lack of skills adds to the stresses in their life. I think we are really stressing too much with kids. our expectations are too high and we are putting all the demands we have, all these new things we have, we are pushing that off on the kids, and making them accountable for so much more. We are so structured, so scheduled that there is not time to do this. We used to sit back. We used to have time to video or go for a walk or take a field trip. In the last few years I can count on my hand the times we have done this. In fact, show and Tell, there is not time for that, there is not even time for flag salute. It is just, get in there and get to work.

The amount of time allocated for instructional goals and objectives provided minimal time for teachers in this study to encourage comprehension, thinking and application. Minimal time was factored into the school day for remediation or enrichment. Yet recent studies on effective schools emphasize mastery and thinking skills for all students (Brookover \& Lezotte, 1979; Marzano et al., 1988).

Carol describes the impact adding and changing curriculum had on her lessons.

We had to cut down, shorten our reading classes, had to move things around, had to adjust time slots, had to cancel reading for a couple of days a week. We had to plan, we had to sit down and actually plan about how we were going to do it all and it took a lot of extra time. It took more time than we really wanted to give, and it was hard. It just stands alone. It's like, oh, here we are--make a spot and then fit it in--out of context $I$ guess is how I would describe it.

The dilemma for teachers is one of providing lessons that "cover" the required content versus lessons that allow for in-depth understanding. Multiple and continuous change fosters and fuels this paradox. 
Commitment Versus Letting Go

The paradox of commitment versus letting go is more subtle and insidious. Teachers are repeatedly encouraged simultaneously to commit and to let go. They are asked to invest precious time and energy in the latest panacea to educational woes and to concurrently disregard as passe a less current innovation introduced with similar verve and plaudits in a not too distant past. "Commitment" requires people to invest, believe, trust, defend, and protect. "Letting go" requires one to give up, to behave non-defensively, to divest, and to not care.

Exacerbated by the historical terminality of most educational panaceas, teachers are told to behave both ways. They are asked to "commit" and to "let go," to accept and not question, and to question and not accept.

Carol commented:

It makes it hard to make a decision, just everything going on all at once and you just don't know where to begin. I think you become a little frantic, you're probably not as effective to your students. It's not fun.

During the interviews, teachers referenced old innovations and curricula adoptions that had "passed through" their districts. Amy talked about all of the different reading approaches she had experienced in her lifetime when she eventually decided to implement "Success in Reading." Amy's statements reflected her increasing distrust of new panaceas and a growing unwillingness to give 
up old ways. It was the proven success of other educators that eventually convinced Amy to try something new. Multiple and continuous change taught Amy to trust teachers over administrators and consultants if she wanted to make a change that would improve her teaching. In order for Amy to believe in new innovations, there needed to be proof that the innovation worked. Otherwise Amy felt her old ways were as good as the new innovations that eventually too would be discarded.

Dale's experience with innovations was similar to that of her colleagues. She said:

I think there are so many different things where people are on the bandwagon, saying you need to do cooperative learning and you need to get Richard strom into your classroom. The new wave is "whole language," and to be a really good teacher, you need to do these things--but the "how" to do this is not really there.

Carol described approaches to reading that had come and gone over the years. She was less susceptible to the proselytizing of new converts. Skepticism reverberated in her belief that current approaches were being replaced with old approaches that were past discards.

Commitment and letting go resonated in Dale's and Adam's descriptions of being transferred to different grade levels. Their motivation to recommit was reduced when they realized past efforts were not valued and were easily cast aside by forces over which they had no control.

Dale noted: 
I think if you are able to stay within the grade level for awhile you can really commit. If you are able to stay put for awhile and you finally have some lessons to fall back on and know good lessons to fall back on, then it's easier. But, there is just so much switching. That was one of the things that I said the first time we met and that comes to mind right now. In most jobs, you can kind of find where you want to be. If you want you can be an assembler all your life, but our job just totally keeps changing. Teachers used to stay put in a building if they wanted to do that. They could stay in the same building from the time they started teaching till they retired at the same grade level, and the only really basic change they would have other than change in children and classrooms would maybe be a new curriculum that would be introduced every six to eight years or whenever they do that. But we have less and less control of the grades we are going to teach, the buildings we are going to teach in, and just less and less control that way. It is very very difficult when you are constantly teaching a different grade or in a different community or different socioeconomic group. Those are really difficult changes for a teacher. It takes five to six years to really feel like you have got it made.

Interviewees were asked to "commit" and "let go" simultaneously despite the fact that teachers often felt school improvement efforts frequently did not improve the school, that lesson plans and daily routines cast aside disrupted teaching and learning, and past implementation efforts rarely produced lasting change. All of the teachers noted past efforts such as ITIP, OTE, math and reading curricula that were not institutionalized. Organizational expectations and rewards became muddied and non-compelling.

The constant shifting of what was in and out combined with the unceasing pressure to simultaneously "let go" and "commit" mitigated teachers' successfully implementing new 
innovations. Organizational members learn to distrust organizational expectations because the skills and behaviors once rewarded might become obsolete and disdained. Organizational members discovered, as Gene once did, that by not committing, the inevitable future consequences of letting go could be avoided.

\section{Fidelity Versus Flexibility}

A final paradox of multiple and continuous change is the paradox of fidelity versus flexibility. With on-going, multiple, and continuous changes, teachers were required to insure that the integrity of their programs was maintained while simultaneously they were forced to adjust and respond to numerous planned and unplanned changes. Powerless to control the onslaught of requisite adjustments besieging their lessons, yet responsible for insuring instruction, teachers were expected to be flexible and adaptable, while maintaining the fidelity of their lessons.

When teachers described their adjustments to change they described "being flexible." Gene discussed the virtues of being flexible when confronted with daily adjustments. Adam learned to be flexible when daily routines and teacher agreements were abandoned to adjust to a growing student population. Dale learned to be flexible in order to adjust to multiple instructional goals.

Carol described how flexibility evolved for her. She noted: 
Well, for instance I have had to decide that penmanship just wasn't going to be a major emphasis in our classroom. At the beginning of the year the children had just learned how to do cursive in the third grade, so they needed to have that reinforcement in the fourth grade and for some students from another school perhaps it was their first time. So I think the first term in fourth grade is really important to have formal instruction and you haven't gotten into the other things quite so much at that point. But, that is one of the things that has gone by the wayside. Computer skills they need to have and that is going to get them of $\bar{x}$ the hook as far as penmanship is concerned anyway. A lot of parents are willing to buy into that, so that one I can get away with.

Flexibility, described earlier as an adjustment to multiple and continuous change, included behaviors that undermined pacing, accountability and fidelity. The flexibility the teachers described allowed them to get along with their peers. It reduced the internalized pressure of not being able to meet all of the expectations when reasonable opportunities were not provided to achieve their goals. It allowed teachers to maintain a positive attitude with children and parents, when children and parents disrupted organizational expectations.

Huberman and Miles (1984a) and Loucks-Horsley et al. (1987) talked about the combination of pressure and support as a means of encouraging implementation and institutionalization of innovations. As teachers give themselves permission to be flexible, pressure becomes a less potent and viable force. Goals and objectives are more easily set aside. The paradox of an innovational fidelity 
and cultural flexibility creates tensions between integrity and adaptability.

SUMMARY

Multiple and continuous change creates situations that produce competing and changing expectations and require seemingly contradictory skills and attitudes that work against change and improvement. The adjustments teachers made in response to multiple and continuous change were rational responses to their experience, yet the adjustments produced very real dilemmas for teachers who were committed to school improvement. While teachers' adjustments to multiple and continuous change may seem to diminish the likelihood of creating excellent schools, those same behaviors also functioned to preserve a semblance of sanity, order, and continuity in the classroom. Equally, as teachers devote increasing time, attention, and energy to school-wide change projects, their effectiveness in their classrooms may well diminish. These efforts to improve schools may results in unintended and unanticipated consequences $v$ is a vis actual effects for children in classrooms. 


\section{CHAPTER VII}

\section{CONCLUSIONS AND RECOMMENDATIONS}

The purpose of this chapter is to delineate the significant conclusions resulting from the study of teacher adjustments to multiple and continuous change. A second intent is to present recommendations that can inform and illuminate future change efforts. The study of multiple and continuous change merits consideration because it contributes to an understanding and appreciation for the complexity and magnitude of restructuring, school improvement, and change. Hopefully, this study will serve as a springboard to future research.

\section{CONCLUSIONS}

Teachers Experience Change as a Multiple and Continuous Experience

This study indicates that teachers experience innovations and change as a multiple and continuous phenomenon. In the world of schools, teachers depict change as both a complex and routine experience.

Interviewees at the primary study site described multiple change efforts that were in various stages of implementation. They also described numerous change efforts 
that had been abandoned or assimilated that also included a plethora of activities that were both planned and unplanned. The interviewees described the changes they experienced as a constant, never-ending phenomenon.

Faculty surveys, the pilot interview, and the principal interviews identified a broad spectrum of national, state, district, and school-wide change efforts that impacted the lives of teachers. These efforts translated into activities including fluctuating demographics, curricula adoptions, state and district based mandates, and technology. These activities, in combination with national and state mandates, compounded exponentially the number of change efforts, improvement goals, and restructuring attempts that required significant teacher change simultaneously over an extended period of time. Schools in this study experienced constant and multiple change, fragmented focus, pressure to do too much and on-going depletion and exhaustion of essential resources. The portrait of schools derived from the data collected in this study was one of multiple planned and unplanned change. It is the researcher's opinion that based on the data collected in this study, change in the real world of schools. is not isolated nor attributable to a single innovation. Change is a phenomenon that is multiple and continuous. 
Planned and Unplanned Actj.vities

Comprise Teachers' Experience of

Change

A conclusion of this study that departs from the research literature is that change in schools is experienced by teachers as a multiple and continuous phenomenon attributable to both planned change and unplanned change. The participants in this study ascribed their adjustment to a variety of planned changes that included curriculum adoptions, growth and decline in student and staff population, mainstreaming of special education students, and English as a second Language students.

These planned activities involved smaller discrete changes sometimes planned but frequently unplanned. The number of changes required to implement a single innovation seemed to be unrecognized and/or underestimated. The misunderstanding of the number of activities that comprise innovation implementation contributed to miscalculation of requisite resources, frustration by the participants, and a snowballing effect of unplanned changes on the total operations.

Also included in teachers' descriptions of their experiences that stimulated change were a vast array of significant unplanned change events that were not formally recognized as change efforts. The participants identified adjustments in teaching assignments, adjustments in daily class schedules, changing demographics, changes in 
leadership, and changing societal values. As already noted, some unplanned changes were by-products of single innovation implementation while some were the result of unanticipated political or societal forces. All of the unplanned changes described by the informants required and exhausted teacher time, focus, and resources. These unplanned changes were experienced by teachers as significant and exponential because of the number and extensiveness of adjustments required by teachers. Unplanned changes frequently were also subject to underestimation, miscalculation, and underrecognition by administrators, change agents, and policy makers who frequently did not demonstrate an awareness of the implications of unplanned change when planning strategically for school improvement. The result was a lack of support and resources designed to support necessary unplanned change and planned change. The aggregation of planned and unplanned change in combination with limited resources contributed to the participants' perceptions and experiences of change as a multiple and continuous phenomenon.

A conclusion of this study is that the activities teachers experienced as comprising change included planned and unplanned activities. Change, therefore, is far more expansive than activities and events attributed to innovational change. Unplanned change exacts significant adjustments from teachers and single innovations triggered 
multiple changes. The scope of activities that provoked teacher change are broader and more comprehensive than heretofore depicted in the literature on change.

Teacher Adjustments to

Multiple and continuous

Change

The most significant finding for policy makers, administrators, and change agents is that teachers make adjustments to change as a multiple and continuous phenomenon. Teachers in this study identified a variety of adjustments that were the products of ongoing change. Teachers learned meta-prescriptions to manage change. Teachers responded to change as a multiple and continuous phenomenon.

Teachers in this study described behavioral and attitudinal adjustments in three domains: instructional, professional, and personal. Teachers described their behaviors as "unchange," "withdrawing," and "avoidance." Teachers described attitudinal adjustments as "teachers know best," "what goes around, comes around," "this too will pass," "being flexible," and "not enough time." All of these adjustments were responses to multiple and continuous change and seemed to assist teachers in their sense of how to manage a work world environment that they experienced as unstable, unpredictable, and ever changing. The behaviors and attitudes teachers described in this study allowed teachers to continue practices they deemed effective, 
maintain instruction when external factors disrupted teaching and learning, and protected teachers from a seemingly arbitrary environment. The adjustments occasionally limited participant commitment, derailed motivation, obscured results, and impaired institutional fidelity. Based on the data collected in this study, many of the teacher adjustments to change were derived from their perceptions of past changes.

The data collected in this research provide accounts of the adjustments teachers make in response to multiple and continuous change. Probably the most significant departure from the research on change and the most important conclusion in this study is the finding that teachers learn adjustments to change based on their experiences and perceptions that change is a multiple and continuous phenomenon.

\section{Paradoxes Produced by Multiple} and Continuous Change

Several paradoxes emerged as products of multiple and continuous change. Paradoxes for the purposes of this study were defined as unresolvable and frequently counterproductive dilemmas. Those dilemmas are important to note because they frequently were the result of situations that stimulated counterproductive adjustments and/or solutions. 
Four paradoxes emerged: classroom versus school change, depth versus breadth, commitment versus letting go, and fidelity versus rigor. Multiple and continuous change seemed to stimulate situations that required contradictory skills and attitudes that undermined or countered school improvement.

The importance of this finding is that as a result of identifying these conundrums, planners of future change efforts will hopefully develop strategies that minimize the negative consequences of multiple and continuous change. These findings can serve as a springboard for researchers and school administrators to maximize change and thereby significantly improve schools.

\section{RECOMMENDATIONS}

\section{Adjust the Change Paradigm}

There are several recommendations that are products of this study. The current paradigm for change needs to be revised and rethought. The foundation for the new change paradigm must be based on an understanding of change as a multiple and continuous phenomenon. The new paradigm should include consideration of the many complex paradoxes that stimulate difficult conundrums for teachers as they grapple with long-term school improvement and short-term instructional effectiveness. 
The new paradigm based on change needs to readdress teacher attitudes and beliefs. A number of teacher adjustments to multiple and continuous change were identified. In this study, the adjustments teachers made in response to multiple and continuous change functioned to preserve stability and conditions necessary for teaching and learning. They also periodically contributed to an undermining of innovational institutionalization and innovational fidelity. The adjustments teachers make to multiple and continuous change influence teachers' responses to future changes. A new paradigm must address and consider teacher adjustments to multiple and continuous change. Change agents, policy makers, administrators, and staff developers must also recognize the interactive and exponential impact change has on teachers and on schools when calculating resources necessary to support and incur lasting school improvement. Embedded in a new change paradigm should be strategies to minimize the limitations and obstacles that have been related to the phenomenon of multiple and continuous change. Sarason (1990) has reflected that the medical profession has acknowledged the limitations and obstacles that are part of its profession. He says:

Why is it that since the rise of scientific medicine in the latter half of the nineteenth century, we have not criticized and indicted the medical researcher and practitioner for not being able to cure the bulk of cancers--or, for that matter, hundreds of other bodily afflictions? Why has it 
not been said that medicine is either a failure or is quackery that does not deserve public support? one part of the answer is that the medical community did not say that it would be able to cure cancers over the next year or twenty years from now. On the contrary, it emphasized the complexity and scope of the problem, the inadequacies of past and present conceptions and practices, the false starts and disappointments that await it and the public in the future, and the need for patience, forbearance, and the long-term view. In short, scientific medicine said: we will do our best, and we will try to learn, but let us not underestimate the obstacles and conundrums we face. (p. 38)

Educators must recognize and accept the obstacles confronting school improvement efforts. Change, any change, must be approached in a manner similar to remodeling. Expect the unintended and assume greater requirements of time, money, and resources. old assumptions and conventional wisdom regarding change must be reconsidered in light of this study and revised or dismantled. New paradigms derived from teachers' lived change experiences must guide future school improvement efforts. Change in schools is a multiple and continuous phenomenon that warrants a different paradigm.

\section{Provide Teachers with strategies} for Managing Change

Teacher education should prepare teachers for the real world of schools. A practitioner's approach to change as well as a theoretical base are components and critical underpinnings in teacher preparation. Teachers new to the profession should be well versed in strategies to manage 
multiple and continuous change such as "action research" and "site-based management."

Administrators, change agents, and policy makers also require similar training and a theoretical base derived from an understanding of the phenomenon of multiple and continuous change management. Administrators, change agents, and policy makers must be well versed in strategies that minimize the deterrents to effective long-term school improvement.

Educators, Teachers, Policy

Makers, and Change Agents

Must Become Change Ecologists

Change is a multiple and continuous phenomenon that requires resources of time, energy, and money. Schools are ecological units with limited resources. Change agents must become selective consumers of improvement efforts that promote sound ecological change. Change agents must eliminate unnecessary planned and unplanned change such as alterations in teacher assignments, schedule changes, switching of classrooms, and unnecessary curriculum adoptions. Change agents should select implementation only of improvements with tigh likelihoods of improving teaching and learning. Finally, improvement efforts for which there ar'e inadequate resources to assure institutionalization should not be undertaken. Just as farmers would not plant seeds in poor soil, change agents must not undertake improvement efforts without sufficient resources. 
Despite the research on conditions requisite for successful change, educators behave as though good seeds will grow in any soil. An implicit assumption prevails among educational change agents that all change requires is the "just do it!" approach of the Nike slogan.

Any effort to restructure or improve the school must proceed cautiously with full knowledge of the past, present, and future implications of previous and current changes. Guiding all changes in schools is the understanding that multiple and continuous change is a phenomenon of schools that will always exist. Multiple and continuous change includes a panoply of activities, planned and unplanned, experienced by teachers as constituting change, and requiring major adjustments that exhaust valuable resources. Understanding the ecology of the school and the future ecological needs should be a precondition to implementing any change.

MORE RESEARCH

Researchers need to investigate the phenomenon of multiple and continuous change. This study surfaced many issues that require more in-depth investigation. Because this study was intended to discover rather than confirm theory, these findings require more research and are not definitive. 
One area that might be useful in providing theory that can inform improvement efforts is the study of teacher adjustments to multiple and continuous change. Ecology of change is another topic worthy of investigation. Research into unnecessary change and unplanned change would be informative in planning school improvement. Another useful study might include examination of the role higher education plays in assisting teachers to learn skills for managing multiple and continuous change. Finally, a replication of this study might surface new questions and confirm some of the preliminary findings already summarized.

\section{SUMMARY}

This study suggests that change is fluid, interactive, past dependent, and exponential in nature. Even change that is planned and strategized has the potential to stimulate numerous micro and macro unplanned changes. Typically the examination of school improvement has been limited in scope and less than panoramic in its inclusion of past, present, and future events and activities.

Change agents, policy makers, administrators, and staff developers need to recognize the impact multiple and continuous change has on the participants and on the ecology of a school. Without the recognition of change as a multiple and continuous phenomenon, a workable change paradigm is unlikely. It is the full composite of planned 
and unplanned change, and past and future change that must be honored and recognized when planning any improvement. Multiple and continuous change is a phenomenon that seems to be an accurate depiction of the world of schools. The phenomenon of multiple and continuous change has significant implications for staff development, school improvement, teacher effectiveness, and school culture. The findings in this study serve to signal researchers that the phenomenon of multiple and continuous change merits more investigation. 


\section{REFERENCES}

Ashton, P. \& Webb, R. (1986). Making a difference: Teachers sense of efficacy and student achievement. New York: Longman.

Bandura, A. (1977). Social learning theory. Englewood cliffs, NJ: Prentice-Hall.

Bandura, A. (1981) . Cultivating competence, self-efficacy, and intrinsic interest through proximal self-

motivation. Journal of Personality and Social Psychology, 4I (3), 586-598.

Becker, H. S. (1964, March). Personal change in adult life. Sociometry, $\underline{27}$ (1), 40-53.

Berman, P., \& McLaughlin, M. W. (1974, September). A model for educational change: Vol. 1. Rand change agent study-federal programs supporting educational change (R-158911-HEW). Santa Monica, CA: Rand Corporation.

Berman, P., \& Mclaughlin, M. W. (1981). Federal programs supporting educational change: Vol. IV. The findings in review. Santa Monica, CA: Rand Corporation.

Best, J., \& Kahn, J. (1986). Research in education (5th ed.). New Jersey: Prentice Hall.

Bloom, B. S. (1976). Human characteristics and school learning. New York: McGraw Hill Book Company.

Blumberg, A., \& Greenfield, W. (1986). The effective principal: Perspectives in school leadership. Boston: Allyn and Bacon.

Bogdan, R. \& Taylor, S. (Undated) Understanding qualitative research. Unpublished manuscript, cornell University.

Bogdan, R., \& Taylor, S. (1975). Introduction to qualitative research methods: A phenomenological approach to the sciences. New York: Wiley.

Brim, O., \& Wheeler, S. (1966). Socialization after childhood: Two essays. New York: John Wiley and Sons. 
Brophy, J., \& Good, T. L. (1974). Teacher-student relationships: Causes and consequences. New York: Holt, Reinhart and Winston, Inc.

Brookover, W. B., Beamer, L., Efthim, H., Hathaway, D., Lezotte, L., Miller, S., Passalacqua, J., \& Tornatcky, L. (1982). Creating effective school: An inservice program for enhancing school learning climate and achievement. Homes Beach, FL: Learning Publications.

Brookover, W. B., \& Lezotte, L. B. (1979). Changes in school characteristics coincident with change in student achievement (Occasional Paper No. 17). East Lansing: Michigan State University, Institute for Research on Teaching.

Butler, J. H. (1988). A review of adult learning theory and staff development research. An unpublished paper, Northwest Regional Educational Laboratory, Portland, OR.

Clark, C., \& Peterson, P. (1986). Teachers' thought processes. In M. C. Wittrock (Ed.), Handbook of research on teaching (3rd ed.) (pp. 255-296). New York: Macmillan Publishing Company.

Crandall, D., Bauchner, J., Loucks, S., \& Schmidt, F. (1982, March). Models of the school improvement process: Factors contributing to success. Paper presented at the annual meeting of the American Educational Research Association, New York.

Denzin, N. K. (1978). The research act: A theoretical introduction to sociological methods (2nd ed.). New York: McGraw Hill.

Duke, D. (1984). Teaching: The imperiled profession. Albany: State University of New York Press.

Duke, D. (1987). School leadership and instructional improvement. New York: Random House.

Duke, D., \& Corno, L. (1981). Evaluating staff development. In B. Dilion-Peterson (Ed.), staff development/organization development ( $\mathrm{pp} .93-112$ ). Alexandria, VA: Association for Supervision and Curriculum Development.

Duttwieler, P., \& Hord, S. (1987). Dimensions of effective leadership. Unpublished document. 
Edmonds, R. (1979). Effective schools for the urban poor. Educational Leadership, 37 (1), 15-24.

Educational Research Service, Inc. (1983). Research brief. Effective schools: A summary of research. Arlington, VA: Author.

Fullan, M. (1982). The meaning of educational change. New York: Teachers College Press, Columbia University.

Fullan, M. (1990). Staff development, innovation, and institutional development. In B. Joyce (Ed.), Changing school culture through staff development (pp. 3-25). Alexandria, VA: Association for Supervision and Curriculum Develpment.

Fuller, F. F. (1969). Concerns of teachers: A developmental conceptualization. American Educational Research Journal, 6 (2), 207-226.

Glaser, B. G., \& Strauss, A. L. (1967). The discovery of grounded theory: strategies for qualitative research. Chicago: Aldine Publishing Company.

Glickman, C. (1989, May). Has Sam and Samantha's time come at last. Educational Leadership, 46, 4-9.

Good, C. V. (1966). Essentials of educational research. New York: Appleton/Century/Crofts.

Good, T., \& Brophy, T. (1982). Looking in classrooms. New York: Harper and Row.

Good, T., \& Brophy, J. (1986). Teacher behavior and student achievement. In M. C. Wittrock (Ed.), Handbook of research on teaching ( $3 \mathrm{rd}$ ed.) (pp. 328-375). New York: Macmillan Publishing Company.

Goodlad, J. (1983). A place called school. New York: McGraw-Hill.

Grace, G. R. (1972). Role conflict and the teacher. Boston: Routledge and Kegan Paul.

Greenfield, T. (1983, April 11-15). Environment as subjective reality. Paper presented at the annual meeting of the American Educational Research Association, Montreal, Quebec.

Griffen, G. A. (1983). Implications of research for staff development programs. Elementary School Journal, 83 (4), 414-425. 
Gross, N., Graquinta, J. B. \& Bernstein, M. (1971) . Implementing organizational innovations: A sociological analysis of planned educational change. New York: Basic Books.

Guba, E. G., \& Lincoln, Y. S. (1983). Epistemological methodological bases of naturalistic inquiry. In G. F. Madaus, M. Scriven, and D. Stufflebeam (Eds.), Evaluation models: Viewpoints on educational and human services evaluation (pp. 311-334). Boston: KluwevMizhoff Publishers.

Guskey, T. R. (1986, May). Staff development, and the process of teacher change. Educational Researcher, 15 (5), 5-12.

Hall, G. E. (1981). Issues in analyzing change process outcomes: A view from the ground. Austin: University of Texas, Research and Development center for Teacher Education.

Hall, G., \& Hord, S. (1987). Change in schools: Facilitating the process. Albany, NY: State University of New York Press.

Hall, G. E., \& Loucks, S. F. (1978). Innovation configurations: Analyzing the adaptations of innovations (Report No. 3049). Austin: University of Texas at Austin, Research and Development Center for Teacher Education.

Hall, G. E., \& Loucks, S. F. (1981, winter). Program definition and adaptation: Implications for inservice. Journal of Research and Development in Education, 14 (2), 46-58.

Hal1, G. E. \& \& Rutherford, W. L. (1983). Three change facilitator styles: How principals affect improvement efforts (Report No. 3155). Austin: The University of Texas at Austin, Research and Development Center for Teacher Education.

Herriot, R. E. (Ed.) (1979). The dynamics of planned educational change. Berkeley, CA: McCutchan Publishing Corporation.

Hord, S. M. \& Hall, G. E. (1982). Procedures for guantitative analysis of change facilitator interventions. Paper presented at the annual meeting of the American Educational Research Association (AERA). 
Hord, S., Rutherford, W., Huling-Austin, L., \& Hall, G. (1987). Taking charge of change. Alexandria, VA: ASCD.

Huberman, M., \& Miles, M. (1984a). Innovation up close: How school improvement works. New York: Plenum Press.

Huberman, M., \& Miles, M. (1984b). Rethinking the quest for school improvement: Some findings from the DESSI study. Teachers College Record, 86, 34-54.

Jackson, P. (1968). Life in classrooms. Chicago: Holt Rineholt and winston.

Janis, I. L., \& Mann, L. (1987). The teacher as decision maker. In F. S. Bolin \& J. McConnel Falk (Ed.), Teacher renewal: Professional issues personal choices (pp. 202-216). New York: Teachers College Press.

Jick, T. D. (1979, December 24). Mixing qualitative and quantitative methods: Triangulation in action. Administrative Science Quarterly, 24 (4), 602-611.

Joyce, B. (1986). Improving America's schools. New York: Longman.

Joyce, B., Hersh, R., \& McKibbin, M. (1983). The structure of school improvement. White Plains, NY: Longman.

Lane, J., \& Walberg, H. (Eds.) . (1987). Effective school leadership. Berkeley: Mccutchan Publishing Corporation.

Lieberman, A. (Ed.). (1986). Rethinking school improvement. New York: Teachers College Press.

Lieberman, A., \& Miller, L. (1981). Synthesis of research on improving schools. Educational Leadership, 38 (7), 583-586.

Lieberman, A., \& Rosenholtz, S. (1987). The road to school improvement: Barriers and bridges. In J. Goodlad (Ed.), The Ecology of school renewal (pp. 79-98). Chicago: University of Chicago Press.

Light, D. (1979, December). Surface data and deep structure observing organization of professional training. American Science Quarterly, 24, 551-559.

Lightfoot, S. F. (1983). The good high school: Portraits of character and culture. New York: Basic Books. 
Little, J. (1981). School success and staff development in urban segregated schools. Paper presented at the annual meeting of the Southwest Educational Research Association, Dallas, TX.

Little, J. W. (1982). Norms of collegiality and experimentation: Workplace conditions of school success. American Educational Research Journal, 19, 325-340.

Lofland, J. (1971). Analyzing social settings: A quide to qualitative observation and analysis. CA: Wadsworth Publishing Company.

Lortie, D. C. (1973). Observations on teaching as work. In R. M. Travers (Ed.), Second handbook of research on teaching (pp. 474-497). Chicago: Rand McNally College Publishing Company.

Loucks-Horsley, S., Harding, C. K., Arbuckle, M. A., Murray, L., Dubea, C., \& Williams, M. K. (1987). Continuing to learn: A guidebook for teacher development. Anodver, MA: The Regional Laboratory for Educational Improvement of the Northeast and Islands.

Loucks-Horsley, S., \& Hergert, L. (1985). An action quide to school improvement. Andover, ME: ASCD.

Marsh, D. D., \& Jordan-Marsh, M. (1985, April). Addressing teachers' personal concerns in staff development efforts. Paper presented at the annual meeting of the American Educational Research Association, Chicago.

Marzano, R. J., Brandt, R. S., Hughes, C. S, Jones, B. F., Pressersen, B. Z., Rankin, S. C., \& Sukor, C. (1988). Demensions of thinking: A framework for curriculum and instruction. Alexandria, VA: ASCD.

McLaughlin, M. \& Berman, P. (1979). An exploratory study of school district adaptation. Los Angeles: Rand Corporation.

Merton, R., Fiske, R., \& Kendall, P. L. (1956). The focused interview: A manual of problems and procedures. Glencoe, IL: The Free Press.

Mintzberg, H. (1979, December). An emerging strategy of "direct" research. American Science Quarterly, 24, 582-589. 
Patterson, J., Purkey, S., \& Jackson, V. (1986). Productive school systems for a nonrational world. Alexandria, VA: ASCD.

Patton, M. (1982). Practical evaluation. Beverly Hills: Sage Publications.

Patton, M. Q. (1980). Qualitative evaluation methods. Beverly Hills: Sage Publications.

Porter, A., \& Brophy, J. (1988, May). Synthesis of research on good teaching: Insights from the work of the Institute for Research on Teaching. Educational Leadership, $\underline{8}$ (45), 74-85.

Roueche, J., \& Baker, G. (1986). Profiling Excellence in America's schools. Arlington, VA: AASA.

Sarason, S. B. (1990). The predictable failure of educational reform: Can we change course before it's too late. San Francisco: Jossey-Bass Publishers.

Showers, B., Joyce, B., \& Bennett, B. (1987, November) Synthesis of research on staff development: A framework for future study and a state-of-the-art analysis. Educational Leadership, 45 (3), 77-87.

Sparks, G. M. (1983). Synthesis of research on staff development. Educational Leadership, 41 (3), 65-72.

Van Maanen, M. (1979). The fact of fiction in organizational ethnography. Administrative science Quarterly, 24 (4), 539-550.

Waller, w. (1930). The sociology of Teaching. New York: J. Wiley and Sons, Inc.

Wolcott, H. F. (1973). The man in the principal's office: An ethnography. New York: Holt, Rinehart and Winston.

Yin, R. K. (1984). Case study research design and methods: Applied social research methods series. Beverly Hills: Sage Publications.

zetterberg, H. I. (1965). On theory and verification in sociology (3rd ed.). Tolowa, NJ: Bedminster. 
APPENDIX A

I AM SMART SCHOOL SURVEY 


\section{AM BMART BCHOOL BURVEY}

I would appreciate your help in understanding how multiple and continuous change is experienced by teachers. This information will be used to analyze information in combination with information provided by teachers from another school district. I Am Smart school was selected because it has a well-deserved reputation for being on the school improvement "cutting edge."

\section{DIRECTIONS}

I would like you to respond to two questions.

1. How have you responded to all of the changes in the school in terms of your attitudes and behaviors professionally and personally?

2. Identify an improvement effort in your school that significantly influenced your teaching and describe how you are different. 
APPENDIX B

I AM SMART SCHOOL 


\section{Am smart school}

\section{History}

Early in 1978, *Superior School District decided to build two elementary schools. Each was to have 18 classrooms and to house 432 students. One site was to be located on Road near with an attendance area carved from the existing Bluedale and Ridge Mountain boundaries. Initially 100 students from Bluedale and 200 from Ridge Mountain were forecast to attend the new school. Shortly after Bill Best was named principal in May 1979, the school was named I Am Smart after an administrator who had played key roles in the growth of the entire district.

Construction of the building began in the fall of 1979. By early February 1980, the personnel office posted the vacancies for the new I Am Smart School and final teacher selections were made in May 1980. During that same month, several community meetings were held at a nearby intermediate school. Monthly newsletters containing construction updates, staffing and curriculum happenings were sent to all identified prospective households. A parent/teacher club was chartered and operating procedures were written and approved by an elected executive board. staff inservice meetings were conducted in May 1980 and for five days in August 1980 dealing with communication skills, working agreements and learning styles.

On August 22, 1980, the new I Am Smart Elementary School was dedicated with an open house honoring I Am Smart and his family. The staff, students, parents and district personnel attended. The smart family presented the school with an oil painting of $\mathrm{Mr}$. Smart, which now hangs in the school foyer. In the spring of 1986, Mr. Smart celebrated with the entire school the graduation of the original first grade class to move through I Am Smart halls.

\section{Demographics}

The I Am Smart attendance area seems to be composed of a middle class, upwardly bound, mobile population. Eighty-two percent of the population owns their own home in comparison to $61 \%$ district-wide. Parents involved in the school (i.e., Parent Teacher Club, Local School Committee, volunteers, youth groups, etc.) seem also to be involved in the high tech industry at Tektronix or Intel. The median family income was $\$ 29,010$ (in 1979) compared with $\$ 22,950$ in the entire district (in 1979).

* pseudonym 


\section{Building Goals}

In 1980-1981, the primary school goal was focused on school/community relations. The initial community survey in May 1980 indicated that:

1. Parents want basic skills emphasized with reading, math and composition prioritized.

2. Parents feel a positive self-image is a high priority.

3. Parents want formal and informal contacts between school and home.

4. Parents want a follow-up survey in 1981-1982.

The following activities were conducted in 1980-1981 and continued through 1985-1986 (unless noted otherwise):

1. Principal's newsletter sent home last day of month with menu.

2. Curriculum nights by grade level each september.

3. Open House each October.

4. Parent/Teacher Club (PTC) meetings each month.

5. Local School committee (LSC) meetings monthly.

6. Parent/teacher conferences (two yearly).

7. Volunteer program with parent coordinators.

8. Student achievement recognition assemblies (1985-1986).

9. Staff ITIP (Instructional Theory Into Practice) trained in 1982-1983).

10. ITIP training site 1984-1986.

The following teaching/learning situations were instituted in 1980 and are still being conducted:

1. Team teaching.

2. Team planning.

3. Multi-age grouping.

4. Common planning time for teachers. 
5. Monthly staff meetings.

6. Team leader meetings.

7. Grade level and/or team meetings.

8. Scope and sequence updating.

9. Teacher evaluation and supervision.

10. Computer education and management program (since 1982).

The school goals for 1985-1986 school year were the following:

1. Implement newly adopted science program.

2. Implement Chapter I program.

3. Develop a process for adoption of social studies and music.

4. Implement the Effective Schools (School Improvement) project.

5. Define, monitor and augment the computer and writing education programs.

\section{staffing}

Thirteen classroom teachers and four specialists were selected to open I Am Smart School in the fall of 1980 . Before the end of the first month, two additional teachers were selected because of increasing student population. This has seemed to be a trend and the grade 1-6 program has increased from 15 classroom teachers in 1980-1981 to 19 classroom teachers in 1985-1986. When kindergarten programs were added to all schools in 1984-1985, I Am Smart school was assigned four sections (two rooms). Three teachers were hired (one full-time and two half-time). Because of additional enrollment, an additional half-time learning disabilities teacher and an aide for music and PE were provided.

In 1985-1986, 13 certified teachers were added to the staff to replace either transferring or retiring teachers. New staff members were also added to kindergarten and to handle increased student population. In March of 1986, a staff services mentor was added to facilitate curriculum coordination, instructional improvement, the school improvement project, and school/community relations. An 
active volunteer program is coordinated by four parents who have divided the responsibilities. Approximately 40

volunteers serve on a regular basis with many more serving on occasional projects.

Currently, 29 certified teachers serve $571 \mathrm{~K}-6$ students at I Am Smart School. Out of the 29 teachers, 15 are original

selections from 1980. In addition, I Am Smart teachers and students are served by 6 classified aides, 2-1/2 custodians, and 4 cooks who provide necessary support services. The principal has 1 full-time secretary. 
G OAL S ET T ING P HASE 
I AM SMART SCHOOL

School Improvement Project (SIT)

Significant Narrative Summaries

In March of 1986, the SIT members gathered all the data together from the four measurement areas: achievement data, staff survey, student surveys, and behavioral observations. Narrative summaries were written to describe many of the results of these measures. By studying those numerous narrative summaries along with the large volume of raw data appearing in the previous section, SIT chose the following 27 narratives which they felt were the most significant.

\section{Academic Achievement}

1. From 1983 to 1985 , at least $82 \%$ of the 3rd-6th grade students scored average or above on SRA tests, with 92-98\% of the 5th grade students scoring average or above.

2. In 1985, however, a smaller percentage of 3rd grade (33\%) and 4 th (36\%) students scored above average than for the district as a whole ( $37 \%$ and $42 \%$ respectively).

3. Scores of I Am Smart students are gradually coming into line with or surpassing district language arts scores in the above average category.

4. As the 3rd graders from 1983 moved through I Am Smart School, the number of students scoring below grade level suddenly decreased during 5 th grade from $11 \%$ in 1983 .

5. In 1983, three out of four grade levels tested had a greater percentage of students scoring above average on SRA math tests than did the overall district.

6. During all three years (1983-1985) at least $87 \%$ of I Am Smart students ( $3 \mathrm{rd}-6 \mathrm{th}$ ) scored either average or above average on SRA math tests.

7. Although the percentage of I Am Smart 3rd grade students scoring in the average range on all three tests either equalled or surpassed district percentages in 1985, percentages of students scoring above average fell 4 to 14 percentage points below the district percentages. 
8. From 1983 to 1985 , the percentage of I Am Smart 4 th graders scoring above average climbed $10 \%$ (from $29 \%$ to $39 \%)$, while the percentage of district students climbed $2 \%$ (from $37 \%$ to $39 \%$ ).

9. The percentages of above average scores of 5 th graders on the three parts of the 1985 SRA tests were 4 to 6 percentage points below district overall averages.

10. While the percentage of district 6 th graders scoring above average in math has increased from 1983 to 1985 (44-53\%), the percentage of I Am Smart students scoring above average has decreased slightly (45-43\%).

11. Students at I Am Smart who do not master basic skills are not retained.

12. Outside interruptions often interfere with the learning process.

\section{Staff/Student Attitudes}

13. The percentage of students who feel there are staff people who can help them with a problem declines as children get older (from $94 \%$ in 3 rd to $78 \%$ in 6 th).

14. Seventy-nine percent of the 3rd-6th grade students are bothered/somewhat bothered by noise from other classrooms while they study, including $53 \%$ who are definitely bothered.

15. Fifty-three percent of 3rd-6th grade students have had something stolen at. I Am Smart.

16. While at least $95 \%$ of $3 \mathrm{rd}, 5 \mathrm{th}$, and 6 th graders feel good about the way the school looks, fewer of the 4 th graders feel that same way ( 898$)$.

17. Ninety-five percent of the 3rd-6th graders are clear/reasonably clear about their rights and responsibilities.

18. An average of $28 \%$ of $k-2$ nd graders and an average of $31 \%$ of 3 rd-6th graders are upset by the changes in rooms or wish they did not have to change so often. (If both YES and "yes" responses are considered, the percentage is $51 \%$ for $3 \mathrm{rd}-6 \mathrm{th}$ graders.)

19. Over four-fifths of the 3 rd-6th graders indicate they have a lot of friends. 
20. Although 948 of the $\mathrm{K}-2$ nd graders identify themselves as happy people, $31 \%$ feel left out of things at school.

21. Ninety-four percent of the $\mathrm{K}-2$ students think school is a happy place.

22. Almost a third of the fourth graders feel they are not easy to like.

23. Over half the 3rd-6th grade students (male an female) feel is pretty tough being themselves. This holds true for all levels except 5th grade girls, where only $32 \%$ feel that way.

24. A average of $96 \%$ of $\mathrm{K}-2$ nd students feel their teachers care about them, and an average of 898 of grade 3-6 students feel staff usually/always takes a real interest in their learning.

25. An average of $95 \%$ of students in 3 rd-6th grade feel they get along with their teachers.

26. An average of $32 \%$ of $K-2$ nd grade students feel that they are slow in finishing their schoolwork.

\section{Student Behavior}

27. Physical aggression and verbal conflicts occur 5.5 times more frequently among $3 \mathrm{rd}$ and 4 th graders as among 5 th and 6 th graders; those behaviors occur 4 times more often among 1 st-2nd graders than among 5 th and 6 th graders. 
Goal statement

As a result of small group interactions among staff members and SIT workshops, the following goal statement was

formulated for the 1985-1987 school year. It reflects the consensus of the staff that these three concerns were of significant importance to most people:

1. That outside interruptions seemed to interfere with the learning process.

2. That students were bothered/somewhat bothered by room changes.

3. That students were bothered/somewhat bothered by noise.

\section{GOA L}

I Am Smart Elementary school's goal is to increase the engaged time of its students by reducing outside interruptions, noise from outside the classroom, and the intrusiveness of transitions and room changes. 